\title{
Phenotypic determinism and stochasticity in antibody repertoires of clonally expanded plasma cells
}

\author{
Daniel Neumeier ${ }^{1, \star}$, Alexander Yermanos ${ }^{1,2,3, \star}$, Andreas Agrafiotis ${ }^{1,2}$, Lucia Csepregi ${ }^{1}$, Tasnia Chowdhury ${ }^{4}$, \\ Roy A Ehling ${ }^{1}$, Raphael Kuhn ${ }^{1}$, Raphaël Brisset-Di Roberto ${ }^{1}$, Mariangela Di Tacchio ${ }^{1}$, Renan Antonialli', Dale \\ Starkie $^{4}$, Daniel J Lightwood ${ }^{4}$, Annette Oxenius², Sai T Reddy ${ }^{1, \#}$
}

${ }^{1}$ Department of Biosystems Science and Engineering, ETH Zürich, 4058 Basel, Switzerland ${ }^{2}$ Institute of Microbiology, ETH Zürich, 8093 Zurich, Switzerland ${ }^{3}$ Department of Pathology and Immunology, University of Geneva, 1205 Geneva, Switzerland ${ }^{4}$ UCB-Celltech Pharma, Berkshire, UK

\#To whom correspondence should be addressed. Tel: +41 6138733 68; Email: sai.reddy@ethz.ch ${ }^{*}$ Contributed equally to this work

\begin{abstract}
The capacity of humoral B cell-mediated immunity to effectively respond to and protect against pathogenic infections is largely driven by the presence of a diverse repertoire of polyclonal antibodies in the serum, which are produced by plasma cells (PCs). ${ }^{1,2}$ Recent studies have started to reveal the balance between deterministic mechanisms and stochasticity of antibody repertoires on a genotypic level (i.e., clonal diversity, somatic hypermutation, germline gene usage).$^{3-8}$ However, it remains unclear if clonal selection and expansion of PCs follows any deterministic rules or is stochastic with regards to phenotypic antibody properties (i.e., antigen-binding, affinity, epitope specificity). Here we report on the in-depth genotypic and phenotypic characterization of clonally expanded PC antibody repertoires following protein immunization. We find that there is only a strong correlation with antigen-specificity among the most expanded clones (top 10), whereas among the rest of the clonal repertoire antigen-specificity is stochastic. Furthermore, we report both on a polyclonal repertoire and clonal lineage level that antibody-antigen binding affinity does not correlate with clonal expansion or somatic hypermutation. Lastly, we provide evidence for convergence towards dominant epitopes despite clonal sequence diversity among the most expanded clones. Our results highlight the extent to which clonal expansion can be ascribed to antigen binding, affinity and epitope specificity and they have implications for the assessment of effective vaccines.
\end{abstract}

\section{Graphical abstract}

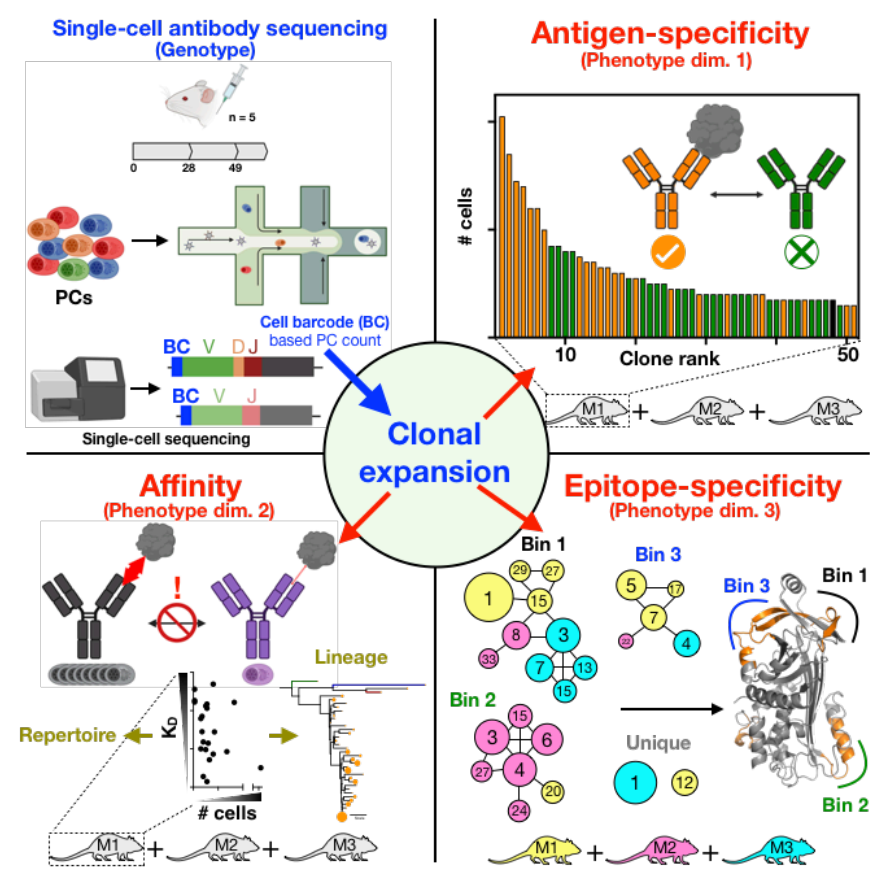




\section{Introduction}

Humoral immunity and successful vaccination require the generation of sustained levels of circulating serum antibodies, ${ }^{9}$ which are produced by clonally expanded PCs, a terminally-differentiated subset of B cells that reside in lymphoid organs (e.g., bone marrow) for an extended period of time (up to years for mice and humans). ${ }^{1,10,11}$ This dynamic process involves the recombination of germline-encoded genetic elements that encode the antibody [or $\mathrm{B}$ cell receptor $(\mathrm{BCR})$ ] in single $\mathrm{B}$ cells; ${ }^{12}$ dogma holds that $\mathrm{B}$ cell clonal selection, iterative expansion, and differentiation to PCs occurs for clones with increased affinity towards the antigen. ${ }^{13-}$ ${ }^{18}$ While there have been numerous studies describing how this process is orchestrated on the genotypic level in several species (e.g., humans, mice and zebrafish), $3,4,6,19-21$ much less is known about the associated phenotypic antibody repertoire metrics comprising features such as antigen-binding, ${ }^{22-25}$ quantitative binding affinity and epitope specificity, which can physically be measured as a consequence of the antibody amino acid (a.a.) sequence composition. Importantly, most of the studies reporting phenotypic antibody repertoire data were confined to memory $B$ cells or short-lived plasma blasts that express surface BCR, and in contrast to PCs, do not secrete large amounts of antibody proteins [immunoglobulin (lg)]. ${ }^{22-24,26-30}$

Previous studies on vaccine-induced PC repertoires (murine- and bone marrow-derived) have found that they are dominated by a few $(\sim 3-5)$ highly expanded clones that are antigen-specific, ${ }^{19,31}$ which correlates with the observation that up to $60-90 \%$ of the total antigen-specific lgG serum repertoire is comprised of only a few clones $(\sim 4-12) .{ }^{32-34}$ However, it remains unclear whether any deterministic factors such as antigen affinity or epitope specificity drive the selection of these highly expanded clones, and how deep antigen specificity tracks within the PC repertoire. Previous results obtained from adoptive B cell transfer and immunization experiments in BCR transgenic mouse models (monoclonal antibody knock-ins) revealed that high affinity $\mathrm{BCRs}$ promote early splenic $\mathrm{B}$ cells to differentiate to $\mathrm{PCs},{ }^{35,36}$ a phenomenon that was also reported in a more recent study. ${ }^{37}$ However, contrasting work showed that instead of PC differentiation, the onset of which was later found to occur during late germinal center reactions, ${ }^{38}$ higher BCR affinity led to increased overall proliferation of antigen-reactive cells. ${ }^{39}$ Therefore, it remains unclear how transferable phenotypic antigen binding data from $B$ cells of isolated germinal centers or individual lymph nodes ${ }^{40,41}$ are for the development of long-lived PC repertoires. Here, we set out to comprehensively address these long-standing questions of clonal selection and expansion of PCs. We developed an integrative genotype-phenotype mapping approach and applied it for the in-depth characterization of clonally expanded PC antibody repertoires across five immunized mice.

\section{Results}

We used single-cell sequencing and computational analysis of antibody repertoires combined with quantitative antibody-antigen-binding, -affinity, epitope-binning and -mapping measurements (Fig. 1a) which resulted in the characterization of $>230$ antibodies (which constitute $\sim 50 \%$ of all captured PCs (IgG) per repertoire). To this end, we repeatedly immunized five BALB/c mice subcutaneously with the T cell-dependent model antigen ovalbumin (OVA) in monophosphoryl lipid A (MPLA) adjuvant. PCs were isolated (based on CD138+ B220low/CD19low/- surface expression) from bone marrow two weeks after the final boost, which represents the peak of PC homing to the bone marrow ${ }^{42,43}$ (Fig. 1a). Next, targeted single-cell sequencing was performed on uniquely barcoded heavy and light chain transcripts, covering all Ig isotypes (10X Genomics V(D)J protocol) (Extended 
Data Fig. 1a). After quality filtering and bioinformatic removal of multiplets, we obtained sequence data on thousands of PCs for each mouse (1891 - 7859 cells) with one paired full-length variable heavy- $\left(V_{H}\right)$ and variable light- $\left(V_{L}\right)$ chain sequence (Extended Data Fig. 1b), which translated to 672 - 1657 distinct clones (a clone being defined as a unique CDRH3-CDRL3 a.a. sequence) per mouse (across all isotypes) (Fig. 1b, Extended Data Fig. 1c). To characterize the state of clonal expansion for each repertoire, we operated under the assumption that since the murine naïve BCR sequence diversity $\left(10^{13}\right)^{6}$ far exceeds the steady-state number of PCs in the bone marrow of a given mouse $\left(\sim 7.5 \times 10^{4}\right),{ }^{43}$ detecting two or more cells with the same clonal CDRH3-CDRL3 sequence could be used to define clonal expansion (irrespective of isotype origin). ${ }^{44,45}$ We found $199-1007$ clones to be expanded for each mouse repertoire (30 - 61\% of all clones per repertoire), whereas a substantial proportion of clones was detected only once (Fig. 1b). Furthermore, all PC repertoires were reproducibly dominated by highly expanded IgM clones (Fig. 1c, Extended Data Fig. 2), some of which made up almost $8 \%$ of the total cellular repertoire count (IgM-1). As expected, the mutational load between isotypes differed significantly when the 30 most expanded clones per isotype were compared, with most of the IgM clones featuring only a single a.a. intraclonal variant, whereas the number of intraclonal variants markedly increased for expanded IgA and IgG clones (Fig. 1d, Extended Data Fig. 2b, 3). Interestingly, when we tested six of the most expanded IgM clones of a single mouse, some of which were also shared between mice, we did not observe any detectable binding to the OVA antigen (or MPLA adjuvant) (Fig. 1e, Extended Data Fig. 4). Likewise, when we screened five of the most expanded IgA clones of the same mouse, no antigen-binding was detected (Fig. 1f, Extended Data Fig. 5). Therefore, we focused our analysis on the expanded IgG compartment and determined the antigen specificity [by enzyme-linked immunosorbent assay (ELISA)] of the 50 - 60 most expanded antibody clones from mouse (MS) -1, -2 and -5 (which were chosen based on their respective sequencing depth), along with 15 of the most expanded clones from MS-3 and -4 (Extended Data Fig. 6a, b). Together, these clones represented $50-54 \%$ of total IgG cells per mouse for MS-1, -2 , and -5 and overall, we found that between $42 \%$ and $48 \%$ of clones per mouse were antigen-specific (Extended Data Fig. 6a; $60 \%$ for MS-3 and MS-4). While the most expanded five to ten clones per repertoire were usually antigenspecific, across the rest of the repertoire, antigen-binding and non-binding clones were evenly distributed (Fig. $\mathbf{1 g}$ ). In light of this high degree of stochasticity, we determined how deep antigen-specificity tracks into the repertoire by testing a set of 15 randomly chosen IgG clones from MS-1, including clones that had a cell count as low as one. Even this deep into the repertoire, several clones corresponding to IgG clone rank 249 - 404 and total clone rank 1008 - 1657 showed detectable antigen-binding (Fig. 1h, Extended Data Fig. 6c, d).

Next, given the context of a polyclonal, multi-epitope directed antibody repertoire, we investigated if clonal expansion of PCs is driven by the affinity to the cognate antigen. To this end, we used biolayer interferometry $(B L I)$ to measure the affinity [apparent equilibrium dissociation constants $\left(K_{D}\right)$ ] of 55 antigen-specific lgG clones from MS-1, -2 , and -5 , resulting in a wide range of affinities $\left(K_{D}=2-450 \mathrm{nM}\right)$ (Extended Data Table 1). This revealed that there was no direct correlation between clonal expansion (based on cell count of a clone) and antigen affinity, as highly expanded clones (cell count $>20)$ were just as likely to have moderate $\left(K_{D} \sim 100\right.$ $450 \mathrm{nM})$ or high $\left(\mathrm{K}_{\mathrm{D}} \sim 10-100 \mathrm{nM}\right)$ affinities, including the surprising observation that the highest affinity $\left(\mathrm{K}_{\mathrm{D}}\right.$ $<10 \mathrm{nM}$ ) clones often had low cell counts $(<10)$ (Fig. 2a). Likewise, we observed highly expanded clones with significantly disparate affinities, as exemplified by the two most expanded clones of MS-5 (5.1 and 5.2), which displayed $K_{D}$ values of $18.7 \mathrm{nM}$ and $451.8 \mathrm{nM}$, respectively (Extended Data Table 1). Moreover, we did not 
observe a direct link between antibody-antigen affinity and the extent of somatic hypermutation, neither on the a.a. (Fig. 2b) nor on the nucleotide (nt) level (Extended Data Fig. 7). In some cases, clones that were closer to germline such as the fourth most expanded clone of MS-5 (5.4, 7 a.a. mutations) exhibited high affinity (KD $=8.8 \mathrm{nM})$, whereas in comparison a highly mutated and highly expanded clone (5.1, 16 a.a. mutations) had a lower affinity $\left(K_{D}=18.7 \mathrm{nM}\right)($ Extended Data Table 1). For some antigens, such as influenza hemagglutinin and the spike protein of SARS-CoV-2, it has been shown that certain germlines are structurally predisposed for antigen-specificity and high affinity. ${ }^{46-48}$ Therefore, we determined whether $\mathrm{V}_{\mathrm{H}} \mathrm{V}_{\mathrm{L}}$ germline gene (IGHVIGKV) combinations impacted the affinity of a given antibody to OVA. For the 31 antigen-specific germline combinations tested, some of which shared the same $V_{H}$ or $V_{L}$ genes, we found that affinity was independent of germline gene usage. Most affinities fell into the same range and in case of multiple data points per $\mathrm{V}_{\mathrm{H}}-\mathrm{V}_{\mathrm{L}}$ combination, the standard deviation for affinity could span a large range ( $\left.K_{D} \pm 250 \mathrm{nM}\right)$ (Fig. 2C). Next, we determined if certain $\mathrm{V}_{\mathrm{H}}-\mathrm{V}_{\llcorner}$germline combinations were enriched in the antigen-binding or non-binding fraction of the tested clones. Analysis of $\mathrm{V}_{\mathrm{H}}-\mathrm{V}_{\mathrm{L}}$ germline gene usage by circos plots of the 79 experimentally verified antigen-binding and 95 non-binding clones did not show enrichment for certain germline combinations in either of the two groups (Fig. 2d). Next, we performed a sequence-similarity network analysis (CDRH3-CDRL3 sequence nodes connected by $<4$ a.a. difference) $)^{49}$ on all IgG clones across all mice (MS-1-5; Extended Data Fig. 8) as well as on all experimentally characterized clones. This revealed the presence of discrete subnetworks (Extended Data Fig. 8, Fig. 2e), which harbored clusters of both antigen-binding and nonbinding clones, highlighting the potential importance of key amino acid sequence motifs beyond the CDRH3CDRL3 that contribute to antigen specificity..$^{50}$

To evaluate whether there were any other features that separate antigen-binding from non-binding clones, we further analyzed common metrics such as distance to germline, number of intraclonal sequence variants, and CDRH3/CDRL3 length and found that only the number of distinct intraclonal antibody sequence variants was significantly increased for antigen-binding clones (Extended Data Fig. 9). Upon closer examination of Ig isotype ( $\lg M, \lg A)$ and $\lg G$ subtype ( $\lg G 1,2 b, 2 c, 3)$, we observed a consistently higher percentage of $\lg G 1$ cells among the antigen-binding fraction of clones (Fig. 2f). When we tested seven clones that were composed of several isotypes (with minimal to no $\operatorname{lgG} 1$ ), none of them showed detectable antigen binding, suggesting that multi-lg class-switch recombination does not correlate with antigen specificity (Fig. 2g, Extended Data Fig. 10).

Since we established that within the context of the polyclonal repertoire, selection of highly expanded clones was not driven by antigen binding affinity, we next sought to determine the relationship between antigen affinity and clonal expansion within the evolutionary trajectory of a clonal lineage (PCs sharing identical V- and Jgenes and identical CDRH3-CDRL3 sequences). We thus expressed antibodies and measured affinities for the most expanded IgG clonal lineage of MS-1, which featured 29 intraclonal sequence variants distributed across a total of 227 cells (Fig. 3a, Extended Data Fig. 11). We observed no direct correlation between expansion of an intraclonal sequence variant and binding affinity to antigen. Moreover, the number of somatic hypermutations (distance to germline) did not correlate with affinity and intraclonal variants with lower affinity $\left(K_{D}>15-50 \mathrm{nM}\right)$ generally originated from earlier ancestral branch points of the lineage tree (Fig. 3b-d, Extended Data Fig. 12). This provides further evidence for the existence of a clonal physiological affinity 
ceiling, as has been proposed in previous work, ${ }^{24,51}$ and which falls within the range of affinities $\left(K_{D}=2-450\right.$ nM) measured for polyclonal antibodies (Fig. 2c).

Next, we investigated whether clones derived from different mice that shared highly similar sequences (identical V- and J-genes, CDRH3-CDRL3 with $<5$ a.a. difference) show similar antigen binding behavior (Extended Data Fig. 13). Nine clones were tested, which were similar to a previously identified antigenspecific clone (5.17) and showed consistently similar affinities $\left(K_{D}=4\right.$ - $\left.26 \mathrm{nM}\right)$ (Fig. 3e-g; Extended Data Fig. 13). Next, we examined a major cluster of a sequence similarity network that contained 129 sequence nodes and 32 unique $V_{H}-V_{L}$ germline combinations (CDRH3-CDRL3 sequence nodes connected $<4$ a.a. difference). Of those, four clones with different germline genes were randomly selected and we could confirm antigen binding for three of them (Fig. $3 \mathbf{h}-\mathbf{j})$.

Finally, we aimed to understand the epitope specificity and targeting space of expanded PC clones. Using BLI, we first performed cross-competition epitope binning experiments with highly expanded antibody clones that possessed moderate to high affinity $\left(K_{D} \sim 3-165 n M\right)$. This revealed that within a given mouse, a majority of clones could be grouped into discrete epitope bins (Fig. 4a, b, Extended Data Fig. 14). Next, when we tested competitive binding of clones originating from across the different mice (MS-1, -2 and -5) (Extended Data Fig. 15a), three dominant epitope bins emerged, some of which contained clones from all mice (bin 1 and 3), whereas others were mainly occupied by clones from a single mouse (bin 2) (Fig. 4c). For clones 1.12 and 5.1 (the most expanded clone of MS-5) we did not observe any competitive binding suggesting that they target unique epitopes compared to all other clones tested. Interestingly, we observed a number of different $\mathrm{V}_{\mathrm{H}}-\mathrm{V}_{\mathrm{L}}$ germline gene combinations for each bin (Fig. 4c, Extended Data Fig. 15b). Clonal diversity in each bin was also observed (based on CDRH3-CDRL3 sequences) (Fig. 4d) and when we mapped the bin epitope space of the expanded clones on to the complete IgG clonal sequence similarity network (CDRH3-CDRL3 sequence nodes connected $<4$ a.a. difference), we could clearly observe epitope convergence despite a high degree of sequence diversity (Fig. 4e). This was particularly evident for the biggest sub-network (containing 32 different $V_{H}-V_{L}$ combinations) which exclusively harbored clones of epitope bin 1. Phenotypically, we again did not observe a correlation between clone affinity and epitope specificity when affinity data from different mice per bin were compared (Extended Data Fig. 15c).

In order to more precisely define epitope specificity in relation to the sequence and structure of the OVA antigen, we used a bacterial linear peptide display system, ${ }^{52}$ where an overlapping 15-mer (a.a.) peptide library of the primary antigen sequence is expressed on the surface of $E$. coli. Highly expanded antibody clones are then used to label the antigen peptide library and sequential rounds of fluorescence-activated cell sorting (FACS) is performed to enrich for peptide binding, followed by targeted deep sequencing of peptide encoding regions. Subsequently, epitopes are identified using sequence-alignment and read count statistics (Fig. 4f). To benchmark the system, we used two commercial monoclonal antibodies with well-defined OVA-specificity for which we could successfully confirm their respective epitopes (Extended Data Fig. 16). We then determined the epitopes of nine highly expanded clones across the different mice (MS-1, -2 and -5) (Fig. $\mathbf{4 g}$, Extended Data Fig. 17). For all clones (except 2.4 and 5.14, for which only a single highly enriched peptide was found to bind the antibody), FACS enrichment followed by read count analysis resulted in a small number 
(3 - 12) of overlapping peptide sequences that were highly enriched compared to the background. Within those, we defined the peptide sequence with the highest read count enrichment (observed 86 - 56,000-fold above background) as the corresponding epitope. Importantly, we identified the same epitope for two clones (2.4 and 2.24) sharing highly similar sequences (identical $V_{H} J_{H}-V_{L} J L$ germline, CDRH3-CDRL3 edit distance of 4 a.a.). Finally, several of the clones were also representative of the identified epitope bins (Fig. 4c), for example clones $1.15,1.17$ and $2.4 / 2.24$, allowing us to precisely map these bins onto the structure of the OVA antigen, which revealed that they were indeed occupying distinct areas of the antigen (Fig. 4h).

\section{DISCUSSION}

Here, we set out to determine if clonal selection and expansion of PC repertoires follows any deterministic rules or is stochastic with regards to their phenotypic antibody properties (i.e., antigen-binding, -affinity, epitope specificity). First, we discovered that except for the most expanded clones ( top 10), antigen specificity was largely stochastic and could not be predicted based on the number of expanded cells (Fig. 19). Next, we determined if PC repertoire affinities allowed for accommodating the widely accepted germinal center $B$ cell selection model: selective expansion of B cells is driven by an avidity-based selection mechanism in germinal centers involving high-affinity BCRs expressed on B cells that consequentially present the highest levels of peptide-MHC to T follicular helper cells, ${ }^{41,53,54}$ which in turn controls the rate of B cell proliferation. ${ }^{55}$ In contrast to this model, we did not observe any deterministic correlation between antibody affinity and clonal expansion of PCs, furthermore affinity was also not correlated with the number of somatic hypermutations; these stochastic findings were consistent both on the polyclonal repertoire level (Fig. 2a, b) and the clonal lineage level (Fig. 3c, d).

While we acknowledge that our experimental setup reflects the collective PC-differentiated integration of multiple germinal center outputs that to some extent mirror ongoing (primarily) naïve $\mathrm{B}$ cell engagement, ${ }^{56}$ similar results have been observed recently for differentially expanded germinal center B cells. ${ }^{40}$ Therefore, we speculate that over time avidity-based selection may not only be a consequence of affinity alone, but for example can also lead to autoantibody redemption via somatic hypermutation. ${ }^{57}$ Furthermore, from a B cell's perspective, capturing of antigen may further be modulated by differential BCR stability and surface expression levels, which can also be fine-tuned by somatic hypermutation. To illustrate, recent work has suggested that somatic hypermutation is associated with decreased conformational antibody stability. ${ }^{58}$ Furthermore, highly differential antibody secretion rates from single plasma cells have been reported, which can span up to $3-4$ log units. ${ }^{59}$ It remains to be determined how these findings translate to surface expression levels of germinal center B cells and subsequent clonal selection, expansion and differentiation to PCs.

Finally, our results also indicate that despite a high level of antibody sequence diversity, the selection of PCs has a deterministic component with regards to specificity towards a few dominant epitopes, which may be attributed to epitope accessibility and availability during B cell maturation and PC differentiation (Fig. 4c-e). This could also provide a rationale for the shifting serum epitope immunodominance hierarchies over time, as observed following influenza $A$ virus infection. ${ }^{60}$ 
Collectively, our findings highlight the fine balance between stochastic and deterministic phenotypic feature selection in differentiated PC repertoires, which only in concert drive clonal selection and expansion. This work has implications for the assessment of vaccine-induced immunity, as understanding how the distribution profile of desired PC clones can be modulated, may support the development of vaccines that provide broad and long-lasting protection by the humoral immune system.

\section{METHODS}

\section{Mouse immunizations}

Mouse immunizations were performed under the guidelines and protocols approved by the Basel-Stadt cantonal veterinary office (Basel-Stadt Kantonales Veterinäramt Tierversuchsbewilligung \#2582). Five female BALB/c mice (Janvier Laboratories France, 9 weeks old) were housed under specific pathogen-free conditions and maintained on a standard chow diet. Mice were repeatedly immunized subcutaneously on day 0,28 and 49 into the flank with $150 \mu$ of a PBS-based immunization cocktail containing $100 \mu \mathrm{g}$ ovalbumin (Sigma, A5503) and $20 \mu \mathrm{g}$ monophosphoryl lipid A (MPLA) adjuvant (Sigma, L6895). Blood samples were collected from the tail vein on day 0 and by heart-puncture on day 63 . On day 63 , mice were euthanized by $\mathrm{CO}_{2}$ asphyxiation and cervical dislocation and femurs and tibias were collected.

\section{Isolation of plasma cells from bone marrow}

Harvested femurs and tibias were clipped with surgical scissors at both ends and the bone marrow was flushed out with $\sim 5 \mathrm{~mL}$ of a chilled and sterile filtered solution of PBS pH 7.2, 0.5\% BSA and 2 mM EDTA using a 30-gauge BD Micro-Fine+ insulin needle. Bone marrow cells were filtered through a $40 \mu \mathrm{m}$ nylon cell strainer (FALCON, 352340). PCs defined as CD138+ B220low/- CD19low/- antibody-secreting plasma cells were isolated by magnetic activated cell sorting (MACS) using the CD138+ Plasma Cell Isolation Kit mouse (Miltenyi Biotech, 130-092-530) following the manufacturer's instructions. Briefly, non-plasma cells were first magnetically depleted using a cocktail of biotinylated antibodies against CD49b (DX5) and CD45R (B220) and anti-Biotin microbeads. Then, plasma cells were positively selected from the pre-enriched cell fraction by direct labeling with CD138 microbeads.

\section{Single-cell sequencing of antibody repertoires}

Single-cell sequencing libraries were constructed from the isolated bone marrow plasma cells following the demonstrated 10X Genomics' protocol: 'Direct target enrichment - Chromium Single Cell V(D)J Reagent Kits' (CG000166 REV A). Briefly, single cells were co-encapsulated with gel beads (10X Genomics, 1000006) in droplets using 5 lanes of one Chromium Single Cell A Chip (10X Genomics, 1000009) with a target loading of 13,000 cells per reaction. V(D)J library construction was carried out using the Chromium Single Cell 5' Library Kit (10X Genomics, 1000006) and the Chromium Single Cell V(D)J Enrichment Kit, Mouse B Cell (10X Genomics, 1000072) according to the manufacturer's instructions. All of the reverse transcribed cDNA was 
bioRxiv preprint doi: https://doi.org/10.1101/2021.07.16.452687; this version posted July 16, 2021. The copyright holder for this preprint (which was not certified by peer review) is the author/funder, who has granted bioRxiv a license to display the preprint in perpetuity. It is made available under aCC-BY-ND 4.0 International license.

used as input for VDJ library construction. Final libraries were pooled and sequenced on the lllumina NextSeq 500 platform (mid output, 300 cycles, paired-end reads) using an input concentration of 1.8 pM with 5\% PhiX.

\section{Repertoire analysis}

Raw sequencing files arising from multiple Illumina sequencing lanes were merged and supplied as input to the command line program cell ranger on a high-performance cluster. Reads were aligned to the germline using cellranger (v3.1.0) segments from the murine VDJ reference (vdj_GRCm38_alts_ensembl-3.1.0) and subsequently assigned into clonal families based on identical combinations of CDRH3+CDRL3 amino acid sequences. Only those clones containing exactly one productive heavy chain and one productive light chain were retained in the analysis. Isotype majority was determined based on the constant region alignment containing the within each clonal family, with all IgG subtypes merged. Full-length variable sequences (spanning from FR1 to FR4) for each cell were obtained by using the call_MIXCR function in Platypus, ${ }^{61}$ which relies upon aligning full-length contig sequences from the all_contig.fasta file output from cellranger using MiXCR. ${ }^{62}$ To quantify unique variants, full-length VDJRegion (defined as FR1-FR4) for both heavy and light chains were appended together for each cell. Similarity networks were created by calculating the pairwise edit distance using the stringdist package ${ }^{63}$ in $\mathrm{R}$ and subsequently creating an adjacency matrix, where each entry (node) corresponded to a unique CDRH3+CDRL3 nucleotide sequence (network shown in Fig. 2e was created based on unique CDRH3+CDRL3 a.a. sequence). Edges were drawn between nodes with an edit distance of three or less amino acid mutations and following networks were created by $\mathrm{R}$ package igraph. Edit distances were calculated using the stringdist package. Circos plots demonstrating germline gene usage were created using the circlize package ${ }^{64}$ in R. The unmutated germline reference gene was determined by Cellranger's alignment and set as the outgroup for the phylogenetic tree. Nucleotide and amino acid distance to germline was determined via IMGT. ${ }^{65}$

\section{Antibody expression}

Antibodies were either transiently expressed at small scale in HEK 293 Expi cells using the ExpiFectamine 293 Transfection Kit (Thermo, A14524) and the pFUSE2ss vector system for both, IgM/lgK and IgG/lgK/L (Invitrogen) according to previous protocols, ${ }^{66}$ or stable hybridoma cell lines were engineered by CRISPR/Cas9 genome editing as described before. ${ }^{67,68}$ Of note, these hybridoma cell lines are able to surface display as well as secrete antibody of the IgG2c isotype, which allows for both, FACS-based as well as ELISAbased specificity profiling.

\section{Hybridoma cell culture}

Hybridoma cell lines were cultivated in high-glucose DMEM Medium (Thermo, 61965-026), supplemented with 10\% (v/v) of ultra-low IgG FBS (Thermo, 16250078), $100 \mathrm{U} / \mathrm{ml}$ Pen/Strep (Thermo, 15140-122), $10 \mathrm{mM}$ HEPES (Thermo, 15630-056) and $50 \mu \mathrm{M}$ 2-mercaptoethanol (Thermo, 31350-010). Cell lines were maintained at $37^{\circ} \mathrm{C}, 5 \% \mathrm{CO}_{2}$ and passaged every 72 hours. 


\section{Antibody validation by ELISA}

$0.2 \mu \mathrm{m}$ sterile-filtered cell culture supernatant of a $6 \mathrm{~d}$ culture was used to confirm both, antibody expression as well as OVA-specificity. ELISA plates were coated with the capturing reagent in PBS [OVA (Sigma, A5503) for antigen ELISAs, anti-mouse IgM ( $\boldsymbol{\gamma}$-chain specific; Sigma, M8644) and anti-mouse IgG (light chain specific; Jackson ImmunoResearch, 115-005-174) for IgM and IgG expression ELISAs] at $4 \mathrm{ug} / \mathrm{ml}$, blocked with PBS supplemented with $2 \%(\mathrm{w} / \mathrm{v})$ milk (AppliChem, A0830) and incubated with (serial dilutions of) cell culture supernatant (supernatant of a hen-egg lysozyme/OVA specific cell line served as negative/positive controls respectively). IgM and IgG binding was detected using anti-mouse kappa light chain-HRP (Abcam, ab99617) or anti-mouse IgG (Fc-specific)-HRP (Sigma, A2554) secondary antibody respectively. Binding was quantified using the 1-Step Ultra TMB-ELISA substrate solution (Thermo, 34028) and 1M H2SO4 for reaction termination. Absorbance at $450 \mathrm{~nm}$ was recorded on an Infinite 200 PRO (Tecan). All commercial antibodies were used according to manufacturer's recommendations. For heatmaps shown in Fig. $\mathbf{1}$ and $\mathbf{2}$, each of the steps was timed to last equally long.

\section{Antibody validation by surface staining of stable hybridoma cell lines}

Flow cytometry scanning of hybridoma cells was performed on a BD FACS Aria III. Typically, $5 \times 10^{5}$ cells were stained for 30 minutes on ice in $50 \mu$ of a labeling mix consisting of anti-lgG2c-AlexaFluor488 (Jackson ImmunoResearch, 115-545-208), anti-IgK-Brilliant Violet421 (BioLegend, 409511) and OVA-AlexaFluor647 $(0.86 \mathrm{mg} / \mathrm{ml})$ at $1: 100,1: 80$ and 1:50 respectively. Before scanning, cells were washed twice.

\section{Antibody affinity measurements}

Supernatants of Expi cultures and monoclonal hybridoma populations were collected, concentrated (Amicon, UFC810008) and filtered through a $0.2 \mu \mathrm{m}$ filter (Sartorius, 16534-K). Affinities were then measured on an Octet RED96e machine (FortéBio) with the following parameters: anti-mouse lgG Fc Capture (AMC) biosensors (FortéBio, 18-5088) were hydrated in conditioned media diluted 1 in 2 with kinetics buffer (1xKB) (FortéBio, 18-1105) for at least 10 min before conditioning through 4 cycles of regeneration consisting of 10 s incubation in $10 \mathrm{mM}$ glycine, $\mathrm{pH} 1.52$ and 10 seconds in 1 xKB. Conditioned sensors were then loaded with concentrated conditioned medium diluted 1 in 2 with $1 \times K$ KB (reference sensor) or cell culture supernatant diluted 1 in 2 with 1xKB. Loaded sensors were then equilibrated in 1xKB and typically incubated with various concentrations of OVA antigen in 1xKB ranging from $0 \mathrm{nM}$ (reference sample) up to $200 \mathrm{nM}$ and $1 \mu \mathrm{M}$ respectively for polyclonal and intraclonal variants mAbs. Finally, sensors were incubated in $1 \times K B$ to allow antigen dissociation. Kinetics analysis was performed in analysis software Data Analysis HT v11.0.0.50 and $K_{D}$-values were calculated from fits with an association $R^{2}>0.85$.

\section{Epitope binning}

Transiently expressed antibodies were purified from $30 \mathrm{ml}$ of HEK 293 Expi cultures using Protein G GraviTrap columns (Sigma, GE28-9852-55) and the Ab Buffer Kit (Sigma, GE28-9030-59) according to the manufacturer instructions. Before epitope binning, purified antibodies were confirmed for OVA-positivity by ELISA and OVA-binding kinetics were reconfirmed by BLI measurements prior to each experiment. 
Epitope binning following a classical sandwich protocol was performed on an Octet RED96e machine (FortéBio), using anti-mouse IgG Fc Capture (AMC) biosensors (FortéBio, 18-5088) with the following steps: (0) hydration of biosensors in 1xKB for 30 min. (1) Baseline equilibration in 1xKB for 60s. (2) First loading of capture antibody at $40-60 \mu \mathrm{g} / \mathrm{ml}$ in 1 xKB for $240 \mathrm{~s}$. (3) Quenching of biosensors in $50 \mu \mathrm{g} / \mathrm{ml}$ polyclonal mouse IgG (Rockland, 010-0102) for 300 s. (4) Baseline in 1xKB for 240 s. (5) Second loading of capture antibody at $40-60 \mu \mathrm{g} / \mathrm{ml}$ in 1 xKB for 240 s. (6) Baseline in 1xKB for $200 \mathrm{~s}$. (7) Loading of OVA at $150 \mathrm{nM}$ in 1xKB for $600 \mathrm{~s}$. (8) Baseline in 1xKB for $60 \mathrm{~s}$. (9) Loading of probe antibody at $25 \mu \mathrm{g} / \mathrm{ml}$ in $1 \times K B$ for $600 \mathrm{~s}$. (10) Regeneration of sensors. Analysis was performed in analysis software Data Analysis HT v11.0.0.50.

\section{Library generation for epitope mapping}

Bacterial epitope mapping was based on the $\mathrm{pB} 33 \mathrm{eCPX}$ plasmid, which was previously established ${ }^{52}$ to fuse a peptide to the enhanced outer membrane protein $X(\mathrm{OmpX})$ for extracellular peptide presentation. First, we modified the plasmid using primers EpMap_1 and EpMap_2 along with ssODN EpMap1_ssODN (Extended Data Table 3) using the NEBuilder Mastermix (NEB, E2621S) following the manufacturer's instructions in order to create hairpin-free overlap regions that could be used for homology-based library cloning. Next, the epitope library was generated using MC1061 E. coli cells, NEBuilder Mastermix, primers EpMap_3 and EpMap_4 (Extended Data Table 3) along with 0.078 pmol of a ssODN library of 105 nucleotides in length [30 bp homology overhangs on each side (GGAACTTCTGTAGCTGGACAATCTGGACAA and GGAGGGCAGTCTGGGCAGTCAGGTGATTAC) flanking a $45 \mathrm{bp}$ stretch encoding a $15 \mathrm{mer}$ amino acid peptide sequence; ssODN library was ordered as a Tier 1 oligo pool from Twist Bioscience]. The library was designed to cover the whole OVA amino acid sequence, with a window size of $45 \mathrm{bp}$ and a cutoff of one codon, resulting in a library size of 372 . The final library size was determined to contain 268,900 transformants using serial dilutions (722x oversampled) and when we analyzed 20 clones by Sanger sequencing using primer EpMap_5, we found that $95 \%$ contained a correct sequence of which 95\% were unique. Glycerol stocks were subsequently stored at $-80^{\circ} \mathrm{C}$ until further use.

\section{Epitope mapping by bacterial surface display}

Bacterial display-based epitope mapping was carried out as described before. ${ }^{69}$ Briefly, $500 \mathrm{ml}$ of LB-medium supplemented with chloramphenicol $(34 \mu \mathrm{g} / \mathrm{ml})$ and $0.2 \%(\mathrm{w} / \mathrm{v}) 0.2 \mu \mathrm{m}$ sterile filtered glucose were inoculated with the transformant library and grown for 12 hours at $37^{\circ} \mathrm{C}$. Next, cells were subcultured 1:50 into $5 \mathrm{ml}$ of LB supplemented with chloramphenicol and grown for 2 hours at $37^{\circ} \mathrm{C}$, before protein expression was induced for 1 hour at $37{ }^{\circ} \mathrm{C}$ using $0.04 \%(w / v)$ L-arabinose. Typically $\sim 1.1 \mathrm{E} 7$ cells were subsequently harvested at $3000 \mathrm{~g}$ for 5 minutes, washed and stained for 30 minutes on ice in $100 \mu \mathrm{l}$ of a labeling mix consisting of $20 \mu \mathrm{l}$ of concentrated and extensively PBS buffer-exchanged hybridoma cell culture supernatant (containing antibody protein of the top expanded clones) and $80 \mu \mathrm{l}$ of PBS pH 7.2, 0.5\% BSA and $2 \mathrm{mM}$ EDTA [for assay establishment, $0.5 \mu \mathrm{g}$ of control antibodies Clone 4B4E6 (Chondrex, 7096) and Clone 2322 (Chondrex, 7094) were spiked into concentrated and buffer exchanged cell culture supernatant of a hybridoma cell line, that did not express antibody]. Cells were washed twice and stained in $100 \mu \mathrm{l}$ for 30 minutes on ice using an anti-mouse IgG-Brilliant Violet421 secondary antibody at 1:90 (BioLegend, 405317). 
bioRxiv preprint doi: https://doi.org/10.1101/2021.07.16.452687; this version posted July 16, 2021. The copyright holder for this preprint (which was not certified by peer review) is the author/funder, who has granted bioRxiv a license to display the preprint in perpetuity. It is made available under aCC-BY-ND 4.0 International license.

Cells were again washed twice, resuspended in $500 \mu$ of PBS and sorted into sterile SOC media using a BD FACS Aria III. Typically, between 10,000 and 50,000 cells were sorted on 2 - 3 consecutive days to enrich for pure antigen-binding populations, before plasmid was extracted and sequencing libraries were generated.

\section{Generation of epitope mapping sequencing libraries}

Bacterial plasmid DNA was extracted from a $3 \mathrm{ml}$ overnight culture using the QIAprep Spin Miniprep Kit (Qiagen, 27104). Next, NGS libraries were generated following a two-step primer extension protocol. ${ }^{70} 30 \mathrm{\mu g}$ of plasmid DNA were amplified using Kapa Hifi HotStart Ready mix (Kapa Biosystems, KK2602) in a $50 \mu \mathrm{l}$ reaction using primers EpMap_7 and EpMap_8 (which bound to regions that were $\sim 70$ bp away from the peptide encoding region) with the following cycling parameter: $95^{\circ} \mathrm{C}$ for 3 minutes, 21 cycles of $98{ }^{\circ} \mathrm{C} 20$ seconds, $59{ }^{\circ} \mathrm{C} 15$ seconds, $72{ }^{\circ} \mathrm{C}$ for 20 seconds and $72{ }^{\circ} \mathrm{C} 30$ seconds final extension.

After gel purification, the final library was constructed the same way using $20 \mu \mathrm{g}$ of PCR1 product along with primer EpMap_9 and one of 20 illumina index primers (EpMap_idx) using the following cycling parameter: 95 ${ }^{\circ} \mathrm{C}$ for 3 minutes, 21 cycles of $98^{\circ} \mathrm{C} 20$ seconds, $56{ }^{\circ} \mathrm{C} 15$ seconds, $72{ }^{\circ} \mathrm{C}$ for 25 seconds and $72{ }^{\circ} \mathrm{C} 30$ seconds final extension. Final libraries of the correct length ( 400 bp) were gel-purified on a $2 \%(w / v)$ agarosegel and subjected to fragment analyzer analysis (Advanced Analytical Technologies) using DNF-473 Standard Sensitivity NGS fragment analysis kit prior to sequencing. High-quality library pools were sequenced on the Illumina MiSeq platform using the reagent kit v3 (2x300 cycles, paired-end) with 10\% PhiX.

\section{Bioinformatic epitope extraction}

Forward and reverse reads were merged in Geneious v10.2.6 and subsequently read into R (v.4.0.4) using the 'read.fasta' function from the 'seqinr' package. The number of occurrences of each epitope within these reads was determined using the 'str_count' function from the 'stringr' package.

\section{Data visualization}

FACS plots were created using FlowJo v10 (BD). Sequence alignments, phylogenetic trees and logo plots were exported from Geneious v10.2.6. Structural epitope visualization was performed using Pymol v2.4.2. $\mathrm{BLI}$ affinity traces were exported from Data Analysis HT v11.0.0.50 (FortéBio). Fig. 1a and $\mathbf{4 f}$ were created with BioRender.com. The generation of all other figures was either already described or they were produced using Prism v8 (Graphpad).

\section{Author contributions}

D.N., A.Y. and S.T.R. conceived the study and wrote the manuscript. D.N. and L.C. performed mouse experiments and library preparations. A.Y., A.A., R.K. performed antibody repertoire and epitope analysis. D.N. and T.C. expressed and validated antibodies. D.N., R.B.R. and T.C. performed BLI measurements. D.N. and R.A.E. performed epitope binning experiments. D.N. performed epitope mapping experiments. M.D.T. and R.A. assisted with cell sorting. S.T.R., A.O. and D.J.L. supervised the study. 
bioRxiv preprint doi: https://doi.org/10.1101/2021.07.16.452687; this version posted July $16,2021$. The copyright holder for this preprint (which was not certified by peer review) is the author/funder, who has granted bioRxiv a license to display the preprint in perpetuity. It is made available under aCC-BY-ND 4.0 International license.

\section{Acknowledgments}

We acknowledge the ETH Zurich D-BSSE Single Cell Unit and the Genomics Facility Basel for excellent support and assistance, in particular I. Nissen, T. Schär, E. Burcklen, T. Horn and C. Beisel. We also would like to thank M.D. Hussherr and G. Camenisch for assistance with animal authorization and experiments. pB33eCPX was a gift from Patrick Daugherty (Addgene plasmid \# 23336; http://n2t.net/addgene:23336; RRID:Addgene_23336). This work was supported by the European Research Council Starting Grant 679403 (to S.T.R.) and ETH Zurich Research Grants (to S.T.R.). The professorship of S.T.R. is supported by an endowment from the S. Leslie Misrock Foundation.

\section{REFERENCES}

1. Slifka, M. K., Antia, R., Whitmire, J. K. \& Ahmed, R. Humoral immunity due to long-lived plasma cells. Immunity 8, 363-372 (1998).

2. Manz, R. A., Hauser, A. E., Hiepe, F. \& Radbruch, A. Maintenance of serum antibody levels. Annu. Rev. Immunol. 23, 367-386 (2005).

3. Weinstein, J. A., Jiang, N., White, R. A., 3rd, Fisher, D. S. \& Quake, S. R. High-throughput sequencing of the zebrafish antibody repertoire. Science 324, 807-810 (2009).

4. Jiang, N. et al. Determinism and stochasticity during maturation of the zebrafish antibody repertoire. Proc. Natl. Acad. Sci. U. S. A. 108, 5348-5353 (2011).

5. Elhanati, Y. et al. Inferring processes underlying B-cell repertoire diversity. Philos. Trans. R. Soc. Lond. B Biol. Sci. 370, 20140243 (2015).

6. Greiff, V. et al. Systems analysis reveals high genetic and antigen-driven predetermination of antibody repertoires throughout B cell development. Cell Rep. 19, 1467-1478 (2017).

7. Briney, B., Inderbitzin, A., Joyce, C. \& Burton, D. R. Commonality despite exceptional diversity in the baseline human antibody repertoire. Nature 566, 393-397 (2019).

8. Soto, C. et al. High frequency of shared clonotypes in human B cell receptor repertoires. Nature 566, 398-402 (2019).

9. Amanna, I. J., Carlson, N. E. \& Slifka, M. K. Duration of humoral immunity to common viral and vaccine antigens. N. Engl. J. Med. 357, 1903-1915 (2007).

10. Ellebedy, A. et al. SARS-CoV-2 infection induces long-lived bone marrow plasma cells in humans. Res Sq (2020) doi:10.21203/rs.3.rs-132821/v1.

11. Akkaya, M., Kwak, K. \& Pierce, S. K. B cell memory: building two walls of protection against pathogens. Nat. Rev. Immunol. 20, 229-238 (2020).

12. Hozumi, N. \& Tonegawa, S. Evidence for somatic rearrangement of immunoglobulin genes coding for variable and constant regions. Proc. Natl. Acad. Sci. U. S. A. 73, 3628-3632 (1976).

13. Eisen, H. N. \& Siskind, G. W. Variations in affinities of antibodies during the immune response. Biochemistry 3, 996-1008 (1964).

14. Weigert, M. G., Cesari, I. M., Yonkovich, S. J. \& Cohn, M. Variability in the lambda light chain sequences of mouse antibody. Nature 228, 1045-1047 (1970).

15. Jacob, J., Kelsoe, G., Rajewsky, K. \& Weiss, U. Intraclonal generation of antibody mutants in germinal centres. Nature 354, 389-392 (1991).

16. Burnet, F. M. A modification of Jerne's theory of antibody production using the concept of clonal selection. CA Cancer J. Clin. 26, 119-121 (1976).

17. Victora, G. D. \& Nussenzweig, M. C. Germinal centers. Annu. Rev. Immunol. 30, 429-457 (2012).

18. Nutt, S. L., Hodgkin, P. D., Tarlinton, D. M. \& Corcoran, L. M. The generation of antibody-secreting plasma cells. Nat. Rev. Immunol. 15, 160-171 (2015).

19. Reddy, S. T. et al. Monoclonal antibodies isolated without screening by analyzing the variable-gene repertoire of plasma cells. Nat. Biotechnol. 28, 965-969 (2010).

20. Laserson, U. et al. High-resolution antibody dynamics of vaccine-induced immune responses. Proc. Natl. Acad. Sci. U. S. A. 111, 4928-4933 (2014).

21. DeKosky, B. J. et al. Large-scale sequence and structural comparisons of human naive and antigenexperienced antibody repertoires. Proc. Natl. Acad. Sci. U. S. A. 113, E2636-45 (2016).

22. Ellebedy, A. H. et al. Defining antigen-specific plasmablast and memory B cell subsets in human blood after viral infection or vaccination. Nat. Immunol. 17, 1226-1234 (2016). 
23. Setliff, I. et al. High-throughput mapping of B cell receptor sequences to antigen specificity. Cell 179, 1636-1646.e15 (2019).

24. Horns, F., Dekker, C. L. \& Quake, S. R. Memory B cell activation, broad anti-influenza antibodies, and bystander activation revealed by single-cell transcriptomics. Cell Rep. 30, 905-913.e6 (2020).

25. Gérard, A. et al. High-throughput single-cell activity-based screening and sequencing of antibodies using droplet microfluidics. Nat. Biotechnol. 38, 715-721 (2020).

26. Goodwin, E. et al. Infants infected with respiratory syncytial virus generate potent neutralizing antibodies that lack somatic hypermutation. Immunity 48, 339-349.e5 (2018).

27. Cao, Y. et al. Potent neutralizing antibodies against SARS-CoV-2 identified by high-throughput singlecell sequencing of convalescent patients' B cells. Cell 182, 73-84.e16 (2020).

28. Gilchuk, P. et al. Integrated pipeline for the accelerated discovery of antiviral antibody therapeutics. Nat. Biomed. Eng. 4, 1030-1043 (2020).

29. Rogers, T. F. et al. Isolation of potent SARS-CoV-2 neutralizing antibodies and protection from disease in a small animal model. Science 369, 956-963 (2020).

30. Wec, A. Z. et al. Broad neutralization of SARS-related viruses by human monoclonal antibodies. Science 369, 731-736 (2020).

31. Wang, B. et al. Facile discovery of a diverse panel of anti-Ebola virus antibodies by immune repertoire mining. Sci. Rep. 5, (2015).

32. Wine, Y. et al. Molecular deconvolution of the monoclonal antibodies that comprise the polyclonal serum response. Proc. Natl. Acad. Sci. U. S. A. 110, 2993-2998 (2013).

33. Lavinder, J. J. et al. Identification and characterization of the constituent human serum antibodies elicited by vaccination. Proc. Natl. Acad. Sci. U. S. A. 111, 2259-2264 (2014).

34. Voss, W. N. et al. Prevalent, protective, and convergent IgG recognition of SARS-CoV-2 non-RBD spike epitopes. Science (2021) doi:10.1126/science.abg5268.

35. Paus, D. et al. Antigen recognition strength regulates the choice between extrafollicular plasma cell and germinal center B cell differentiation. J. Exp. Med. 203, 1081-1091 (2006).

36. Phan, T. G. et al. High affinity germinal center B cells are actively selected into the plasma cell compartment. J. Exp. Med. 203, 2419-2424 (2006).

37. Taylor, J. J., Pape, K. A., Steach, H. R. \& Jenkins, M. K. Humoral immunity. Apoptosis and antigen affinity limit effector cell differentiation of a single naïve B cell. Science 347, 784-787 (2015).

38. Weisel, F. J., Zuccarino-Catania, G. V., Chikina, M. \& Shlomchik, M. J. A temporal switch in the germinal center determines differential output of memory B and plasma cells. Immunity 44, 116-130 (2016).

39. Chan, T. D. et al. Antigen affinity controls rapid T-dependent antibody production by driving the expansion rather than the differentiation or extrafollicular migration of early plasmablasts. J. Immunol. 183, 3139-3149 (2009).

40. Tas, J. M. J. et al. Visualizing antibody affinity maturation in germinal centers. Science $\mathbf{3 5 1}, \mathbf{1 0 4 8 - 1 0 5 4}$ (2016).

41. Gitlin, A. D., Shulman, Z. \& Nussenzweig, M. C. Clonal selection in the germinal centre by regulated proliferation and hypermutation. Nature 509, 637-640 (2014).

42. Slifka, M. K., Matloubian, M. \& Ahmed, R. Bone marrow is a major site of long-term antibody production after acute viral infection. J. Virol. 69, 1895-1902 (1995).

43. Manz, R. A., Thiel, A. \& Radbruch, A. Lifetime of plasma cells in the bone marrow. Nature 388, 133-134 (1997).

44. Han, A., Glanville, J., Hansmann, L. \& Davis, M. M. Linking T-cell receptor sequence to functional phenotype at the single-cell level. Nat. Biotechnol. 32, 684-692 (2014).

45. Gate, D. et al. Clonally expanded CD8 T cells patrol the cerebrospinal fluid in Alzheimer's disease. Nature 577, 399-404 (2020).

46. Lingwood, D. et al. Structural and genetic basis for development of broadly neutralizing influenza antibodies. Nature 489, 566-570 (2012).

47. Barnes, C. O. et al. SARS-CoV-2 neutralizing antibody structures inform therapeutic strategies. Nature 588, 682-687 (2020).

48. Kreer, C. et al. Longitudinal isolation of potent near-germline SARS-CoV-2-neutralizing antibodies from COVID-19 patients. Cell 182, 1663-1673 (2020).

49. Miho, E., Roškar, R., Greiff, V. \& Reddy, S. T. Large-scale network analysis reveals the sequence space architecture of antibody repertoires. Nat. Commun. 10, 1321 (2019).

50. Friedensohn, S. et al. Convergent selection in antibody repertoires is revealed by deep learning. bioRxiv (2020) doi:10.1101/2020.02.25.965673. 
51. Batista, F. D. \& Neuberger, M. S. Affinity dependence of the B cell response to antigen: a threshold, a ceiling, and the importance of off-rate. Immunity 8, 751-759 (1998).

52. Rice, J. J. \& Daugherty, P. S. Directed evolution of a biterminal bacterial display scaffold enhances the display of diverse peptides. Protein Eng. Des. Sel. 21, 435-442 (2008).

53. Victora, G. D. et al. Germinal center dynamics revealed by multiphoton microscopy with a photoactivatable fluorescent reporter. Cell 143, 592-605 (2010).

54. Shulman, Z. et al. Dynamic signaling by $T$ follicular helper cells during germinal center $B$ cell selection. Science 345, 1058-1062 (2014).

55. Gitlin, A. D. et al. HUMORAL IMMUNITY. T cell help controls the speed of the cell cycle in germinal center B cells. Science 349, 643-646 (2015).

56. Mesin, L. et al. Restricted clonality and limited germinal center reentry characterize memory B cell reactivation by boosting. Cell 180, 92-106.e11 (2020).

57. Burnett, D. L. et al. Germinal center antibody mutation trajectories are determined by rapid self/foreign discrimination. Science 360, 223-226 (2018).

58. Shehata, L. et al. Affinity maturation enhances antibody specificity but compromises conformational stability. Cell Rep. 28, 3300-3308.e4 (2019).

59. Eyer, K. et al. Single-cell deep phenotyping of IgG-secreting cells for high-resolution immune monitoring. Nat. Biotechnol. 35, 977-982 (2017).

60. Angeletti, D. et al. Defining B cell immunodominance to viruses. Nat. Immunol. 18, 456-463 (2017).

61. Yermanos, A. et al. Platypus: an open-access software for integrating lymphocyte single-cell immune repertoires with transcriptomes. NAR Genom Bioinform 3, lqab023 (2021).

62. Bolotin, D. A. et al. MiXCR: software for comprehensive adaptive immunity profiling. Nat. Methods 12, 380-381 (2015).

63. Loo, M. J. vander. The stringdist Package for Approximate String Matching. $R$ J. 6, 111 (2014).

64. Gu, Z., Gu, L., Eils, R., Schlesner, M. \& Brors, B. circlize Implements and enhances circular visualization in R. Bioinformatics 30, 2811-2812 (2014).

65. Brochet, X., Lefranc, M.-P. \& Giudicelli, V. IMGT/V-QUEST: the highly customized and integrated system for IG and TR standardized V-J and V-D-J sequence analysis. Nucleic Acids Res. 36, W503-8 (2008).

66. Vazquez-Lombardi, R. et al. Transient expression of human antibodies in mammalian cells. Nat. Protoc. 13, 99-117 (2018).

67. Pogson, M., Parola, C., Kelton, W. J., Heuberger, P. \& Reddy, S. T. Immunogenomic engineering of a plug-and-(dis)play hybridoma platform. Nat. Commun. 7, 12535 (2016).

68. Parola, C. et al. Antibody discovery and engineering by enhanced CRISPR-Cas9 integration of variable gene cassette libraries in mammalian cells. MAbs 11, 1367-1380 (2019).

69. Getz, J. A., Schoep, T. D. \& Daugherty, P. S. Peptide discovery using bacterial display and flow cytometry. Methods Enzymol. 503, 75-97 (2012).

70. Menzel, U. et al. Comprehensive evaluation and optimization of amplicon library preparation methods for high-throughput antibody sequencing. PLoS One 9, e96727 (2014). 
A

A
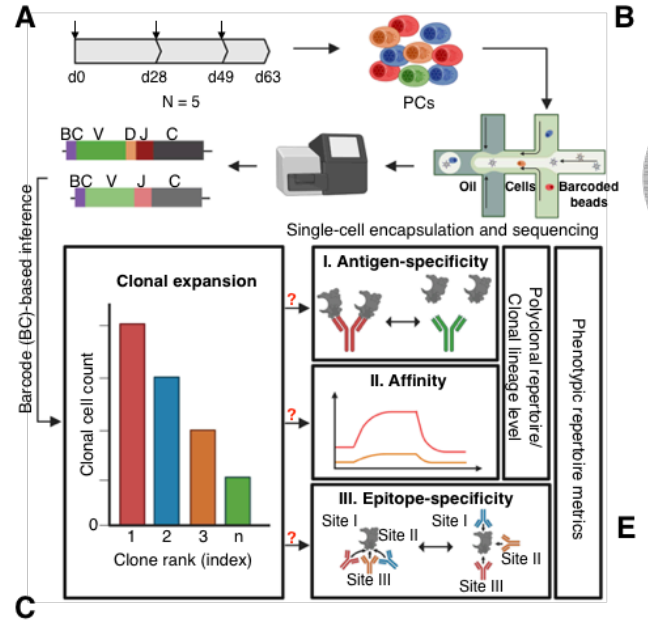

c

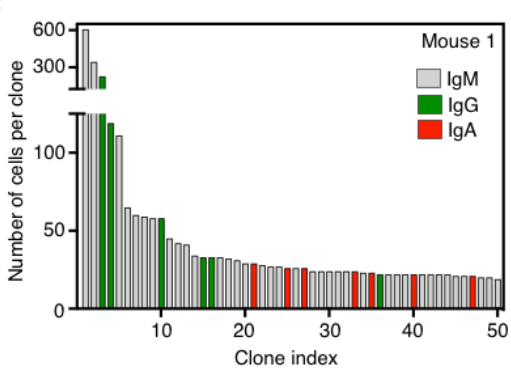

D
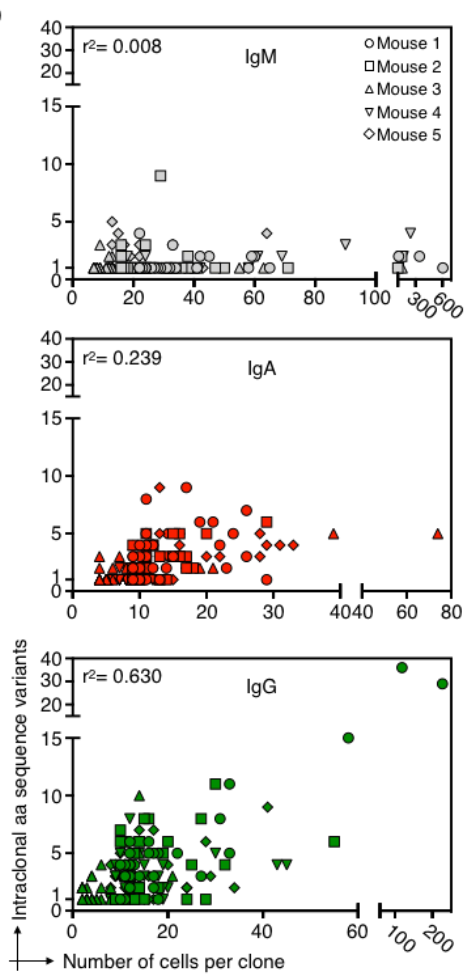

B

G

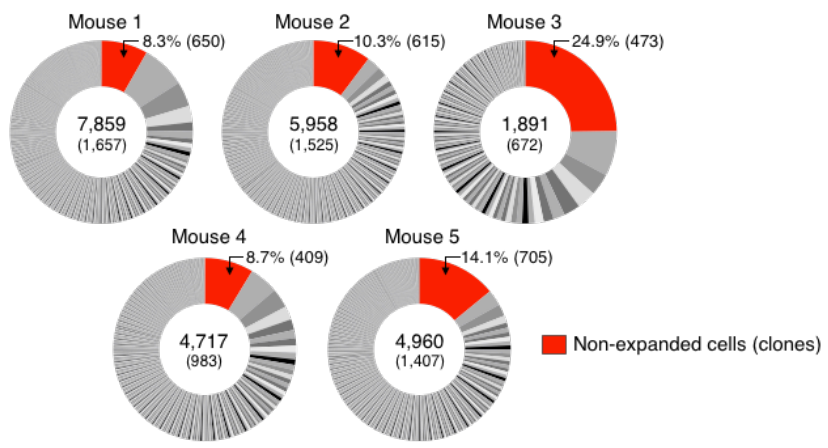

E Surface display ELISA $\mathbf{F}$

F Surface display ELISA
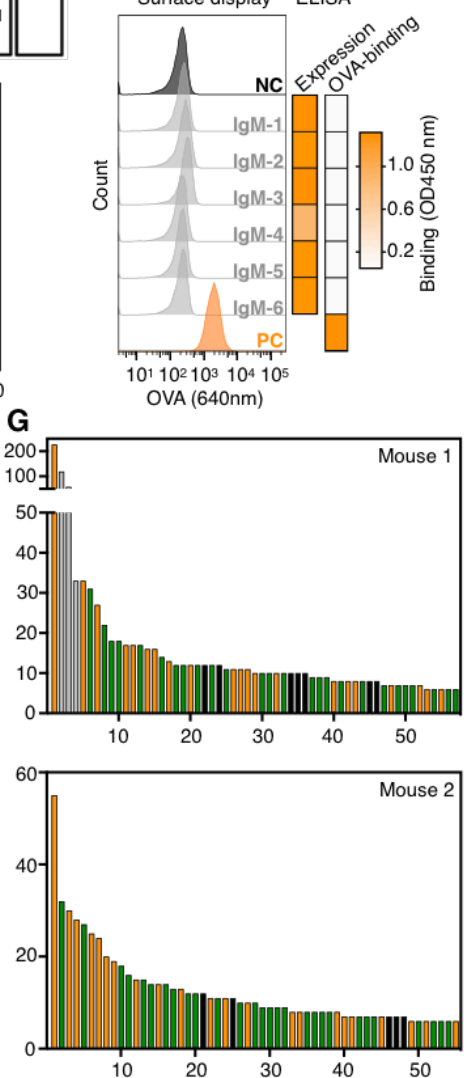

$\mathrm{H}$
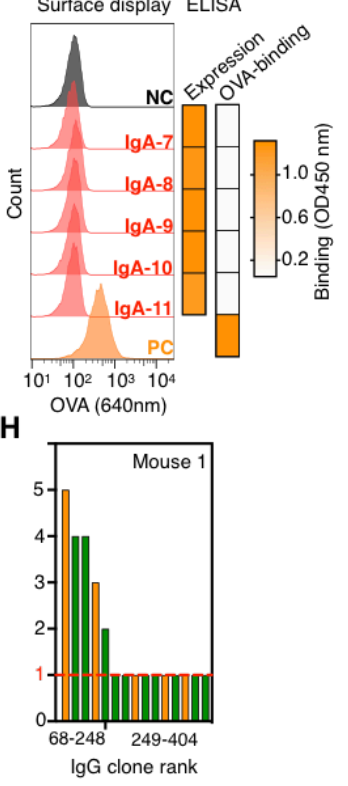

$\square$ Binder

No binder

$\square$ No expression

not tested

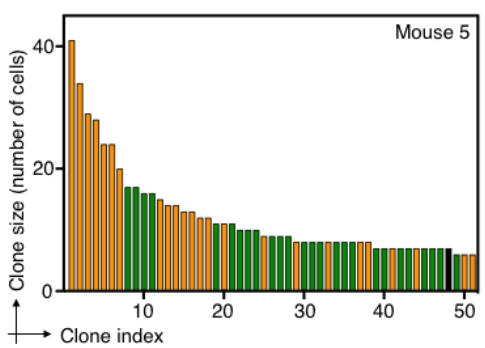

Figure 1. The antigen specificity of clonally expanded plasma cell antibody repertoires. a. Schematic project outline. Arrows on top of the timeline graph (top left) indicate time points of mouse immunization. $\mathbf{b}$. Pie charts indicate the fraction of productive plasma cells (PCs) per clone and mouse captured by single-cell sequencing (scSeq). Numbers in the center indicate the total number of productive cells (top) and clones (bottom). Unexpanded clones are shown in red and their cellular percentages and total numbers are indicated on top. Clone definition is based on unique CDRH3-CDRL3 amino acid (a.a.) sequence. c. Representative clonal expansion profile for the 50 most expanded clones of Mouse 1 (MS-1). Clones are colored by isotype majority and color-coded in grey $(\operatorname{lgM})$, green $(\lg G)$ and red $(\lg A)$. Profiles of all mice are shown in Extended Data Figure 2. d. Correlation between the number of intraclonal antibody sequence variants (a.a.) and the number of cells per clone for the 30 most expanded clones per isotype. e, f. Screening of six and five 
bioRxiv preprint doi: https://doi.org/10.1101/2021.07.16.452687; this version posted July 16, 2021. The copyright holder for this preprint (which was not certified by peer review) is the author/funder, who has granted bioRxiv a license to display the preprint in perpetuity. It is made available under aCC-BY-ND 4.0 International license.

expanded IgM and IgA clones of MS-1 for antigen binding. Left: Flow cytometry histogram plot shows ovalbumin (OVA) labeling of hybridoma cell lines with stable surface expression of selected antibody clones (from IgM or IgA PCs) or expression of positive or negative controls (antibodies with defined binding to OVA (PC, orange) or to hen egg lysozyme (NC, dark grey)). Right: heatmaps indicate antibody expression and binding to OVA based on endpoint ELISA (data obtained from Extended Data Figure 4d and 5b). g. Antigenspecificity profiling of the top 50-60 expanded clones of MS-1, -2 and -5 . Clones with an endpoint ELISA signal $>0.2$ (three-fold above background) are designated as antigen binders (see also Extended Data Figure 6a). h. Antigen-specificity of clones showing lower to no clonal expansion (cell count $=1$, red dotted line) from MS-1. 
bioRxiv preprint doi: https://doi.org/10.1101/2021.07.16.452687; this version posted July 16, 2021. The copyright holder for this preprint (which was not certified by peer review) is the author/funder, who has granted bioRxiv a license to display the preprint in perpetuity. It is made available under aCC-BY-ND 4.0 International license.

A
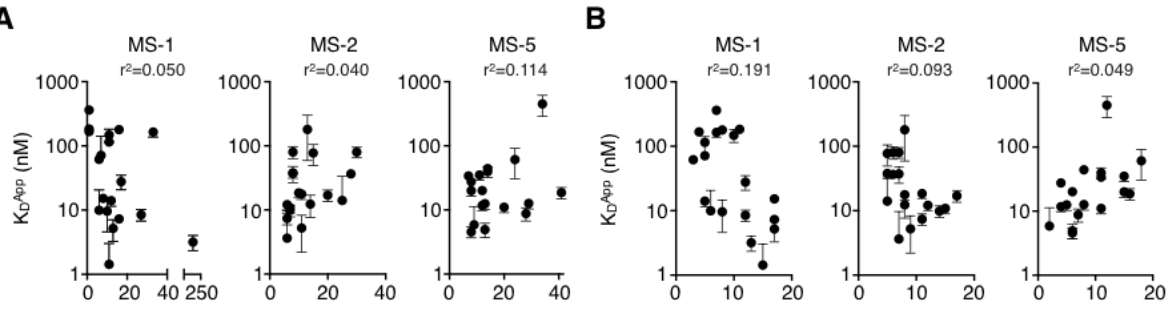

C

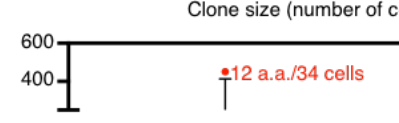

Amino acid distance to germline

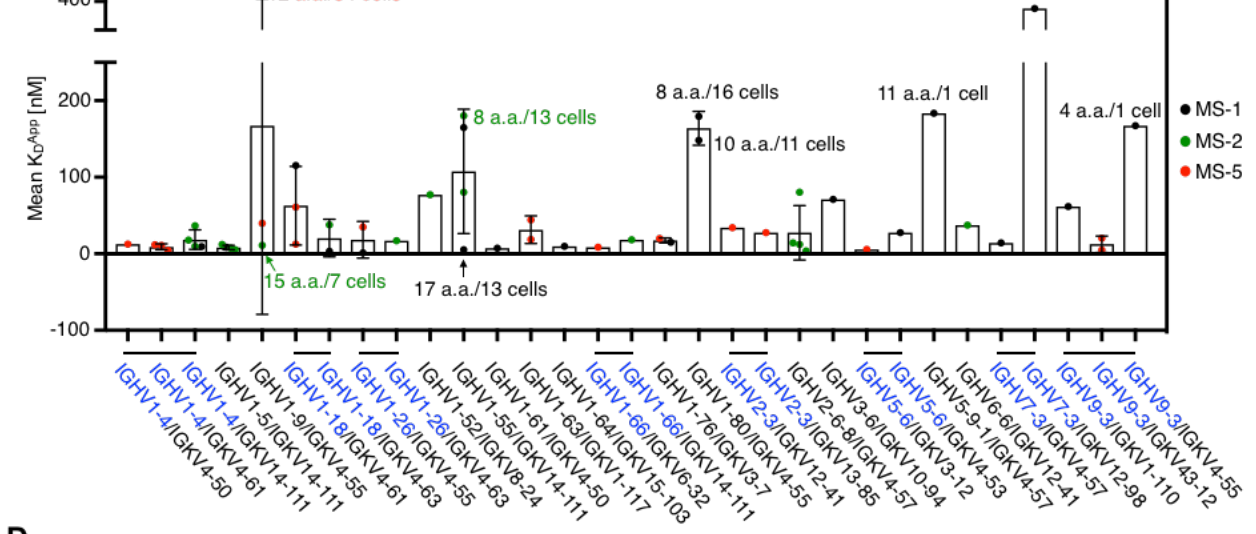

D
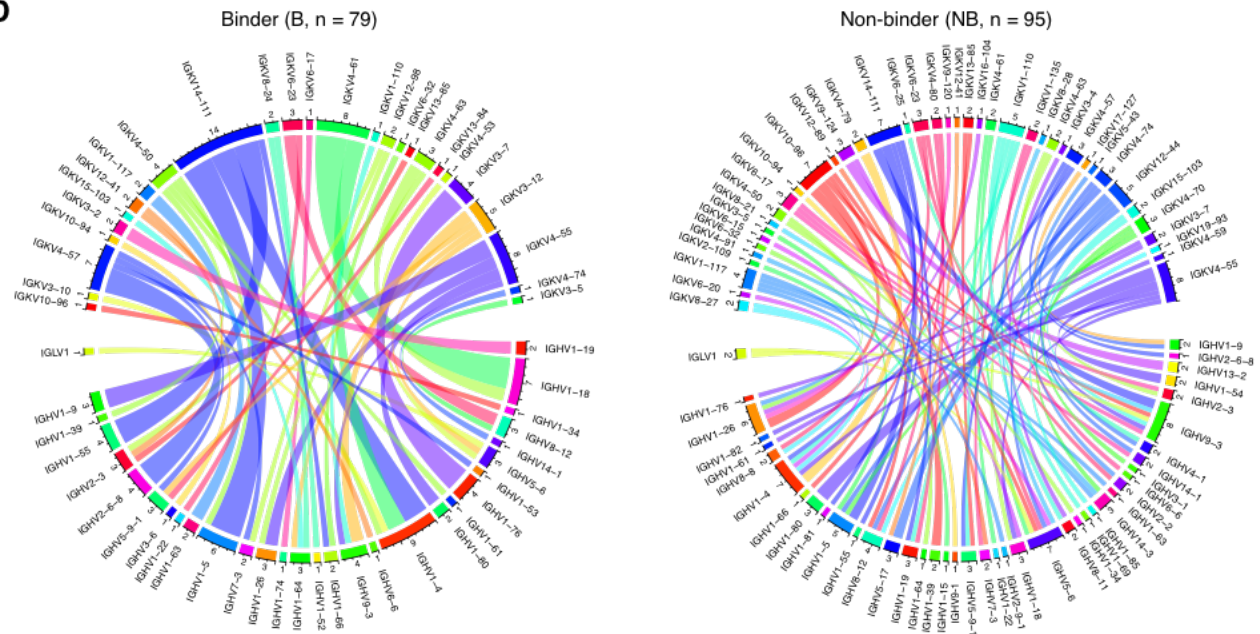

E

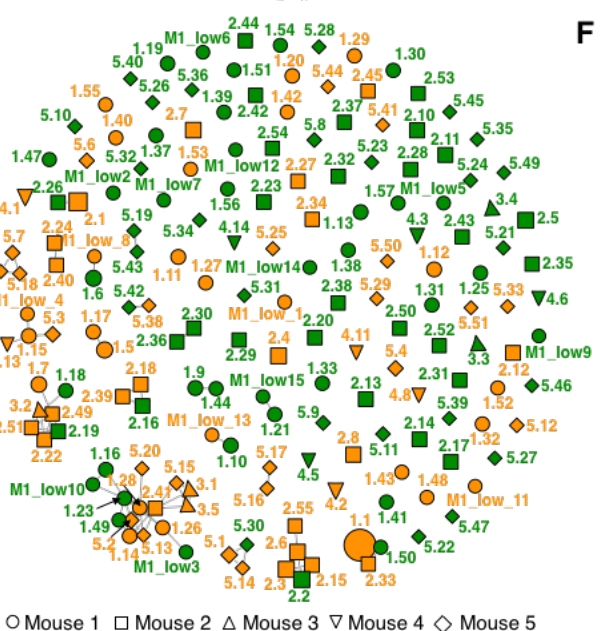

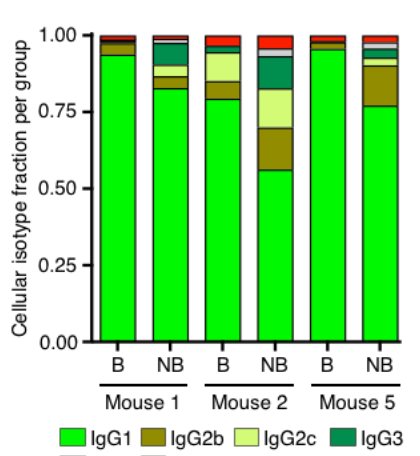

$\square \lg M \quad \square \operatorname{Ig} A$

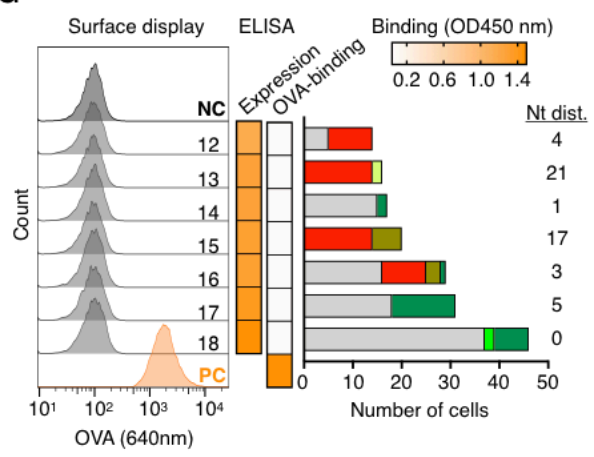

Figure 2. Genotype-phenotype correlations of polyclonal antigen-specific plasma cell repertoires. a, b. Correlation between clonal apparent dissociation constant $\left(K_{D}\right)$ and clone size (number of cells per clone, a) as well as clonal a.a. distance to germline (b) for MS-1, -2 and -5 . Error bars indicate standard deviation $(n=$ 2-3 measurements of $K_{D}$ ). c. Correlation between $K_{D}$ and $V_{H}-V_{L}$ germline $V$-gene usage. $V$-gene pairs featuring shared $V_{H}$ are indicated in blue with a shared horizontal bar on top. Some data points at the extremes are 
bioRxiv preprint doi: https://doi.org/10.1101/2021.07.16.452687; this version posted July 16, 2021. The copyright holder for this preprint (which was not certified by peer review) is the author/funder, who has granted bioRxiv a license to display the preprint in perpetuity. It is made available under aCC-BY-ND 4.0 International license.

additionally labeled with the amino acid (a.a.) distance to germline and number of cells for their respective clones. Error bars indicate standard deviation. $d$. Circos plots show the diversity of $\mathrm{V}_{\mathrm{H}}-\mathrm{V}_{\mathrm{L}}$-gene pairings in the antigen-binding and non-binding group of clones. Each line indicates the germline V-gene usage for an individual $\mathrm{V}_{\mathrm{H}}-\mathrm{V}_{\mathrm{L}}$ gene pair. The inner track number and the corresponding thickness of the bar indicate the number of clones utilizing a given germline gene. Color corresponds to the respective germline gene. e. Similarity network plot for all 174 antigen-binders and non-binders tested across all mice. Edges represent clones separated by edit distance of $<4$ a.a. in CDRH3-CDRL3 sequences. Extent of clonal expansion is reflected by the size of the nodes. Annotated labels of each node are according to clone ID in Extended Data Table 1 and 2. f. Cellular isotype fractions for all binders (B) and non-binders (NB) per mouse. g. Validation of multi-isotype clones by hybridoma surface staining and ELISA screening. Left and middle: flow cytometry histograms and heatmaps similar to as shown in 1e, f. (ELISA data shown in Extended Data Figure 11). Right: cellular isotype composition of each clone and associated nt distance from germline. 


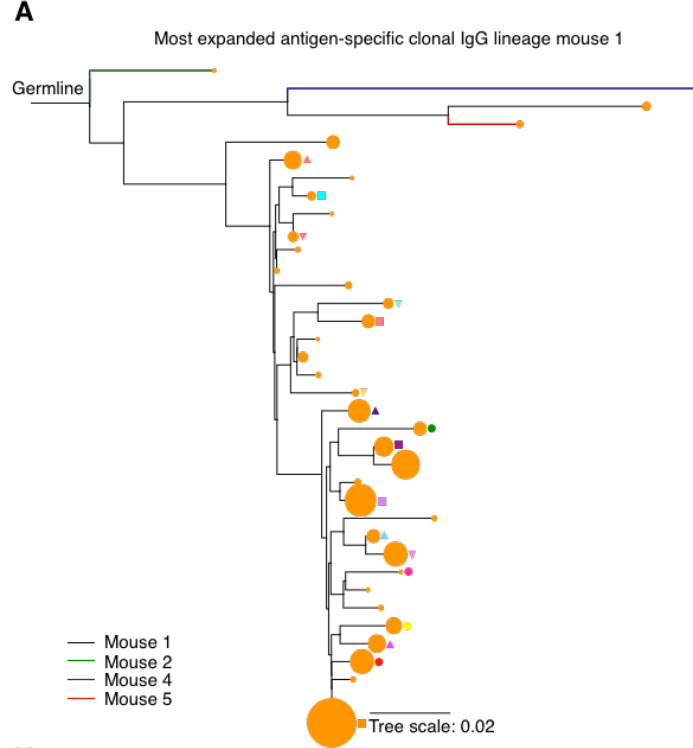

H

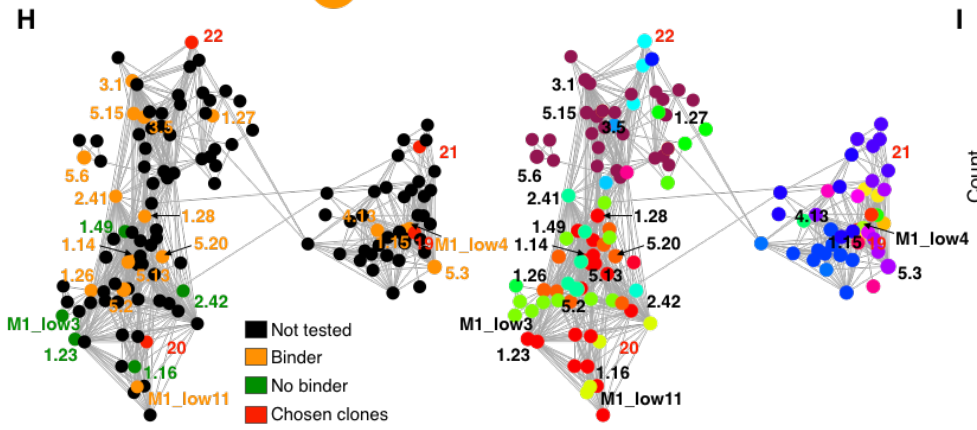

C
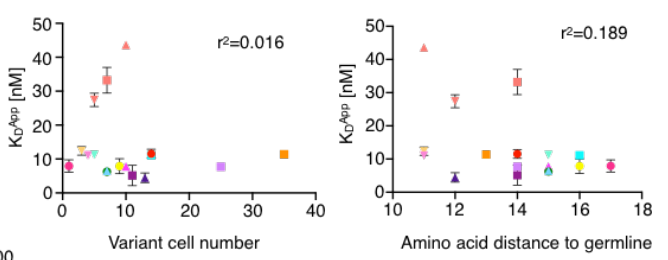

$\mathrm{K}_{\mathrm{D}}^{\mathrm{App}}[\mathrm{nM}]$
$->50-500$
$>15-50$
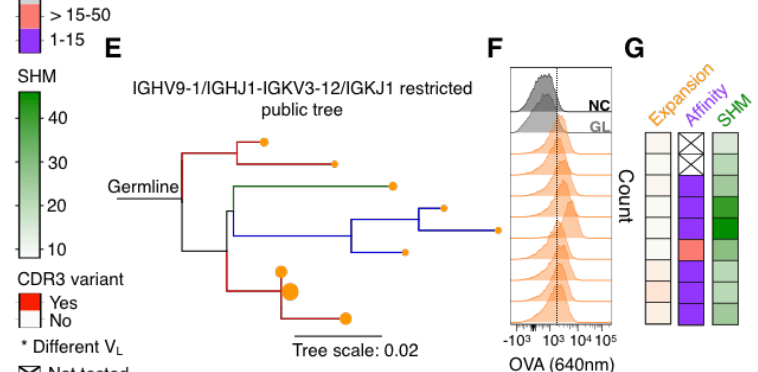

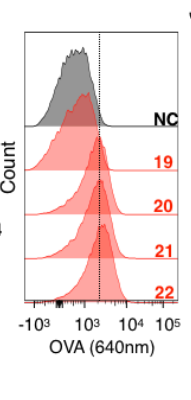

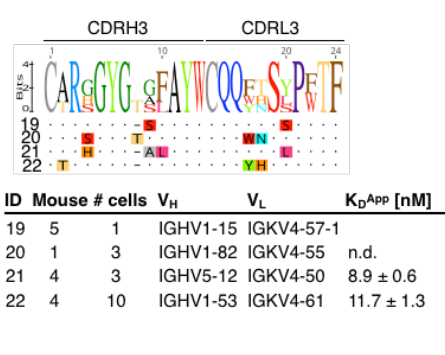

Figure 3. Phenotypic antibody profiling within plasma cell clonal lineages. a. Phylogenetic lineage tree of the most expanded IgG clone of MS-1 (see also Extended Data Fig. 12a and b). Related clones from different mice are indicated by different colors. The size of the orange nodes at the tip of each branch indicates the number of cells per intraclonal variant. Shapes indicate identity of intraclonal variants plotted in c. and d. b. From left to right: heatmaps correspond to intraclonal variant expansion (number of cells per variant), binding affinity $\left(\mathrm{K}_{\mathrm{D}}\right)$, somatic hypermutations (SHM; nucleotide distance to germline) and CDR3 variants (1-6 a.a. edit distance in CDRH3-CDRL3). Clones featuring a different $V_{L}$ are marked by an asterisk. Intraclonal variants from top to bottom correspond to lineage tree variants, as shown in a. c. Correlation between apparent dissociation constant $\left(K_{D}\right)$ and intraclonal variant cell number for all variants indicated in $\mathbf{a}$. Error bars indicate standard deviation $\left(n=3-5\right.$ measurements of $\left.K_{D}\right)$. d. Correlation between $K_{D}$ and amino acid distance to germline. Error bars indicate standard deviation $\left(n=3-5\right.$ measurements of $\left.K_{D}\right)$. e. Phylogenetic lineage tree of clones originating from several mice that have similar sequences (identical $V$ and J-genes, CDRH3-CDRL3 with < 5 a.a. difference) (see also Extended Data Fig. 13a-c). Branch colors reflect mouse ID from a. and node sizes reflect clone size. f. Flow cytometry histograms for OVA binding, similar to 1e, 2f. GL denotes germline, clones correspond to lineage tree shown in e. g. Heatmap shown is similar to $\mathbf{3 b}$. $\mathbf{h}$. Network plots of connected IgG sequence nodes from all mice harboring various $V_{H}-V_{L}$ gene combinations. Edges represent clones separated by edit distance of three or less a.a. based on the concatenated CDR3 sequences. Left: verified binders, non-binders, not tested clones as well as newly chosen clones are shown. Clone ID according to Extended Data Table 1 and 2. Right: $V_{H}-V_{L}$ gene usage visualization. Color code according to Extended Data Fig. 14c. i. Flow cytometry histograms for OVA binding, similar to 1e, 2f, 3f. j. Concatenated CDRH3-CDRL3 a.a. sequence logos for clones selected in $\mathbf{h}$ (red nodes) as well as their antibody characteristics. 

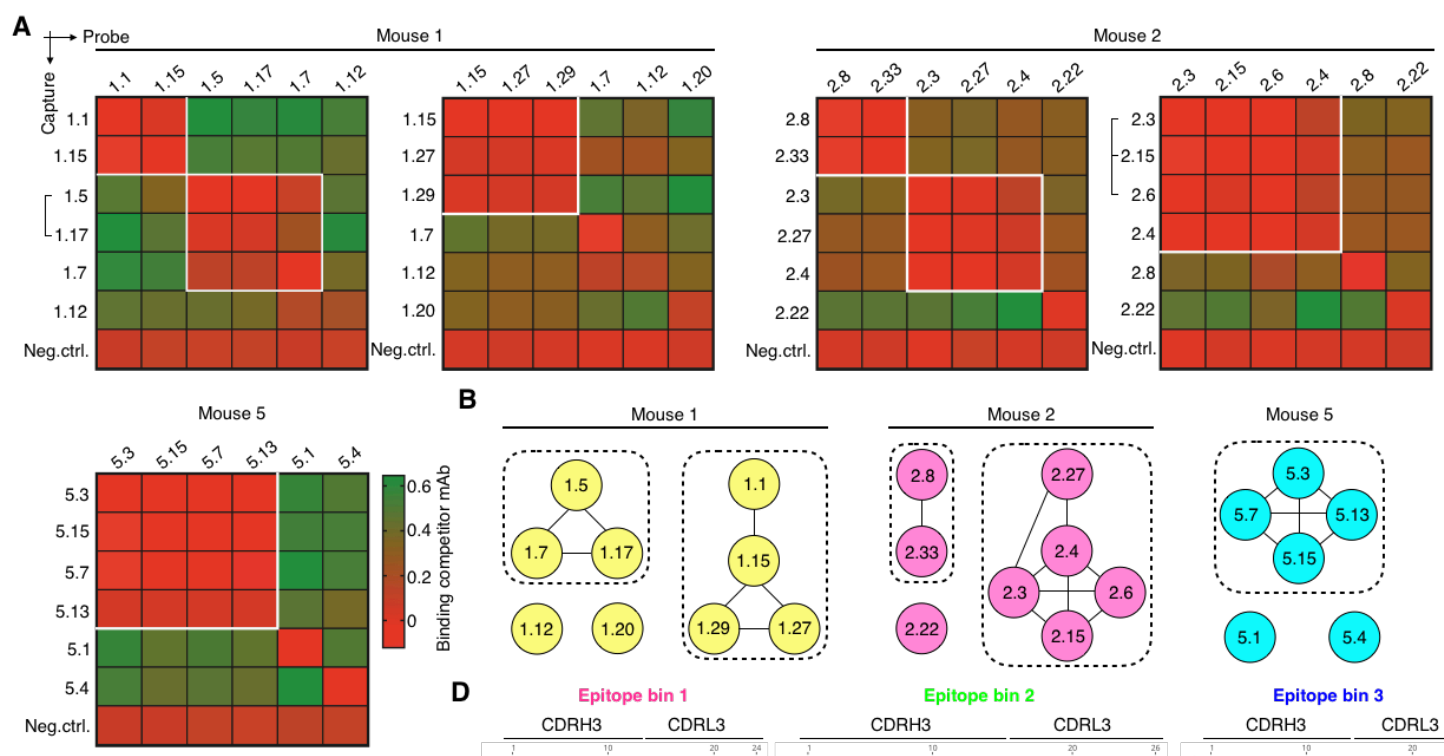

B Mouse 1
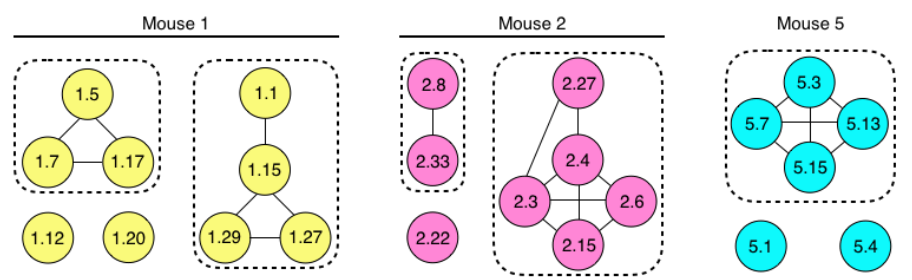

Epitope bin 2
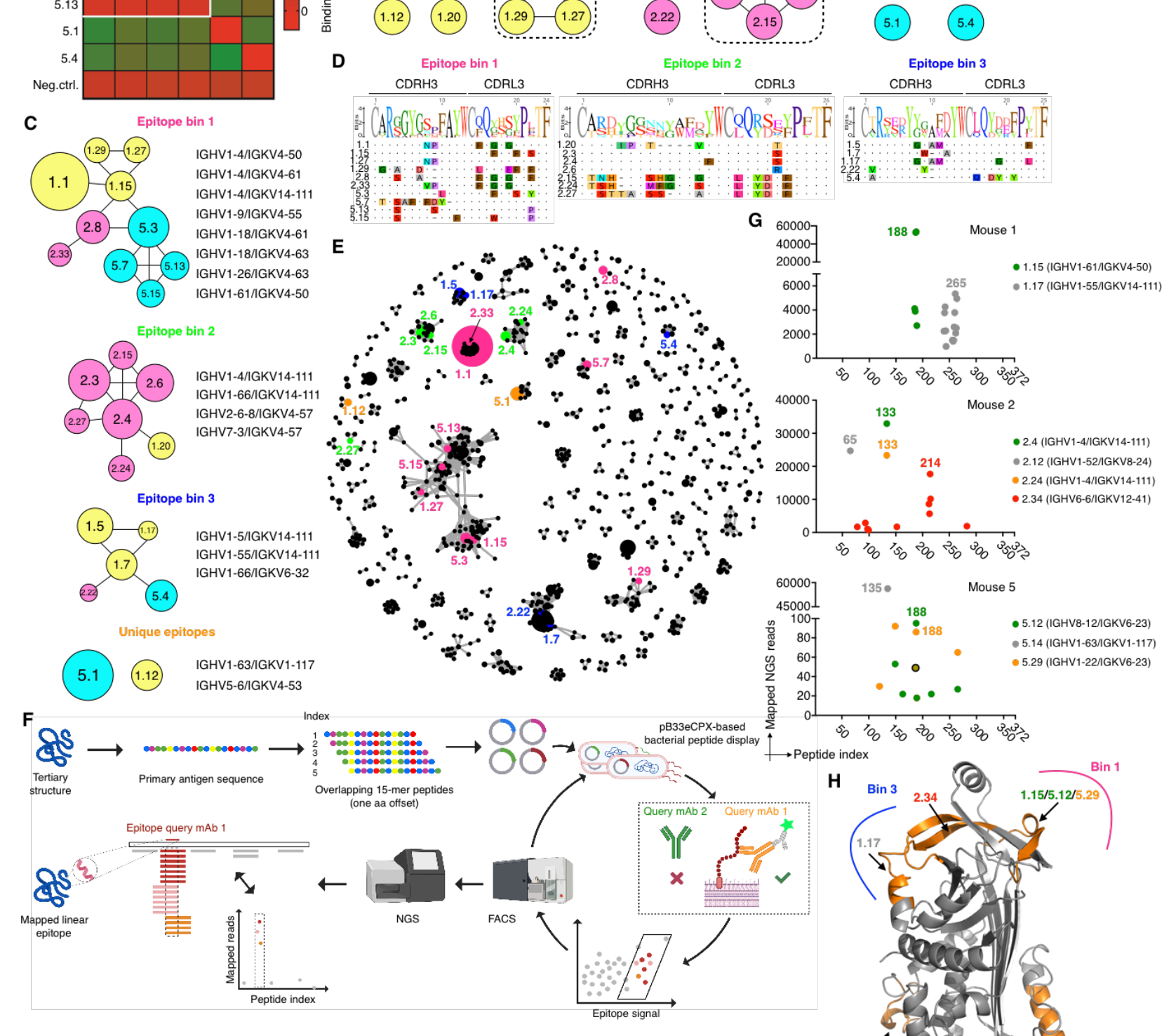

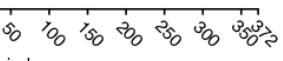

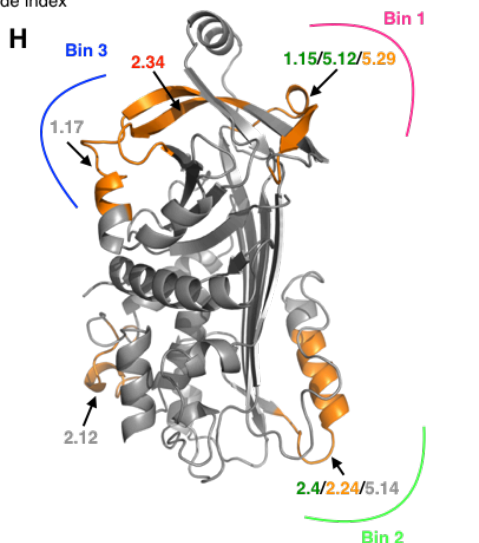

Figure 4. Epitope-targeting space of top expanded clones. a. Heatmaps show competitive antigen binding based on BLI assays for highly expanded antibody clones in each mouse. Antibodies indicated on the left were captured and probe antibodies on top were used to determine cross-competition for epitope access. Red indicates no binding of the probe antibody as a consequence of epitope blocking by the capture antibody, whereas green denotes binding of the competitor antibody. Groups of antibodies that target the 
bioRxiv preprint doi: https://doi.org/10.1101/2021.07.16.452687; this version posted July 16, 2021. The copyright holder for this preprint (which was not certified by peer review) is the author/funder, who has granted bioRxiv a license to display the preprint in perpetuity. It is made available under aCC-BY-ND 4.0 International license.

same epitope (epitope bins) are highlighted in white squares. Brackets indicate clonal variants that share the same $V_{H} V_{L}$ germline $V$-genes which differed only in CDRH3/CDRL3 a.a. sequence. An anti-RSVF capture antibody, which does not bind the antigen was used as negative control for all experiments. Clone ID according to Extended Data Table 1. b. Epitope bins with associated clones as determined in a. Nodes are connected based on observed direct cross-competition. c. Epitope bins as defined by the cross-competition of clones from different mice. Representative V-gene combinations are shown on the right. Nodes are connected based on direct cross-competition and sizes indicate clone size (number of cells per clone). Colors represent mouse ID as shown in b. Results are reflective of Extended Data Fig. 16. d. CDRH3/CDRL3 sequence alignment of bin-specific clones. Sequence logo is shown on top and a.a. residues are highlighted if they are in disagreement with the consensus sequence. e. Mapping of epitope space as determined in $\mathbf{c}$ on a sequence similarity network of all IgG clones across all mice (Extended Data Fig. 9). Edges represent clones with < 4 a.a. difference in CDRH3-CDRL3 sequence. Node color according to bin color in c. Size of clones is reflected by node size. Only those nodes with at least one edge are plotted for visualization purposes. Clone 1.20 is not shown since it was not connected. f. Linear epitope-mapping workflow using bacterial peptide display. g. Epitope mapping results of select clones from MS-1, -2 and -5 . For visualization purposes, only data points with $>700$ mapped reads are shown for MS-1 and -2 and clone 5.14 of MS-5; for clones 5.12 and 5.29 only data points with $>18$ mapped reads are shown. Shared data point between 5.12 and 5.29 is indicated with a circle. Corresponding V-gene combinations are indicated. Separate scatter plots featuring all data points are provided in Extended Data Fig. 18. $\mathbf{h}$. Mapping of epitope bins from $\mathbf{c}$ on to the OVA crystal structure using antibody epitope information obtained in $\mathbf{g}$ (PDB: 1OVA). 
A

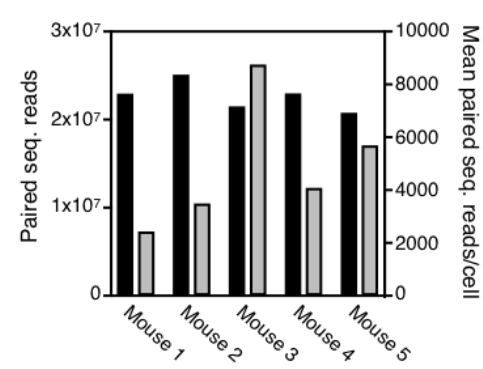

C
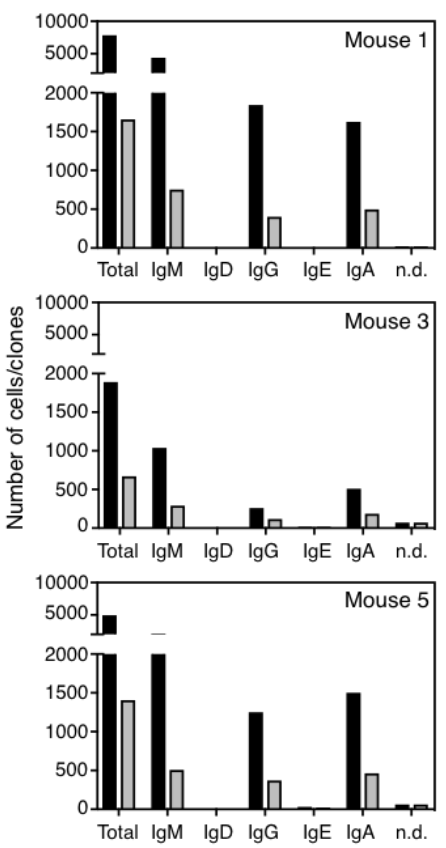

B

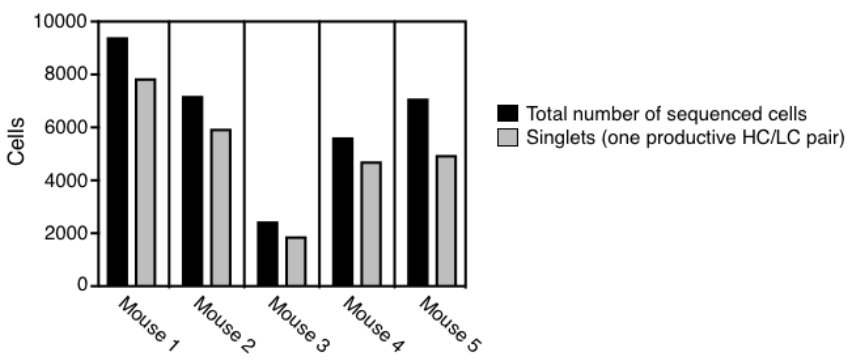

Extended Data Figure 1. Single-cell sequencing statistics. a. Total number of paired sequencing reads per mouse (black, left axis) and mean paired sequencing reads per cell (grey, right axis) for all mice. b. Number of all sequenced cells per mouse (black) and number of cells with one productive, full-length heavy- and lightchain pair (grey). c. Number of sequenced productive cells (black) and clones (grey) with isotype resolution for each mouse. Clonotype definition is based on unique CDRH3-CDRL3 amino acid combination. 
bioRxiv preprint doi: https://doi.org/10.1101/2021.07.16.452687; this version posted July 16, 2021. The copyright holder for this preprint (which was not certified by peer review) is the author/funder, who has granted bioRxiv a license to display the preprint in perpetuity. It is made available under aCC-BY-ND 4.0 International license.

A
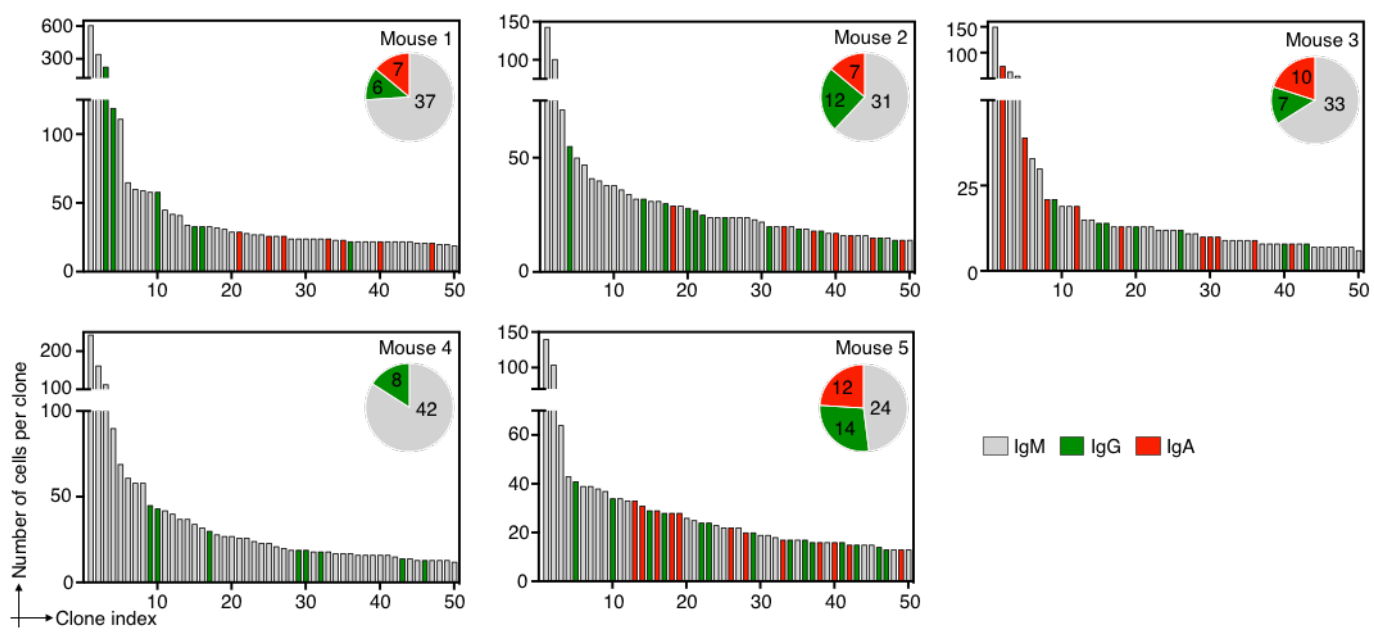

$\square \lg M \square \lg G \square \lg A$

B
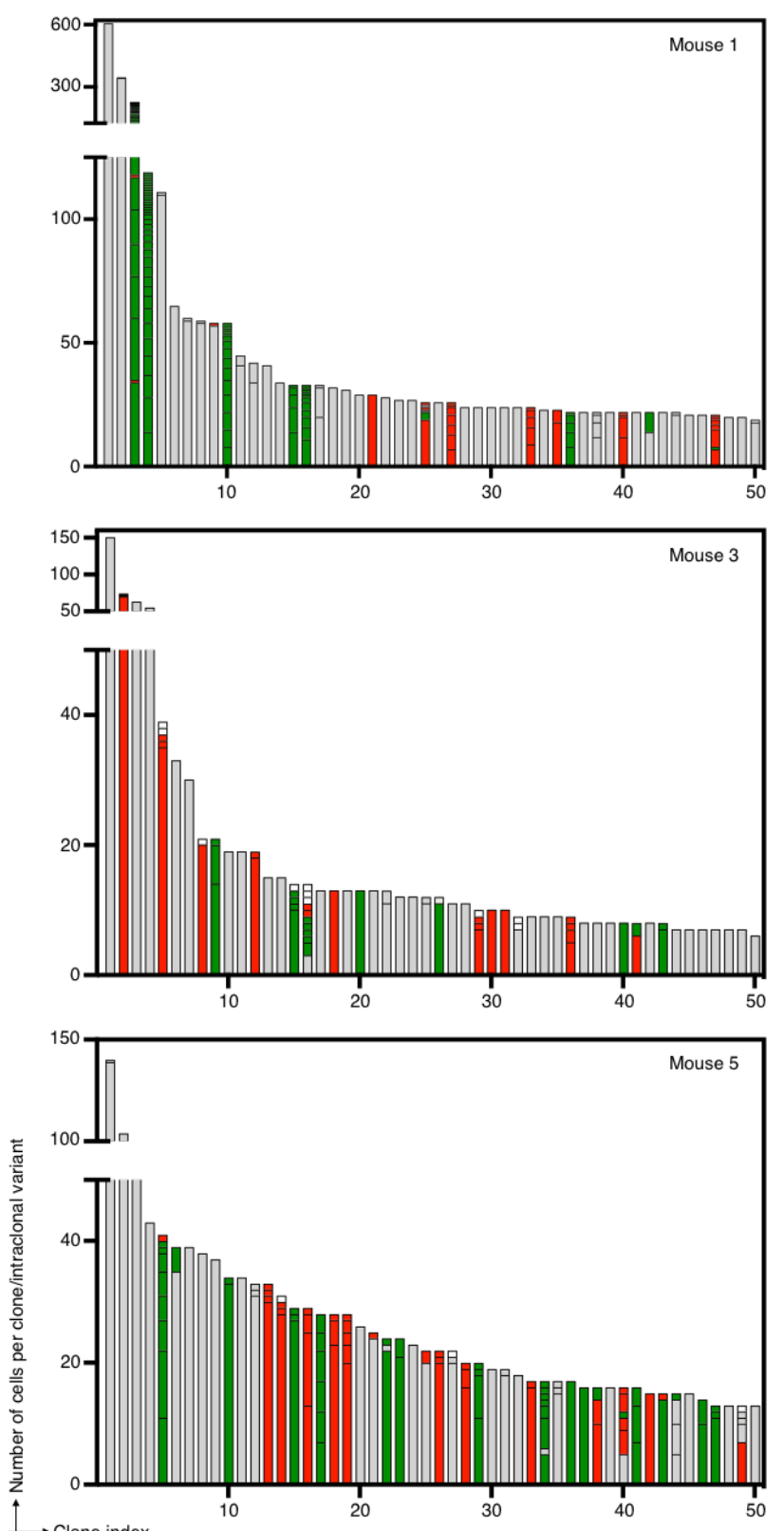
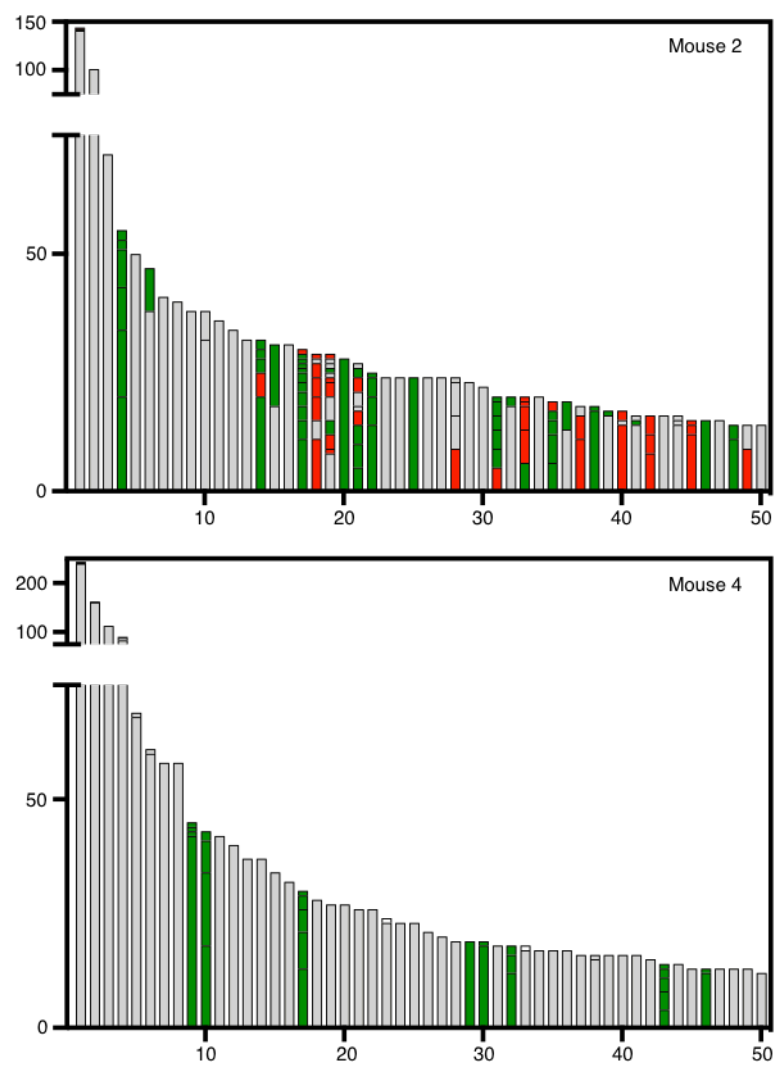

$\square \lg M \square \operatorname{IgG} \square \operatorname{lgA} \square$ n.d.

Extended Data Figure 2. Clonal expansion profiles for the $\mathbf{5 0}$ most expanded clones per mouse. a. Clonal expansion profiles based on isotype majority. Isotypes are indicated in grey (IgM), green (IgG) and red 
bioRxiv preprint doi: https://doi.org/10.1101/2021.07.16.452687; this version posted July 16, 2021. The copyright holder for this preprint (which was not certified by peer review) is the author/funder, who has granted bioRxiv a license to display the preprint in perpetuity. It is made available under aCC-BY-ND 4.0 International license.

(IgA) respectively. Pie-chart inlet indicates the numbers of isotype clones among the top 50 clones shown. $\mathbf{b}$. Clonal expansion profiles indicating all clonal amino acid sequence variants per clone and their respective isotype assignment. Separate clonal sequence variants are shown in stacked bar plots ordered by their respective size from bottom to top. Whenever a smaller sized bar of different isotype origin intersects two bigger bars, this indicates that these cells belong to the clonal variant below. Coloring scheme according to a with unassigned isotype cells shown in white. 
A
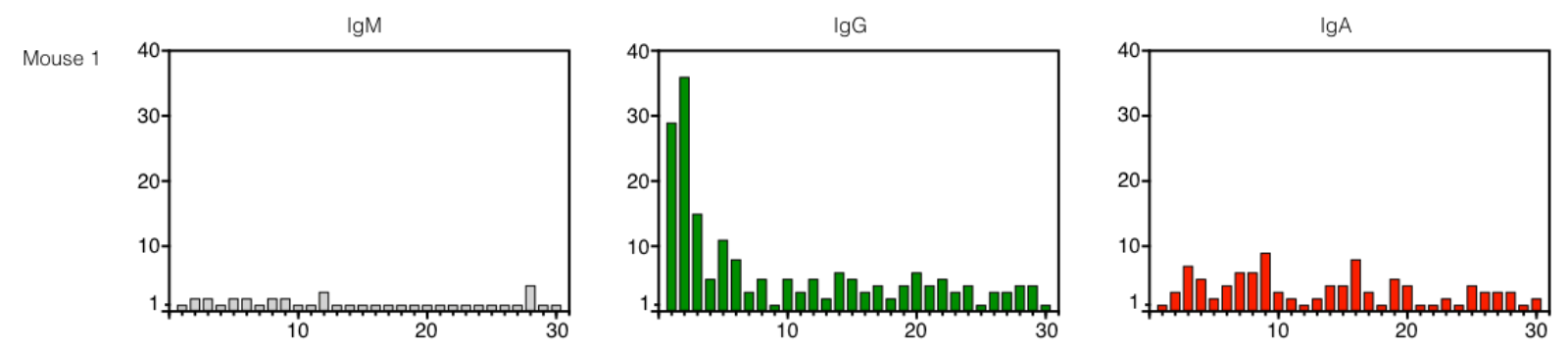

Mouse 2
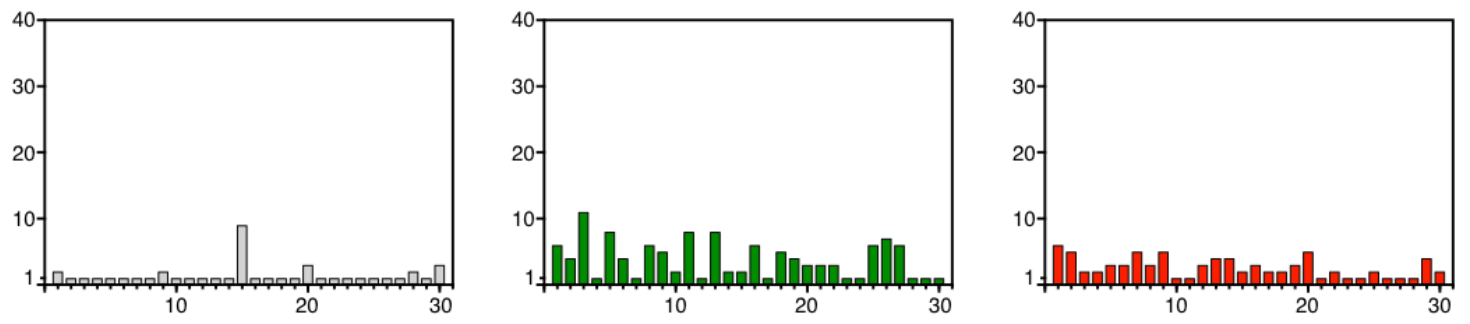

Mouse 3
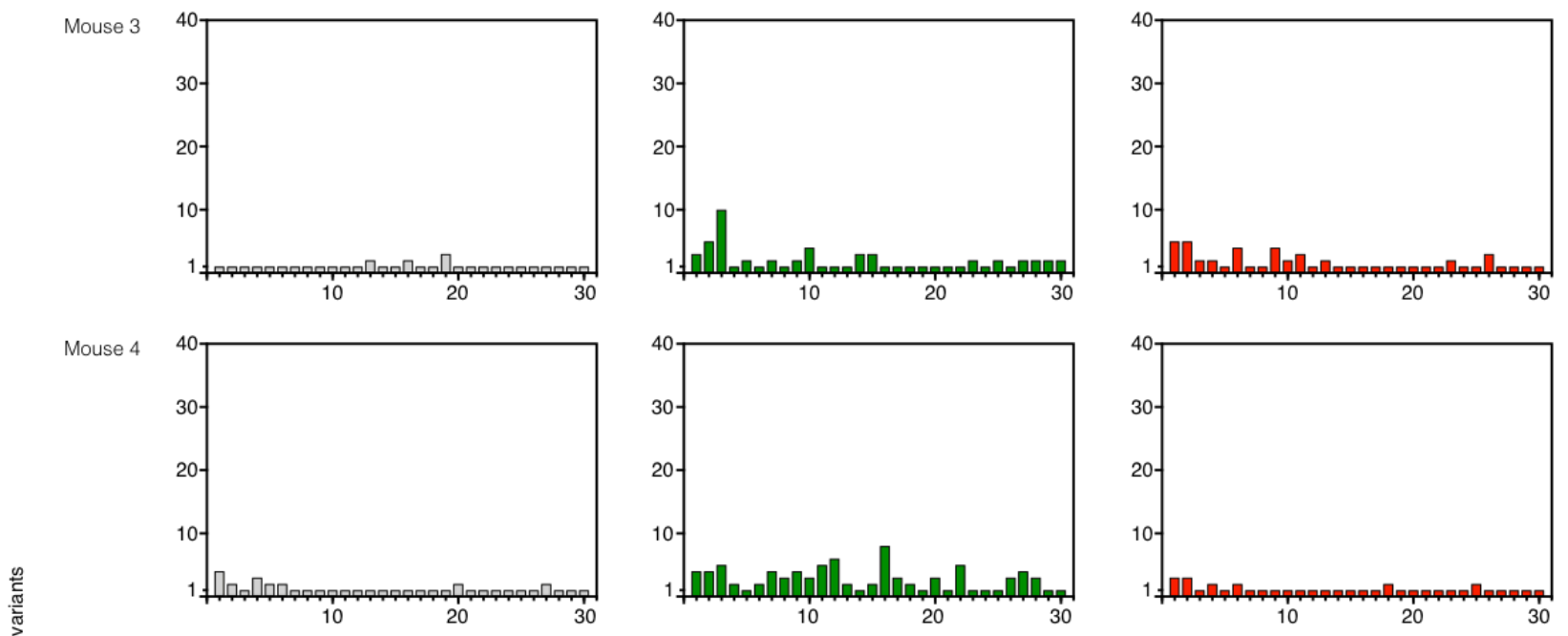

Mouse 5
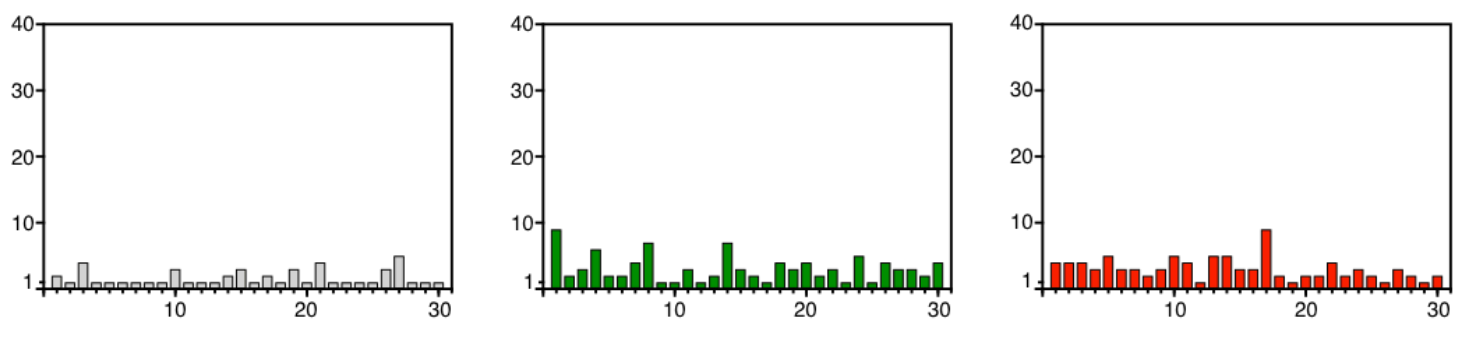

B

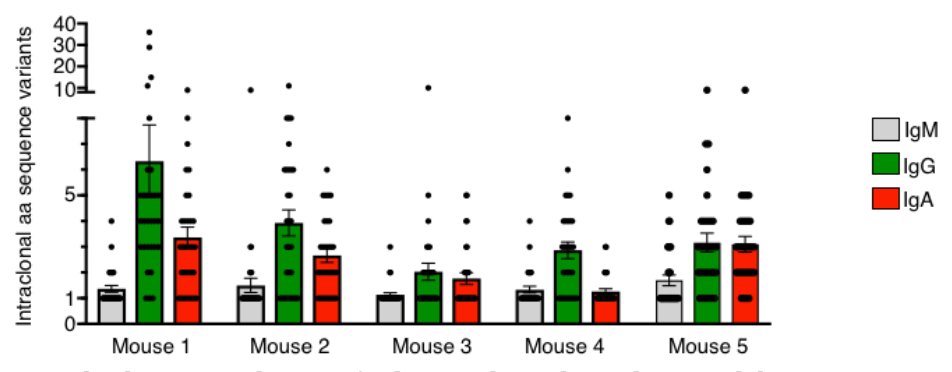

Extended Data Figure 3. Intraclonal amino acid sequence variants for the $\mathbf{3 0}$ most expanded clones per isotype. a. Total number of intraclonal amino acid sequence variants per individual clone per isotype for all mice. b. Mean number of intraclonal amino acid sequence variants per isotype for all mice. 
bioRxiv preprint doi: https://doi.org/10.1101/2021.07.16.452687; this version posted July 16, 2021. The copyright holder for this preprint (which was not certified by peer review) is the author/funder, who has granted bioRxiv a license to display the preprint in perpetuity. It is made available under aCC-BY-ND 4.0 International license.

A

\begin{tabular}{lcrlllll} 
ID & Clone rank IgM & \# cells & $\mathbf{V}_{\mathbf{H}}$ & CDRH3 & V $_{\mathbf{L}}$ & CDRL3 & nt dist. (aa-changes) \\
\hline IgM-1 & 1, public (2 mice) & 607 & IGHV3-1 & CATMITTWFAYW & IGKV3-2 & CQQSKEVPWTF & 0 \\
IgM-2 & 2 , public (5 mice) & 345 & IGHV11-2 & CMRYGNYWYFDVW & IGKV14-126 & CLQHGESPFTF & 0 \\
IgM-3 & 3 & 111 & IGHV12-3 & CAGDRWGYWYFDVW & IGKV4-91 & CQQGSSIPYTF & 0 \\
IgM-4 & 4 & 65 & IGHV1-64 & CANWDYW & IGKV5-48 & CQQSNSWWTF & $1(0)$ \\
IgM-5 & 5 , public (5 mice) & 58 & IGHV7-1 & CARDNWDWYFDVW & IGKV15-103 & CQQGQSYPLTF & 0 \\
IgM-6 & $27-33$, public (5 mice) 21 & IGHV7-1 & CARDDYDWYFDVW & IGKV15-103 & CQQGQSYPLTF & 0
\end{tabular}

B

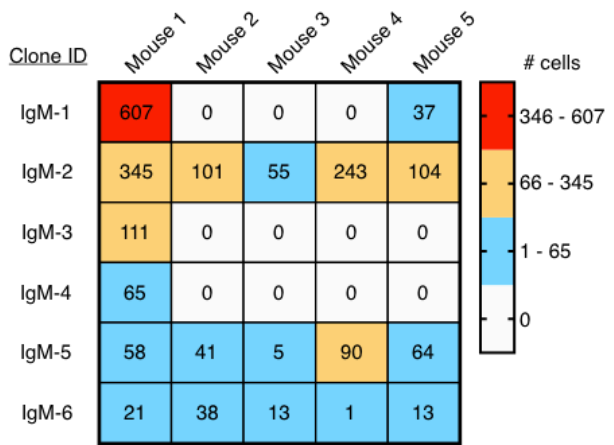

C

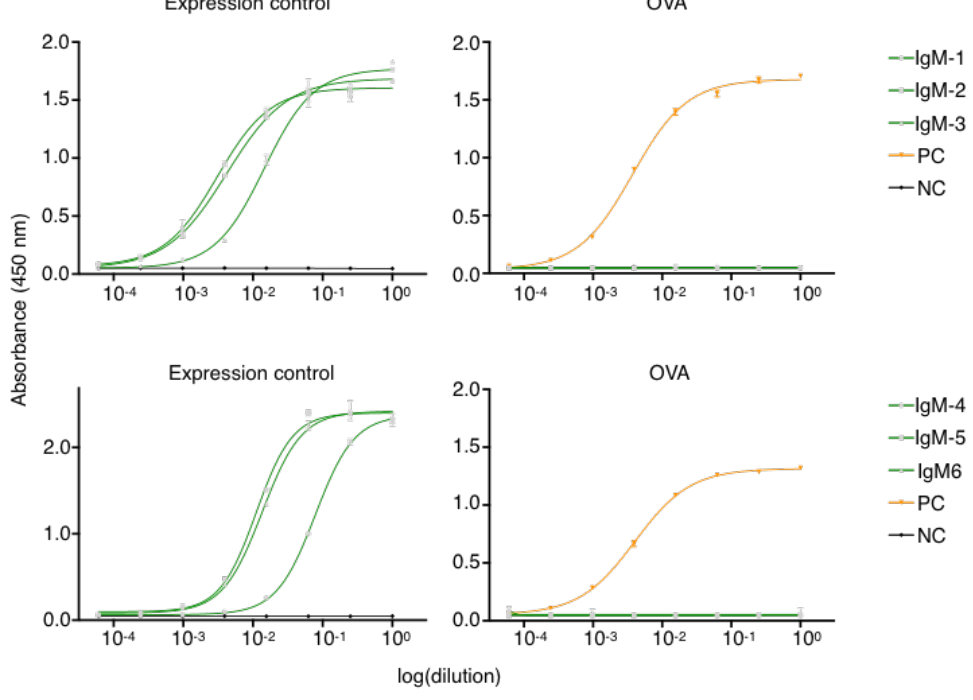

D
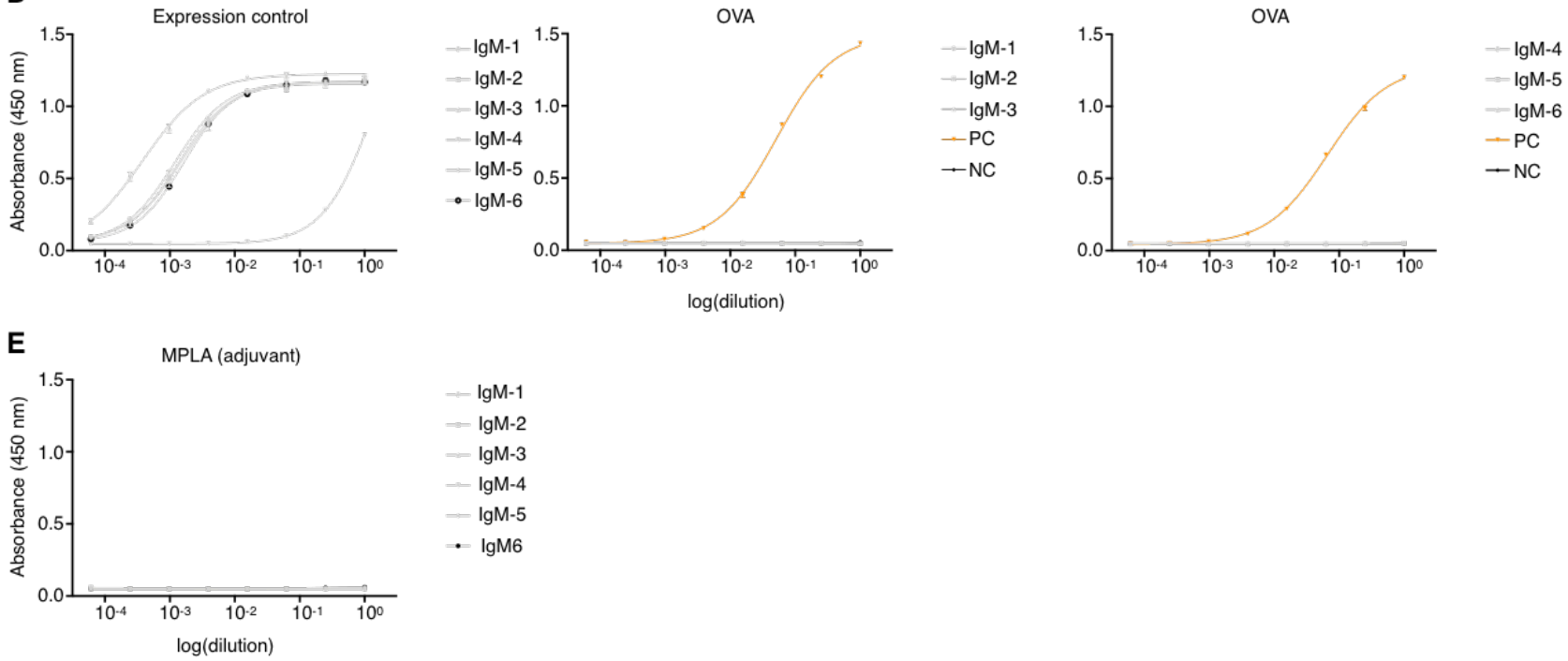

Extended Data Figure 4. Profiling of expanded IgM clones of MS-1. a. Characteristics of chosen clones. b. Heatmap indicating the number of cells per mouse with identical clonal CDRH3-CDRL3 amino acid sequence per chosen clone. Clone ID follows a. c. Sandwich ELISA results of 3-fold serially diluted stable hybridoma cell culture supernatant of engineered cell lines expressing selected clones as IgGs. Plots on the 
bioRxiv preprint doi: https://doi.org/10.1101/2021.07.16.452687; this version posted July 16, 2021. The copyright holder for this preprint (which was not certified by peer review) is the author/funder, who has granted bioRxiv a license to display the preprint in perpetuity. It is made available under aCC-BY-ND 4.0 International license.

left indicate IgG expression levels and plots on the right show binding to OVA. For each sample, two technical replicates were analysed and a four-parameter logistical curve was fitted to the data by nonlinear regression. Data are presented as the mean and error bars indicate standard deviation. Supernatant of a hybridoma cell line that does not express antibody served as negative control (NC, black) for the expression ELISA (left) and supernatant of an OVA specific inhouse cell line was used as positive control (PC, orange) for the antigen ELISA (right). d. Sandwich ELISA results of 3-fold serially diluted transient HEK-293 cell culture supernatant of cells expressing selected clones as IgM following c. Supernatant of IgM reformatted RSVF specific inhouse antibody served as negative control (NC, black) and supernatant of IgM reformatted positive clone from c served as positive control (PC, orange). e. Sandwich ELISA results on transient HEK-293 cell culture supernatant of cells expressing selected clones as IgM for binding to MPLA adjuvant. 
bioRxiv preprint doi: https://doi.org/10.1101/2021.07.16.452687; this version posted July 16, 2021. The copyright holder for this preprint (which was not certified by peer review) is the author/funder, who has granted bioRxiv a license to display the preprint in perpetuity. It is made available under aCC-BY-ND 4.0 International license.

A

\begin{tabular}{|c|c|c|c|c|c|c|c|}
\hline ID C & e rank $\lg A$ & \# cells & $V_{H}$ & CDRH3 & $\mathrm{V}_{\mathrm{L}}$ & CDRL3 & nt dist. (aa-changes) \\
\hline $\lg A-7$ & 1 & 29 & IGHV1-22 & CVRRGPSDTYYFDYW & IGKV5-43 & CQQSNSWPLTF & $24 \mathrm{nt}(18)$ \\
\hline $\lg A-8$ & $2-3$ & 26 & IGHV1-53 & CARSLYDYDGAYW & IGKV10-94 & CQQYSKLPRTF & $8 \mathrm{nt}(1)$ \\
\hline $\lg A-9$ & $2-3$ & 26 & IGHV3-1 & CARSGTTPDYW & IGKV6-15 & CQQYNSYPLTF & 22nt (8) \\
\hline $\lg A-10$ & 5 & 23 & IGHV7-3 & CPREYFGSFAYW & IGKV15-103 & CQQGQSYPWTF & 12nt (9) \\
\hline $\lg A-11$ & 7 & 21 & IGHV3-1 & CARGGNYPSYFDYW & IGKV4-61 & CQQYHSYPPTF & 22nt (15) \\
\hline
\end{tabular}

B

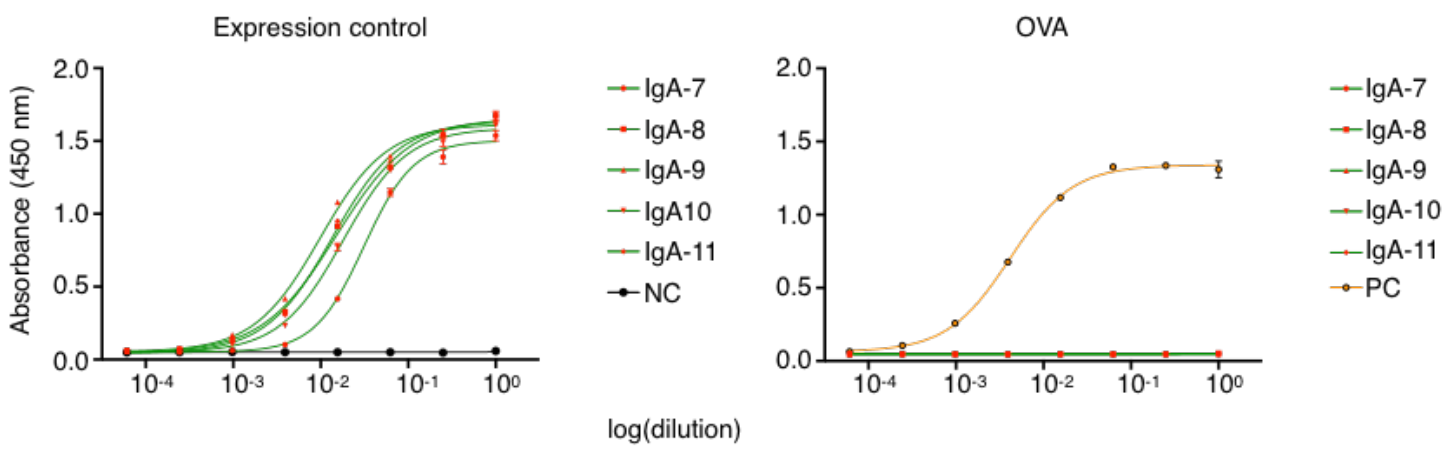

Extended Data Figure 5. Profiling of expanded IgA clones of MS-1. a. Characteristics of chosen clones. b. Sandwich ELISA results of 3-fold serially diluted stable hybridoma cell culture supernatant of engineered cell lines expressing selected clones as IgGs. Plot on the left indicates IgG expression levels and plot on the right shows binding to OVA. For each sample, two technical replicates were analysed and a four-parameter logistical curve was fitted to the data by nonlinear regression. Data are presented as the mean and error bars indicate standard deviation. Supernatant of a hybridoma cell line that does not express antibody served as negative control (NC, black) for the expression ELISA (left) and supernatant of an OVA specific inhouse cell line was used as positive control (PC, orange) for the antigen ELISA (right). 
bioRxiv preprint doi: https://doi.org/10.1101/2021.07.16.452687; this version posted July 16, 2021. The copyright holder for this preprint (which was not certified by peer review) is the author/funder, who has granted bioRxiv a license to display the preprint in perpetuity. It is made available under aCC-BY-ND 4.0 International license.

A

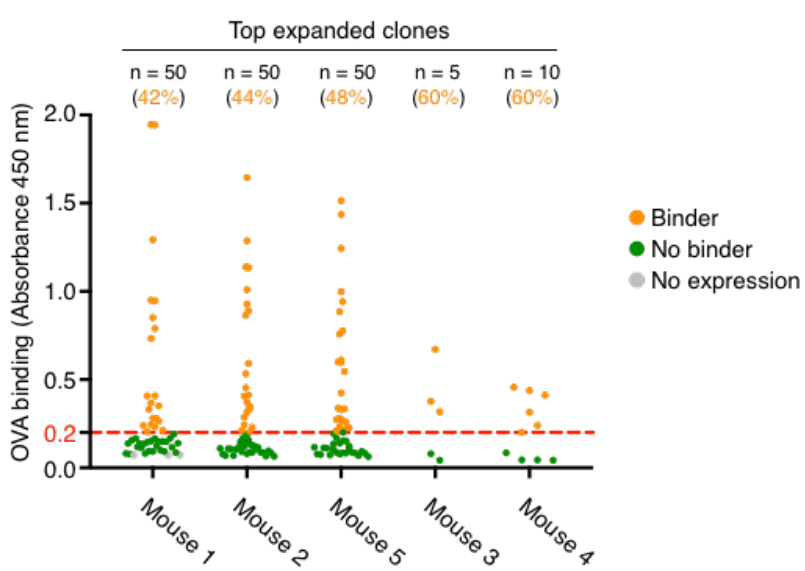

B

ID Mouse IgG clone rank in mouse Binder

\begin{tabular}{llcl}
\hline 3.1 & 3 & 1 & + \\
3.2 & 3 & $2-3$ & + \\
3.3 & 3 & $2-3$ & - \\
3.4 & 3 & 4 & - \\
3.5 & 3 & 5 & + \\
4.1 & 4 & 1 & + \\
4.2 & 4 & 2 & + \\
4.3 & 4 & 3 & - \\
4.5 & 4 & $5-6$ & - \\
4.6 & 4 & $5-6$ & - \\
4.8 & 4 & 8 & + \\
4.11 & 4 & 11 & + \\
4.13 & 4 & 13 & + \\
4.14 & 4 & 14 & -
\end{tabular}

$\mathrm{V}_{\mathrm{H}} \quad \mathrm{CDRH}$

$\mathrm{V}_{\mathrm{L}}$

CDRL3

nt dist. (aa-changes)

C

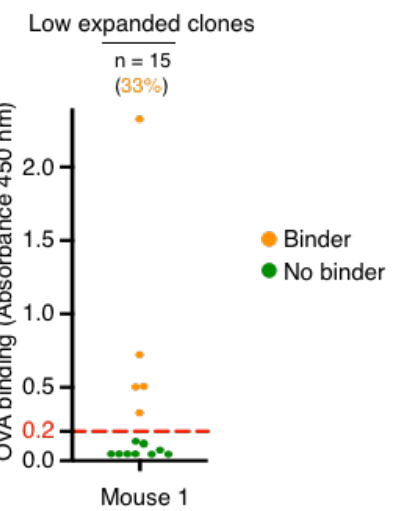

D

\begin{tabular}{lcccc} 
ID & \# cells & Binder & IgG clone rank & Total clone rank \\
\hline M1_low1 & 5 & + & $68-96$ & $280-390$ \\
M1_low2 & 4 & - & $97-137$ & $391-539$ \\
M1_low3 & 4 & - & $97-137$ & $391-539$ \\
M1_low4 & 3 & + & $138-189$ & $540-741$ \\
M1_low5 & 2 & - & $190-248$ & $742-1007$ \\
M1_low6 & 1 & - & $249-404$ & $1008-1657$ \\
M1_low7 & 1 & - & $249-404$ & $1008-1657$ \\
M1_low8 & 1 & + & $249-404$ & $1008-1657$ \\
M1_low9 & 1 & - & $249-404$ & $1008-1657$ \\
M1_low10 & 1 & - & $249-404$ & $1008-1657$ \\
M1_low11 & 1 & + & $249-404$ & $1008-1657$ \\
M1_low12 & 1 & - & $249-404$ & $1008-1657$ \\
M1_low13 & 1 & + & $249-404$ & $1008-1657$ \\
M1_low14 & 1 & - & $249-404$ & $1008-1657$ \\
M1_low15 & 1 & - & $249-404$ & $1008-1657$
\end{tabular}

Extended Data Figure 6. Profiling of top and low expanded IgG clones per mouse. a. ELISA profiling results of all top expanded clones tested per mouse. Clones were denoted binders if ELISA signal was $>0.2$ (3-fold above background; red dotted line). Binders are shown in orange, whereas clones that did not bind OVA or could not be expressed are shown in green and grey respectively. b. Overview of tested top expanded clones of MS-3 and -4 . + denotes ELISA signal $>0.2$. c. ELISA profiling results of all low expanded MS-1 clones tested. d. Table indicating binding of low expanded clones as well as number of cells and corresponding $\lg G$ and total clone ranks within MS-1 repertoire. 


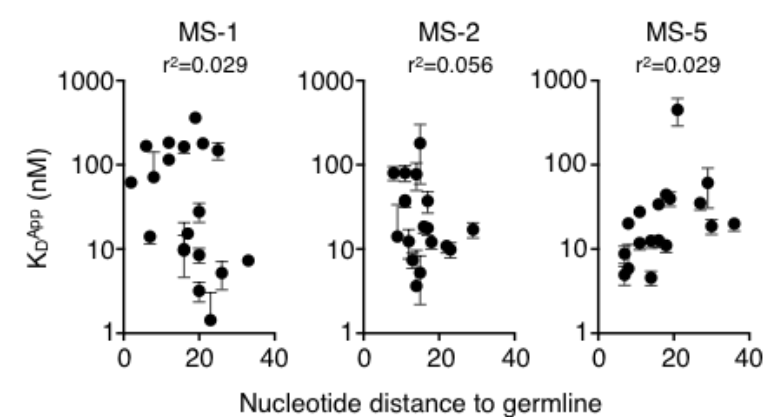

Extended Data Figure 7. Correlation between apparent dissociation constant $\left(\mathrm{K}_{\mathrm{D}}{ }^{\mathrm{App}}\right)$ and nucleotide distance to germline of clones shown in Fig. 2a, b.

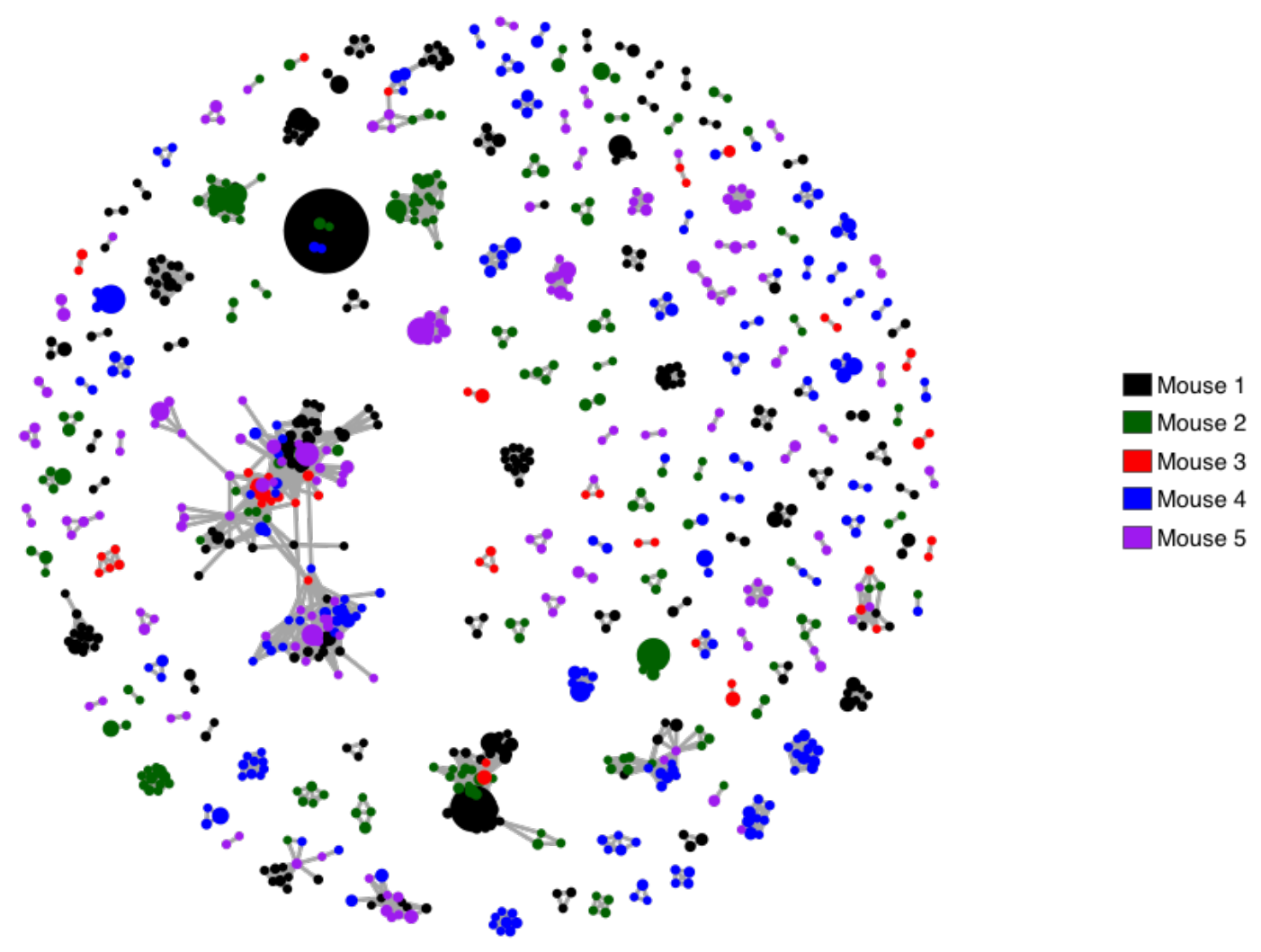

Extended Data Figure 8. IgG similarity network. Global lgG similarity network plot for all IgG clones across all mice. Edges represent sequence nodes separated by edit distance of less than four a.a. Only those nodes with at least one edge are plotted for visualization purposes. Clones from different mice are indicated in different colors respectively. Extent of clonal expansion per clone is reflected by the size of the nodes. 
A
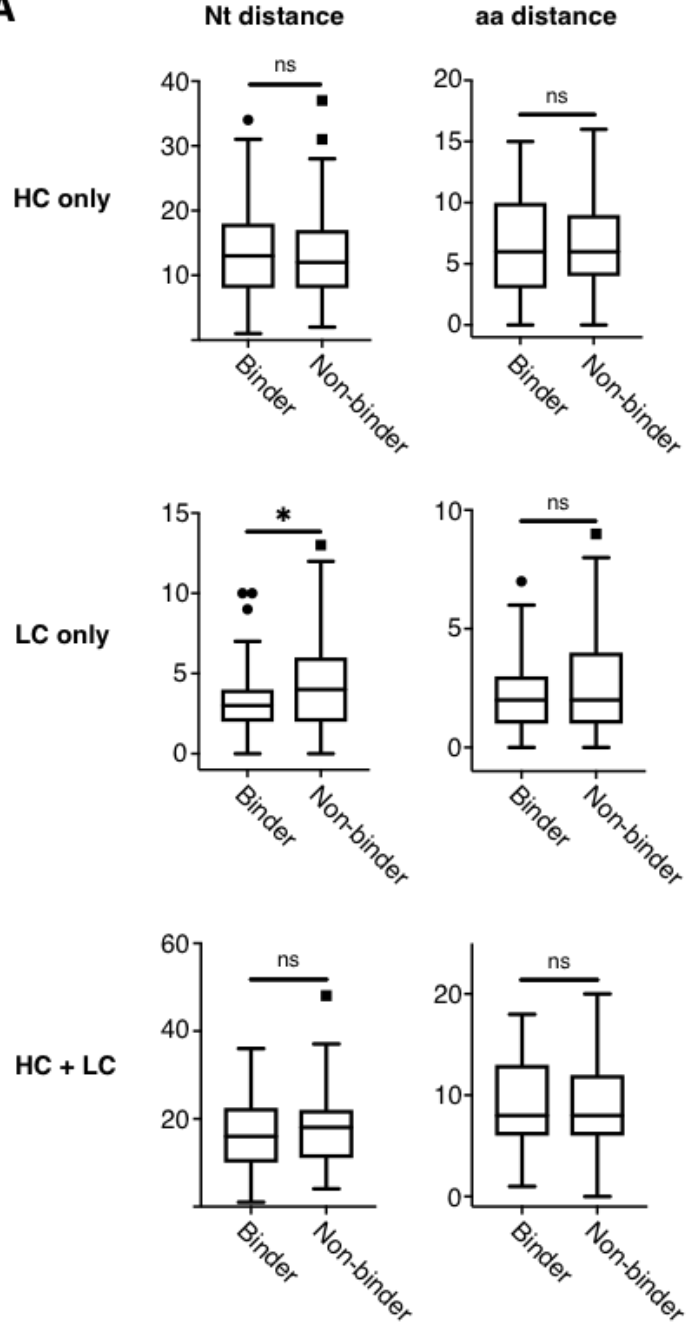

B

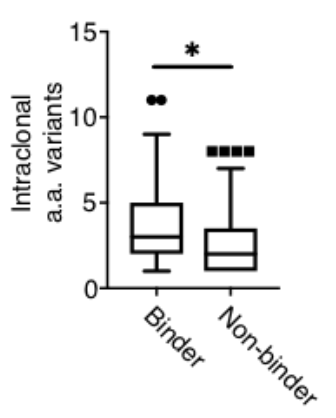

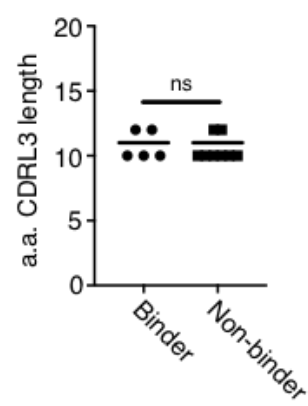

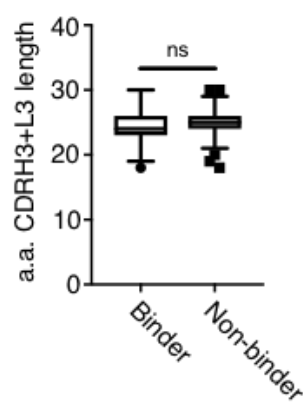

Extended Data Figure 9. Selected metrics for binder- and non-binder pools of clones. a. Left: nucleotide distance to germline for heavy- and light-chain only as well as across heavy- and light-chain combined. Top: ns, not significant $(P=0.70)$; middle: ${ }^{*} P=0.02$; bottom: ns, not significant $(P=0.64)$; unpaired Student's $t$-test. Right: amino acid distance to germline for heavy- and light-chain only as well as across heavy- and lightchain combined. Top: ns, not significant ( $P=0.77)$; middle: ns, not significant $(P=0.11)$; bottom: ns, not significant $(P=0.69)$; unpaired Student's $t$-test. Analysis encompassed 174 experimentally verified sequences (79 binder and 95 non-binder) provided in Extended Data Table 1 and 2 respectively. b. Number of intraclonal amino acid sequence variants. ${ }^{*} \mathrm{P}=0.02$, unpaired Student's $t$-test. Analysis contained all sequences provided in Extended Data Table 1 and 2 except for singlet clones (76 binder and 87 non-binder). c. CDR3 amino acid length for CDRH3 and CDRL3 as well as CDRH3/L3 combined. Top: ns, not significant ( $P=0.44)$; middle: ns, not significant $(P=0.49)$; bottom: ns, not significant $(P=0.49)$; unpaired Student's $t$-test. Analysis encompassed experimentally verified sequences (79 binder and 95 non-binder) provided in Extended Data Table 1 and 2. 
bioRxiv preprint doi: https://doi.org/10.1101/2021.07.16.452687; this version posted July 16, 2021. The copyright holder for this preprint (which was not certified by peer review) is the author/funder, who has granted bioRxiv a license to display the preprint in perpetuity. It is made available under aCC-BY-ND 4.0 International license.
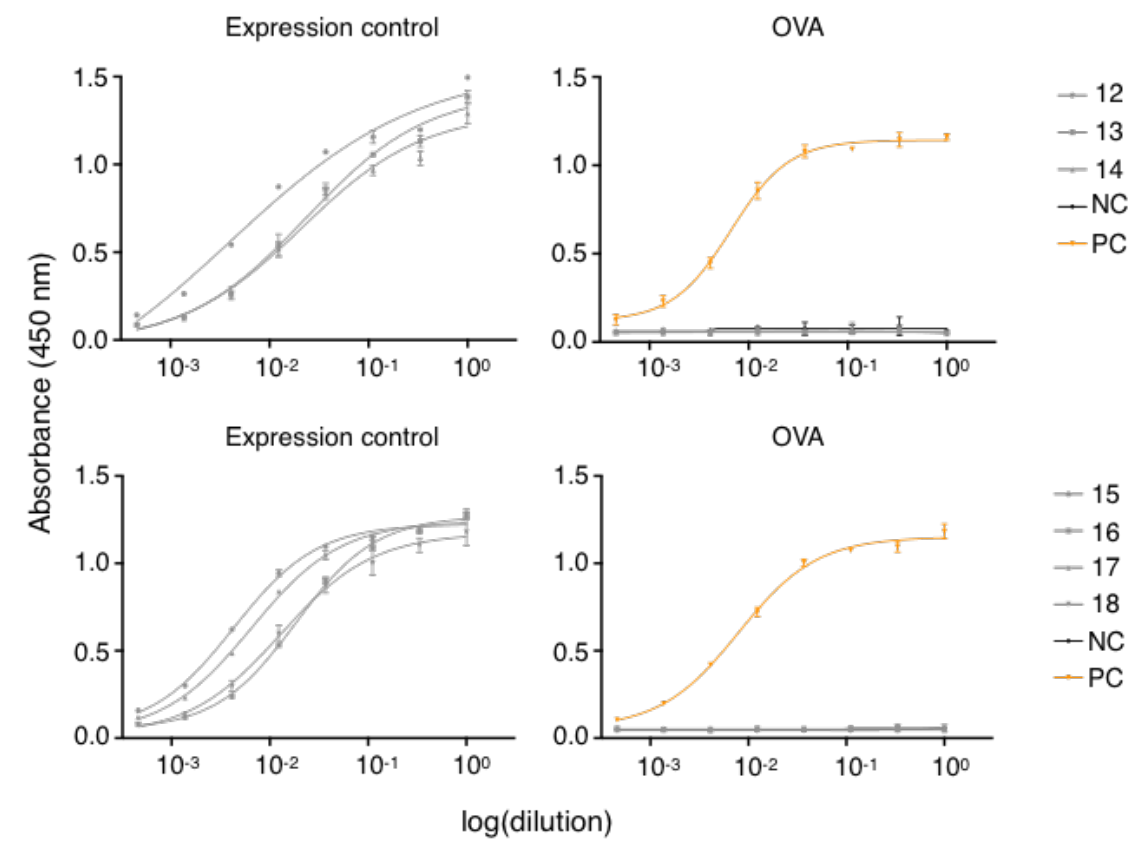

Extended Data Figure 10. ELISA screening of multi-isotype clones shown in Fig. 2g. Sandwich ELISA results of 3-fold serially diluted stable hybridoma cell culture supernatant of engineered cell lines expressing selected clones as IgGs. Plots on the left indicate IgG expression levels and plot on the right shows binding to OVA. For each sample, two technical replicates were analysed and a four-parameter logistical curve was fitted to the data by nonlinear regression. Data are presented as the mean ( $\mathrm{n}=2$ measurements) and error bars indicate standard deviation. Supernatant of a HEL specific hybridoma cell line served as negative control (NC, black) and supernatant of an OVA specific inhouse cell line was used as positive control (PC, orange). 
bioRxiv preprint doi: https://doi.org/10.1101/2021.07.16.452687; this version posted July 16, 2021. The copyright holder for this preprint (which was not certified by peer review) is the author/funder, who has granted bioRxiv a license to display the preprint in perpetuity. It is made available under aCC-BY-ND 4.0 International license.

A

\begin{tabular}{|c|c|c|c|c|c|c|}
\hline ID. & \# cells & $K_{D^{A P p}}^{A n M]}$ & nt dist. (aa) & $\mathrm{VH} / \mathrm{VL}$ & CDRH3/L3 & Mouse \\
\hline Germline & & n.d. & $0 \mathrm{nt}(0)$ & IGHV1-18/IGKV4-63 & CARGGYGNPFAYW/CFQGSGYPLTF & \\
\hline alX & 1 & $315.6 \pm 93.9$ & $8 \mathrm{nt}(6)$ & IGHV1-18/IGKV4-63 & CARGGYGVPFAYW/CFQGNGYPLTF & 2 \\
\hline alll & 4 & $8.9 \pm 1.0$ & $20 \mathrm{nt}(10)$ & IGHV1-18/IGKV4-61 & CTRGGYGTPFAYW/CQQYHSYPLTF & 1 \\
\hline bX & 3 & $4.0 \pm 1.2$ & $11 \mathrm{nt}(6)$ & IGHV1-18/IGKV4-61 & CARGGYGC-FAYW/CQQYHSYPLTF & 5 \\
\hline bVIII & 10 & $43.7 \pm 0.6$ & $16 \mathrm{nt}(11)$ & IGHV1-18/IGKV4-63 & CARGGYGNPFAYW/CFQGSGYPLTF & 1 \\
\hline bVII & 4 & $11.1 \pm 0.2$ & $16 \mathrm{nt}(11)$ & IGHV1-18/IGKV4-63 & CARGGYGNPFAYW/CFQGSGYPLTF & 1 \\
\hline cVII & 5 & $27.4 \pm 2.0$ & $18 \mathrm{nt}(12)$ & IGHV1-18/IGKV4-63 & CARGGYGNPFAYW/CFQGSGYPLTF & 1 \\
\hline dll & 5 & $11.3 \pm 1.1$ & $20 \mathrm{nt}(15)$ & IGHV1-18/IGKV4-63 & CARGGYGNPFAYW/CFQGSGYPLTF & 1 \\
\hline aVII & 7 & $33.2 \pm 3.8$ & $18 \mathrm{nt}(14)$ & IGHV1-18/IGKV4-63 & CARGGYGNPFAYW/CFQGSGYPLTF & 1 \\
\hline $\mathrm{clX}$ & 1 & $23.3 \pm 1.0$ & $15 \mathrm{nt}(11)$ & IGHV1-18/IGKV4-63 & CARGGYGTPFAYW/CFQGSGYPLTF & 1 \\
\hline bll & 3 & $12.4 \pm 1.3$ & $19 \mathrm{nt}(11)$ & IGHV1-18/IGKV4-63 & CARGGYGNPFAYW/CFQGSGYPLTF & 1 \\
\hline all & 13 & $4.5 \pm 1.4$ & $18 \mathrm{nt}(12)$ & IGHV1-18/IGKV4-63 & CARGGYGNPFAYW/CFQGSGYPLTF & 1 \\
\hline dVII & 7 & $6.3 \pm 0.9$ & $26 \mathrm{nt}(15)$ & IGHV1-18/IGKV4-63 & CARGGYGNPFAYW/CFQGSGYPLTF & 1 \\
\hline dIII & 11 & $5.2 \pm 3.0$ & $22 \mathrm{nt}(14)$ & IGHV1-18/IGKV4-63 & CARGGYGNPFAYW/CFQGSGYPLTF & 1 \\
\hline blx & 25 & $7.7 \pm 0.4$ & $21 \mathrm{nt}(14)$ & IGHV1-18/IGKV4-63 & CARGGYGNPFAYW/CFQGSGYPLTF & 1 \\
\hline $\mathrm{clV}$ & 2 & $451.1 \pm 36.4$ & $24 \mathrm{nt}(19)$ & IGHV1-18/IGKV4-63 & CARGGYGNPFTYW/CFQGSEYPLTF & 1 \\
\hline al & 7 & $6.5 \pm 0.7$ & $20 \mathrm{nt}(15)$ & IGHV1-18/IGKV4-63 & CARGGYGNPFAYW/CFQGSGYPLTF & 1 \\
\hline aVIII & 14 & $11.1 \pm 0.7$ & $23 \mathrm{nt}(16)$ & IGHV1-18/IGKV4-63 & CARGGYGNPFAYW/CFQGSGYPLTF & 1 \\
\hline aVI & 1 & $7.9 \pm 1.8$ & $24 \mathrm{nt}(17)$ & IGHV1-18/IGKV4-63 & CARGGYGNPFAYW/CFQGSGYPLTF & 1 \\
\hline dIV & 1 & $6.4 \pm 0.9$ & $19 \mathrm{nt}(15)$ & IGHV1-18/IGKV4-63 & CTRGGYGNPFAYW/CFQGSGYPLTF & 1 \\
\hline blll & 9 & $7.9 \pm 2.2$ & 22 nt (16) & IGHV1-18/IGKV4-63 & CARGGYGNPFAYW/CFQGSGYPLTF & 1 \\
\hline cVIII & 10 & $7.8 \pm 0.3$ & $22 \mathrm{nt}(15)$ & IGHV1-18/IGKV4-63 & CARGGYGNPFAYW/CFQGSGYPLTF & 1 \\
\hline bIV & 14 & $11.6 \pm 1.3$ & $19 \mathrm{nt}(14)$ & IGHV1-18/IGKV4-63 & CARGGYGNPFAYW/CFQGSGYPLTF & 1 \\
\hline dVIII & 35 & $11.4 \pm 0.6$ & $20 \mathrm{nt}(13)$ & IGHV1-18/IGKV4-63 & CARGGYGNPFAYW/CFQGSGYPLTF & 1 \\
\hline
\end{tabular}

B
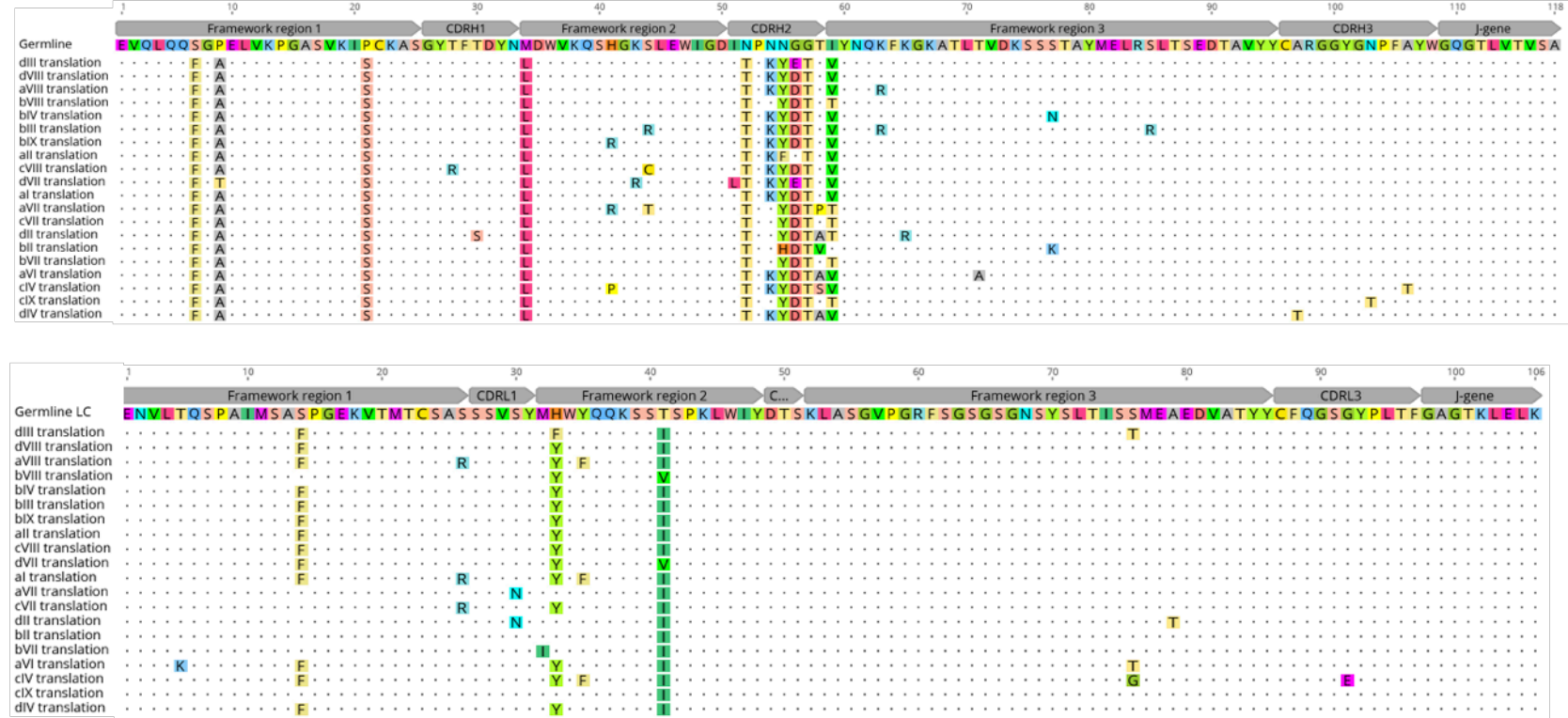

Extended Data Figure 11. Characteristics of tested intraclonal sequence variants shown in Fig. 3b. a. Characteristics of tested variants. Differences in $V_{L}$ gene usage and CDR3 amino acid sequence as well as sequences coming from different mice are indicated in red. b. Heavy (top) and light-chain (bottom) amino acid sequence alignment of clones with shared V/J genes. Sequence disagreements to germline are highlighted.

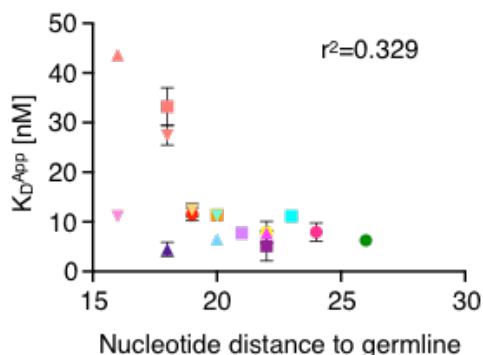

Extended Data Figure 12. Correlation between apparent dissociation constant $\left(K_{D}{ }^{A p p}\right)$ and nucleotide distance to germline. Error bars indicate standard deviation $\left(n=3-5\right.$ measurements of $\left.K_{D}\right)$. 
bioRxiv preprint doi: https://doi.org/10.1101/2021.07.16.452687; this version posted July 16, 2021. The copyright holder for this preprint (which was not certified by peer review) is the author/funder, who has granted bioRxiv a license to display the preprint in perpetuity. It is made available under aCC-BY-ND 4.0 International license.

A

\begin{tabular}{lccllllll} 
ID & Mouse & \# cells & $\mathbf{V}_{\mathbf{H}}$ & CDRH3 & $\mathbf{V}_{\mathbf{L}}$ & CDRL3 & nt dist. (aa-changes) & $\mathbf{K}_{\mathbf{D}}{ }^{\text {App }}$ [nM] \\
\hline Germline & & & IGHV9-1 & CAREASYWYFDVW IGKV3-12 & CQHSRELRTF & 0 nt (0) & \\
cVI & 5 & 3 & IGHV9-1 & CAREASYWYFDVW IGKV3-12 & CQHSRELRTF & $15 \mathrm{nt}(10)$ & n.d. \\
dl & 5 & 2 & IGHV9-1 & CAREASYWYFDVW IGKV3-12 & CQHSRELRTF & $21 \mathrm{nt}(14)$ & n.d. \\
cX & 2 & 3 & IGHV9-1 & CARTESYWYFDVW IGKV3-12 & CQHRRELWTF & $25 \mathrm{nt}(16)$ & $7.7 \pm 3.8$ \\
alV & 4 & 2 & IGHV9-1 & CARVSTYWYFDVW IGKV3-12 & CQHSRDLWTF & $41 \mathrm{nt}(20)$ & $3.4 \pm 0.2$ \\
dX & 4 & 2 & IGHV9-1 & CARVSTYWYFDVW IGKV3-12 & CQHSRDLWTF & $46 \mathrm{nt}(22)$ & $3.8 \pm 1.0$ \\
dV & 4 & 2 & IGHV9-1 & CARVSTYWYFDVW IGKV3-12 & CQHSRDLWTF & $29 \mathrm{nt}(19)$ & $26.0 \pm 4.9$ \\
cl & 5 & 5 & IGHV9-1 & CARLQSYWYFDVW IGKV3-12 & CQHSRELRTF & $21 \mathrm{nt}(11)$ & $11.9 \pm 0.3$ \\
aX & 5 & 8 & IGHV9-1 & CARLQSYWYFDVW IGKV3-12 & CQHSRELRTF & $21 \mathrm{nt}(11)$ & $14.4 \pm 1.5$ \\
bVI & 5 & 5 & IGHV9-1 & CARLQSYWYFDVW IGKV3-12 & CQHSRELRTF & $25 \mathrm{nt}(14)$ & $10.3 \pm 1.6$
\end{tabular}

B
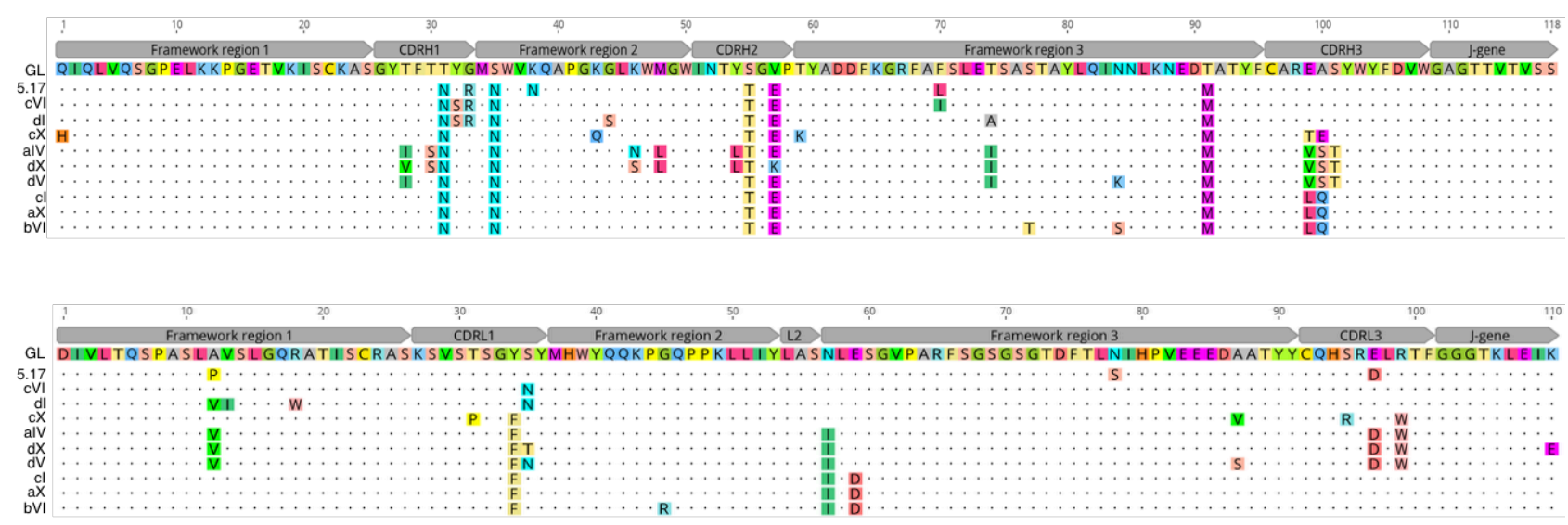

Extended Data Figure 13. Characteristics of tested clones shown in Fig. 3e-g. a. Characteristics of tested clones. Differences in CDR3 amino acid sequence are indicated in red. b. Heavy (top) and light-chain (bottom) amino acid sequence alignment of tested clones. Sequence disagreements to germline are highlighted. 
bioRxiv preprint doi: https://doi.org/10.1101/2021.07.16.452687; this version posted July 16, 2021. The copyright holder for this preprint (which was not certified by peer review) is the author/funder, who has granted bioRxiv a license to display the preprint in perpetuity. It is made available under aCC-BY-ND 4.0 International license.

A

\begin{tabular}{lccllllll} 
ID & Mouse & \# cells & $\mathbf{V}_{\mathbf{H}}$ & CDRH3 & $\mathbf{V}_{\mathbf{L}}$ & CDRL3 & nt dist. (aa-changes) & $\mathbf{K}_{\mathbf{D}}^{\text {App }}$ [nM] \\
\hline 19 & 5 & 1 & IGHV1-15 & CARGGGGSFAYW & IGKV4-57-1 & CQQFTSSPFTF & 22 nt (14) & \\
20 & 1 & 3 & IGHV1-82 & CARSGYGTGFAYW & IGKV4-55 & CQQWNSYPWTF & 19 nt (6) & n.d. \\
21 & 4 & 3 & IGHV5-12 & CARHGYGALAYW & IGKV4-50 & CQQFTSLPFTF & 14 nt (7) & $8.9 \pm 0.6$ \\
22 & 4 & 10 & IGHV1-53 & CTRGGYGGFAYW & IGKV4-61 & CQQYHSYPWTF & 29 nt (14) & $11.7 \pm 1.3$
\end{tabular}

B

C
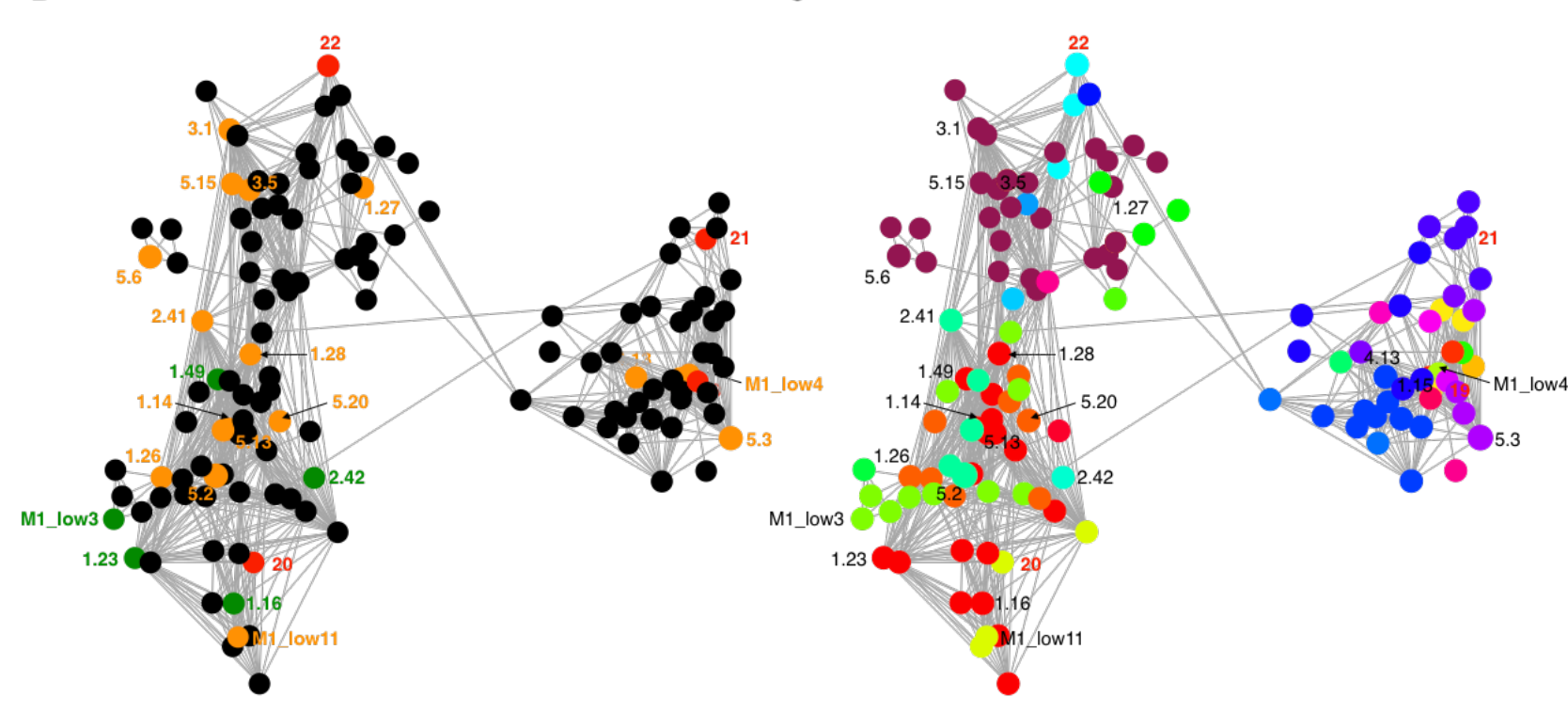

M1_low3

1.23

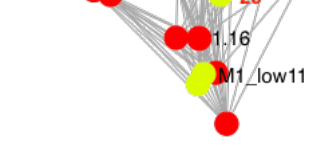

\begin{tabular}{|c|c|c|c|c|}
\hline & IGHV1-4/IGKV4-50 & $\square$ IGHV1-15/IGKV6-32 & $\square$ IGHV1-39/IGKV4-50 & $\square$ IGHV1-55/IGKV4-61 \\
\hline & $\square$ IGHV1-4/IGKV4-59 & IGHV1-18/IGKV3-2 & IGHV1-42/IGKV4-50 & IGHV1-61//GKV4-50 \\
\hline Not tested & IGHV1-5/IGKV4-50 & IGHV1-18//GKV4-50 & $\square$ IGHV1-52/IGKV4-50 & I IGHV1-64//GKV4-61 \\
\hline Binder & $\square$ IGHV1-9/IGKV4-50 & $\square$ IGHV1-18/IGKV4-55 & IGHV1-53/IGKV4-50 & $\square$ IGHV1-80/IGKV4-50 \\
\hline No binder & $\square$ IGHV1-9/IGKV4-55 & IGHV1-18/IGKV4-61 & $\square$ IGHV1-53/IGKV4-61 & IGHV1-80/IGKV4-55 \\
\hline Chosen clones & $\square$ IGHV1-9/IGKV4-61 & $\square$ IGHV1-19/IGKV4-55 & IGHV1-54/IGKV4-50 & $\square$ IGHV1-82//GKV4-55 \\
\hline & $\square$ IGHV1-9/IGKV6-13 & $\square$ IGHV1-26/IGKV4-55 & IGHV1-54/IGKV4-61 & $\square$ IGHV1-84/IGKV4-50 \\
\hline & IGHV1-15/IGKV4-57-1 & IGHV1-34//GKV4-50 & IGHV1-54//GKV10-94 & IGHV5-12/GKV4-50 \\
\hline
\end{tabular}

Extended Data Figure 14. Characteristics of tested clones shown in Fig. $3 \mathrm{~h}-\mathrm{j}$. a. Characteristics of tested clones. b. Subnetwork plot of connected IgG clones from all mice shown in Extended Data Fig. 9. Edges represent clones separated by edit distance of three or less based on the concatenated CDR3 aa sequence. Binders, non-binders, not tested clones as well as newly chosen clones are shown in orange, green, black and red respectively. Indicated clone ID according to Extended Data Table 1 and 2. c. Identical network plot as in $\mathbf{b}$. Color code indicates differential $V_{H}-V_{L}$ gene usage as indicated. 
bioRxiv preprint doi: https://doi.org/10.1101/2021.07.16.452687; this version posted July 16, 2021. The copyright holder for this preprint (which was not certified by peer review) is the author/funder, who has granted bioRxiv a license to display the preprint in perpetuity. It is made available under aCC-BY-ND 4.0 International license.

A

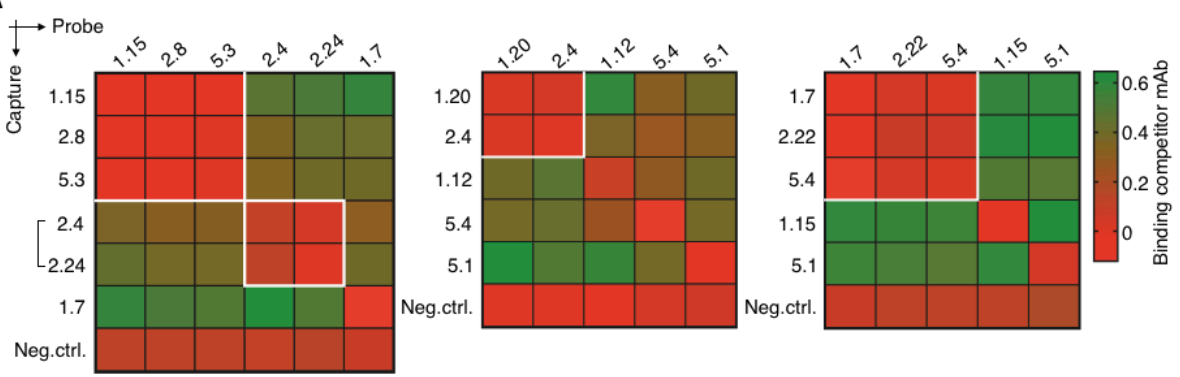

B

\begin{tabular}{|c|c|c|c|c|c|c|c|c|c|c|c|c|}
\hline ID & Mouse & Bin & Clone rank in mouse & \# cells & $V_{H}$ & $J_{H}$ & CDRH3 & $\mathrm{V}_{\mathrm{L}}$ & $\mathrm{J}_{\mathrm{L}}$ & CDRL3 & nt dist. (aa-changes) & $\mathrm{K}_{\mathrm{D}}^{\mathrm{App}}[\mathrm{nM}]$ \\
\hline 1.1 & 1 & 1 & 1 & 227 & IGHV1-18 & IGHJ3 & CARGGYGNPFAYW & IGKV4-63 & IGKJ5 & CFQGSGYPLTF & $20 \mathrm{nt}(13)$ & $3.2 \pm 0.8$ \\
\hline 1.15 & 1 & 1 & $14-15$ & 16 & IGHV1-61 & IGHJ3 & CARGGYGSFAYW & IGKV4-50 & IGKJ2 & CQQFTSFPSTF & $33 \mathrm{nt}(17)$ & $7.3 \pm 1.0$ \\
\hline 1.27 & 1 & 1 & $25-28$ & 11 & IGHV1-18 & IGHJ3 & CARGGYGNPFAYW & IGKV4-61 & IGKJ5 & CQQYHSYPLTF & $12 \mathrm{nt}(5)$ & $115.2 \pm 15.1$ \\
\hline 1.29 & 1 & 1 & $29-36$ & 10 & IGHV1-4 & IGHJ3 & CGRAGYDSFAYW & IGKV14-111 & IGKJ4 & CLQYHEFPFTF & 16 nt (8) & $9.6 \pm 5.0$ \\
\hline 2.8 & 2 & 1 & 8 & 20 & IGHV1-26 & IGHJ3 & CARSGYASFAYW & IGKV4-63 & IGKJ4 & CFQGSGYPFTF & $29 \mathrm{nt}(17)$ & $17.0 \pm 3.4$ \\
\hline 2.33 & 2 & 1 & $33-39$ & 8 & IGHV1-18 & IGHJ3 & CARGGYGVPFAYW & IGKV4-63 & IGKJ2 & CFQGSGYPLTF & $11 \mathrm{nt}(5)$ & $37.9 \pm 6.4$ \\
\hline 5.3 & 5 & 1 & 3 & 29 & IGHV1-4 & IGHJ3 & CARGGYGSLAYW & IGKV4-50 & IGKJ2 & CQQFTSSPYTF & $16 \mathrm{nt}(8)$ & $12.7 \pm 2.3$ \\
\hline 5.7 & 5 & 1 & 7 & 20 & IGHV1-4 & IGHJ2 & CTRSAFGFDYYW & IGKV4-61 & IGKJ5 & CQQYHSYPLTF & $18 \mathrm{nt}(11)$ & $11.0 \pm 1.9$ \\
\hline 5.13 & 5 & 1 & 13-14 & 14 & IGHV1-9 & IGHJ3 & CARSGYGSFAFW & IGKV4-55 & IGKJ2 & CQQWSSYPPTF & $19 \mathrm{nt}(11)$ & $39.7 \pm 7.7$ \\
\hline 5.15 & 5 & 1 & $15-16$ & 13 & IGHV1-18 & IGHJ3 & CARSGYGSSFAYW & IGKV4-61 & IGKJ1 & CQQYHSYPPTF & 14 nt (5) & $12.6 \pm 2.3$ \\
\hline 1.20 & 1 & 2 & $18-24$ & 12 & IGHV7-3 & IGHJ2 & CARDIPGTVYW & IGKV4-57 & IGKJ5 & CQQRSTYPLTF & $7 \mathrm{nt}(5)$ & $14.1 \pm 2.6$ \\
\hline 2.3 & 2 & 2 & 3 & 30 & IGHV2-6-8 & IGHJ4 & CARDYGGNNYAMDYW & IGKV4-57 & IGKJ4 & CQQRSSYPFTF & $8 \mathrm{nt}(7)$ & $80.3 \pm 15.1$ \\
\hline 2.4 & 2 & 2 & 4 & 28 & IGHV1-4 & IGHJ3 & CTNHGSSHGWFGYW & IGKV14-111 & IGKJ5 & CLQYDEFPLTF & $11 \mathrm{nt}(6)$ & $36.7 \pm 1.2$ \\
\hline 2.6 & 2 & 2 & 6 & 25 & IGHV2-6-8 & IGHJ4 & CARDYGSNNYAMDFW & IGKV4-57 & IGKJ4 & CQQRSSYPFTF & $9 \mathrm{nt}(5)$ & $14.1 \pm 19.5$ \\
\hline 2.15 & 2 & 2 & $14-16$ & 14 & IGHV2-6-8 & IGHJ4 & CARDYGGNNYAMDYW & IGKV4-57 & IGKJ4 & CQQRSRYPFTF & $12 \mathrm{nt}(8)$ & $12.3 \pm 4.7$ \\
\hline 2.24 & 2 & 2 & $22-25$ & 11 & IGHV1-4 & IGHJ3 & CTSHGSMFGWFSYW & IGKV14-111 & IGKJ5 & CLQYDEFPLTF & 17 nt (8) & $17.8 \pm 3.1$ \\
\hline 2.27 & 2 & 2 & $26-28$ & 10 & IGHV1-66 & IGHJ3 & CASTTATSSWFAYW & IGKV14-111 & IGKJ2 & CLQYDEFPYTF & $16 \mathrm{nt}(11)$ & $18.4 \pm 3.0$ \\
\hline 1.5 & 1 & 3 & $4-5$ & 33 & IGHV1-55 & IGHJ4 & CTRYSRYGGAMDYW & IGKV14-111 & IGKJ5 & CLQYDEFPFTF & $16 \mathrm{nt}(7)$ & $164.9 \pm 27.3$ \\
\hline 1.7 & 1 & 3 & 7 & 27 & IGHV1-5 & IGHJ3 & CTRSEDYYWFAYW & IGKV14-111 & IGKJ2 & CLQYDDFPYTF & $20 \mathrm{nt}(12)$ & $8.5 \pm 1.7$ \\
\hline 1.17 & 1 & 3 & 17 & 13 & IGHV1-55 & IGHJ4 & CTRYSRYGGAMDYW & IGKV14-111 & IGKJ5 & CLQYGDFPLTF & $26 \mathrm{nt}(17)$ & $5.2 \pm 1.9$ \\
\hline 2.22 & 2 & 3 & $22-25$ & 11 & IGHV1-5 & IGHJ2 & CVRSEDYYYFDYW & IGKV14-111 & IGKJ2 & CLQYDEFPYTF & $15 \mathrm{nt}(9)$ & $5.2 \pm 3.0$ \\
\hline 5.4 & 5 & 3 & 4 & 28 & IGHV1-66 & IGHJ2 & CARRVLYYFDYW & IGKV6-32 & IGKJ2 & CQQDYRYPYTF & $7 \mathrm{nt}(7)$ & $8.8 \pm 2.0$ \\
\hline 1.12 & 1 & n.d. & $11-13$ & 17 & IGHV5-6 & IGHJ3 & CARDRYYGFSEWFAHW & IGKV4-53 & IGKJ5 & CQQWSSYPLTF & $20 \mathrm{nt}(12)$ & $27.8 \pm 7.1$ \\
\hline 5.1 & 5 & n.d. & 1 & 41 & IGHV1-63 & IGHJ2 & CARKNYYGNTYFDYW & IGKV1-117 & IGKJ1 & CFQGSHVPWTF & $30 \mathrm{nt}(16)$ & $18.7 \pm 3.7$ \\
\hline
\end{tabular}

C

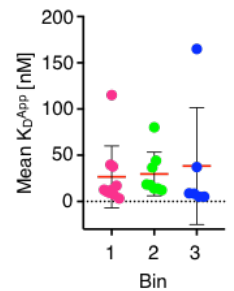

Extended Data Figure 15. Cross-competition epitope binning between clones from different mice. a. Heatmaps show competitive antigen binding between top expanded, bin specific (according to Fig. 4b) clones from different mice. Antibodies indicated on the left were captured and probe antibodies on top were used to determine cross-competition for epitope access. Red indicates no binding of the probe antibody as a consequence of epitope blocking by the capture antibody, whereas green denotes binding of the competitor antibody. Groups of antibodies that target the same epitope (epitope bins) are highlighted in white squares. Brackets indicate clonal variants that share the same $V_{H} V_{L}$ as well as CDR3 length and only differ in their CDR3 amino acid sequence. An anti-RSVF capture antibody, which does not bind the antigen was used as negative control for all experiments. Clone ID according to Extended Data Table 1. b. Characteristics of bin-specific clones. c Apparent dissociation constant $\left(K_{D}{ }^{\text {App }}\right)$ for binders separated by epitope bin. 
A
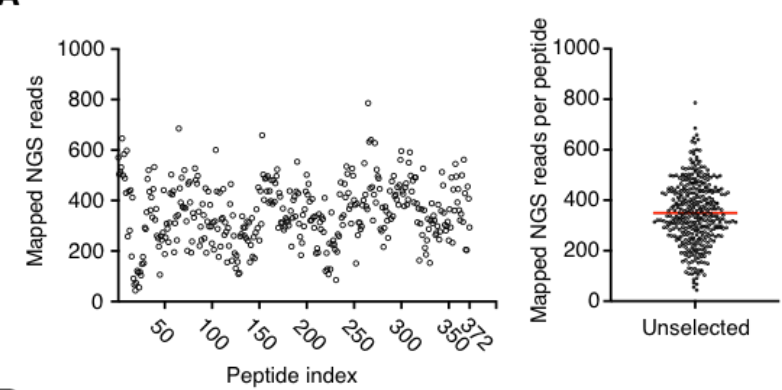

в
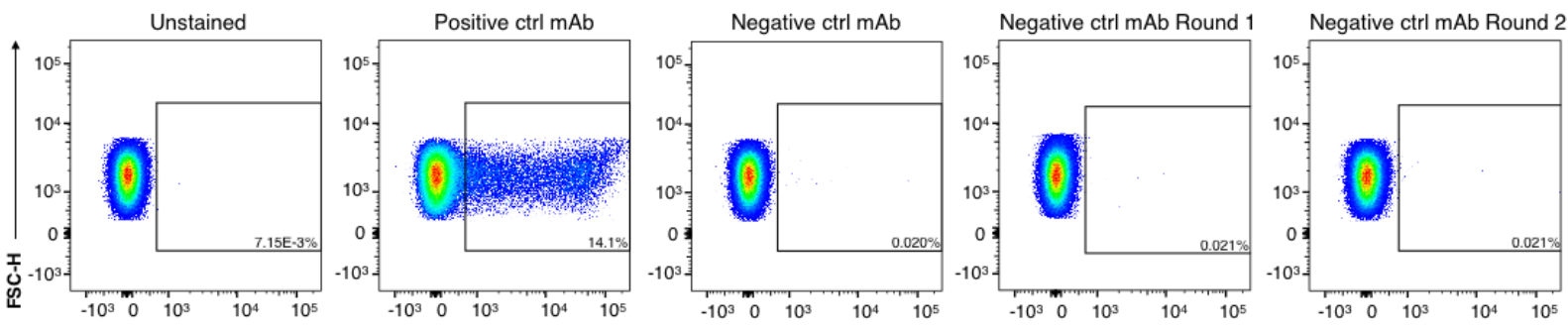

IgG-BV421 $(405 \mathrm{~nm})$

C
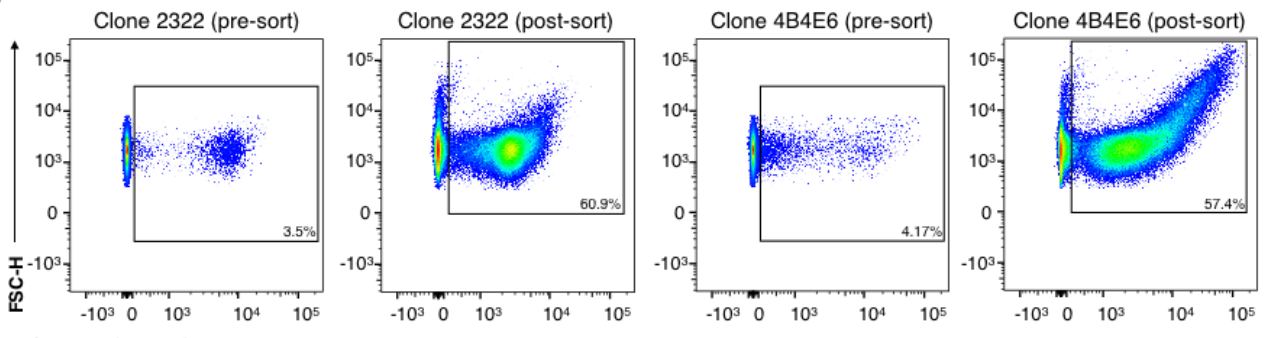

lgG-BV421 (405 nm)

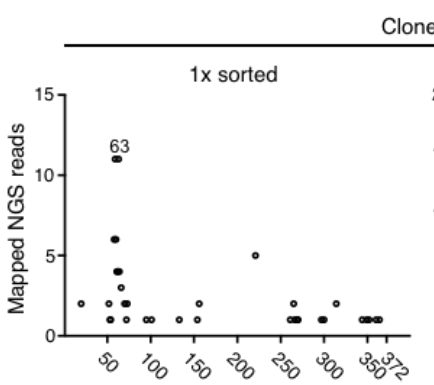

Clone 2322
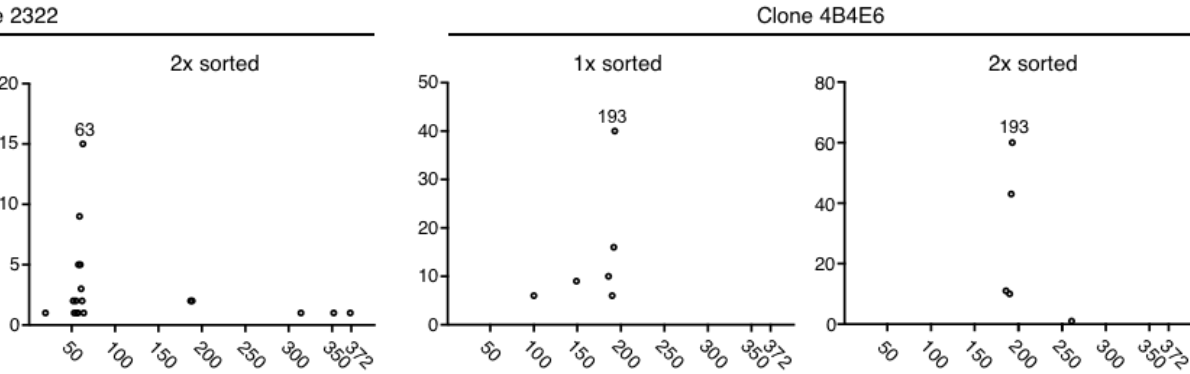

Peptide index

\begin{tabular}{lll} 
Test mAb & Epitope (Manufacturer) & Experimentally determined epitope \\
\hline Clone 2322 & OVA 61-68: DKLPGFGD & OVA 63-77: LPGFGDSIEAQSGTS \\
Clone 4B4E6 & OVA 191-202: DEDTQAMPFRVT & OVA 193-207: DTQAMPFRVTEQESK
\end{tabular}

Extended Data Figure 16. Establishment of a bacterial peptide display workflow for linear epitope mapping. a. Quality control of the unselected cloned OVA epitope library by NGS. All 372 peptide 15-mer windows (one amino acid offset) were observed (left) at comparable frequencies (right). Mean window occurrence for the respective NGS run is indicated in red. b. Flow cytometry dot plots show that secondary FACS antibody does not lead to unspecific enrichment after two rounds of enrichment. Unstained denotes no primary antibody. Positive and negative control primary mAb used were OVA specific mAb Clone 2322 (Chondrex, 7094) and an inhouse RSVF specific mouse IgG. c. Assay establishment with two OVA specific antibodies with known epitope specificity. Top: FACS dot plots show FACS enrichment of cells binding to commercial antibodies Clone 2322 (Chondrex, 7094) (left) and Clone 4B4E6 (Chondrex, 7096) (right). Middle: NGS results after one and two rounds of FACS enrichment. Bottom: experimentally determined epitope identity compared to epitope information provided by the manufacturer. Epitope overlap is indicated in bold red. 
bioRxiv preprint doi: https://doi.org/10.1101/2021.07.16.452687; this version posted July 16, 2021. The copyright holder for this preprint (which was not certified by peer review) is the author/funder, who has granted bioRxiv a license to display the preprint in perpetuity. It is made available under aCC-BY-ND 4.0 International license.

A

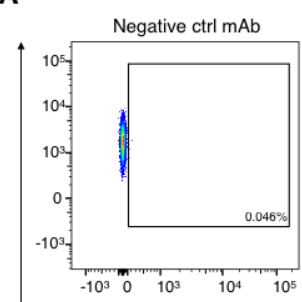

B
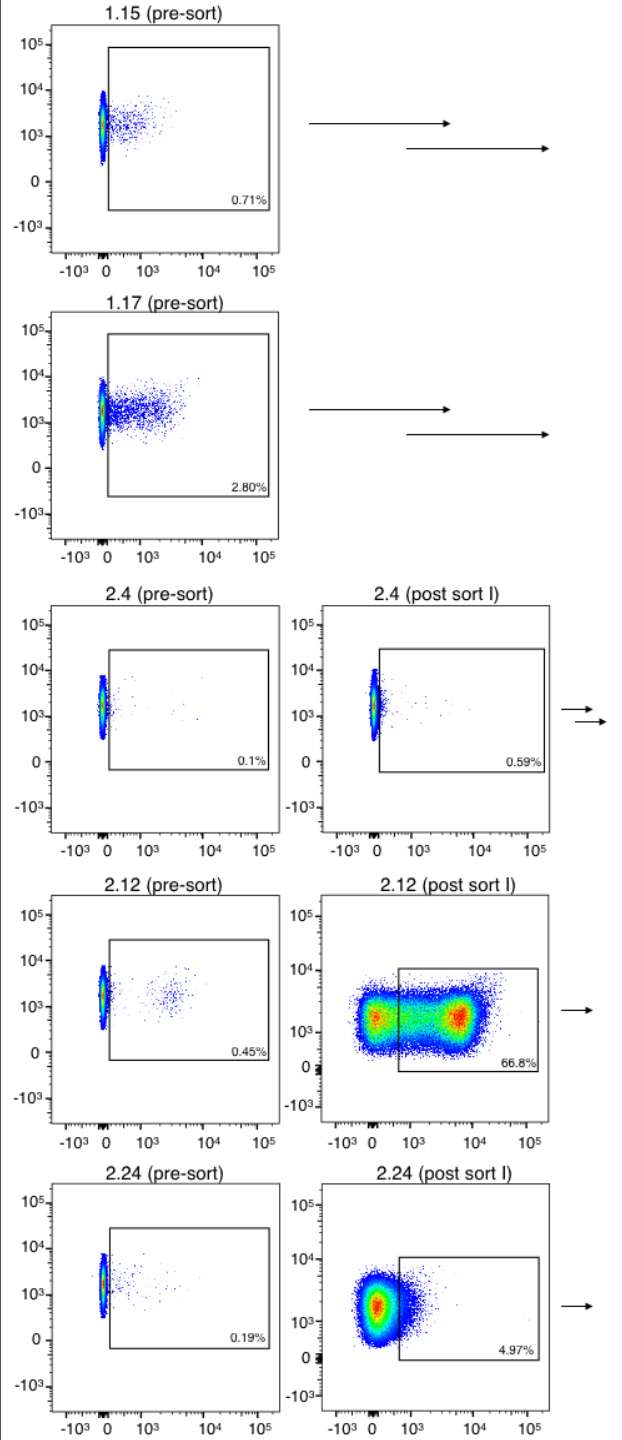

2.34 (pre-sort)

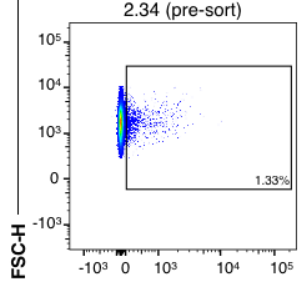

lgG-BV421 (405 nm)

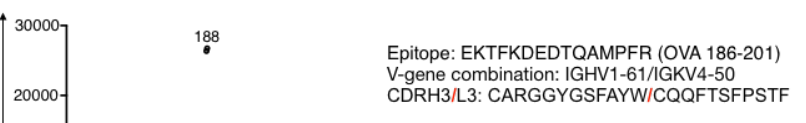

CDRH3/L3: CARGGYGSFAYW/CQQFTSFPSTF
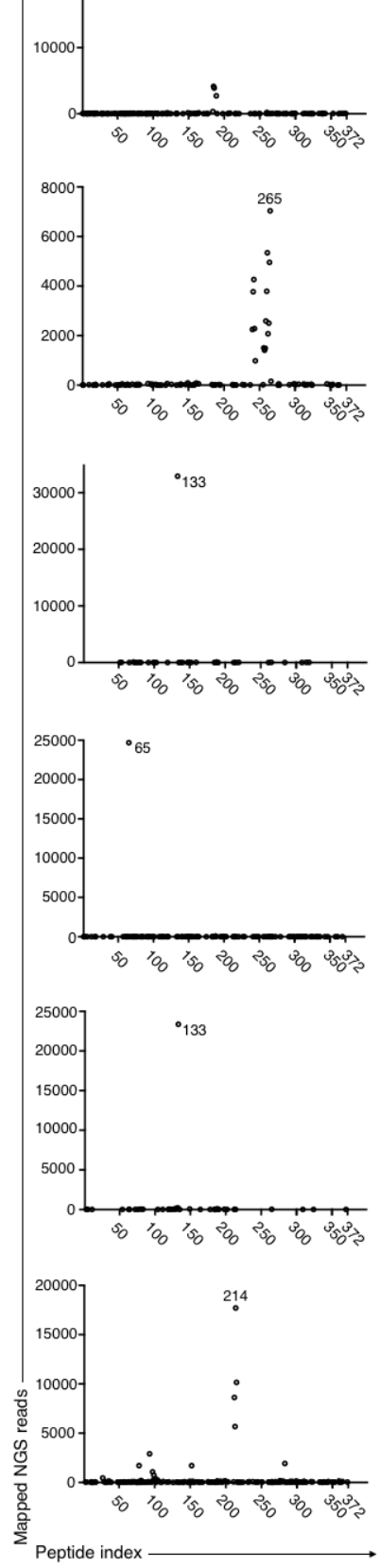

Epitope: INFQTAADQARELIN (OVA 133-148) V-gene combination: IGHV1-4/IGKV14-111

Epitope: GFGDSIEAQCGTSVN (OVA 65-80) V-gene combination: IGHV1-52/GKV8-24 CDRH3/L3: CARGGYW/CQQHYSTPFTF

Extended Data Figure 17. Epitope mapping results of clones with linear epitope specificity as shown in Fig. 4e. a. Flow cytometry dot plots indicate FACS enrichment of positive clones for each antibody. b. Deep sequencing results of positive FACS output and epitope assignment for each antibody. Numbers correspond to the peptide index that was enriched the most. Only peptides with one or more occurrences are shown. 
bioRxiv preprint doi: https://doi.org/10.1101/2021.07.16.452687; this version posted July 16, 2021. The copyright holder for this preprint

(which was not certified by peer review) is the author/funder, who has granted bioRxiv a license to display the preprint in perpetuity. It is made available under aCC-BY-ND 4.0 International license.

\begin{tabular}{|c|c|c|c|c|c|c|c|c|c|}
\hline ID & Mouse & IgG clone rank in mouse & \# cells & $V_{H}$ & CDRH3 & $\mathrm{V}_{\mathrm{L}}$ & CDRL3 & nt dist. (aa-changes) & $\mathrm{K}_{\mathrm{D}}^{\mathrm{App}}[\mathrm{nM}]$ \\
\hline 1.1 & 1 & 1 & 227 & IGHV1-18 & CARGGYGNPFAYW & IGKV4-63 & CFQGSGYPLTF & $20 \mathrm{nt}(13)$ & $3.2 \pm 0.8$ \\
\hline 1.5 & 1 & $4-5$ & 33 & IGHV1-55 & CTRYSRYGGAMDYW & IGKV14-111 & CLQYDEFPFTF & $16 \mathrm{nt}(7)$ & $164.9 \pm 27.3$ \\
\hline 1.7 & 1 & 7 & 27 & IGHV1-5 & CTRSEDYYWFAYW & IGKV14-111 & CLQYDDFPYTF & $20 \mathrm{nt}(12)$ & $8.5 \pm 1.7$ \\
\hline 1.11 & 1 & $11-13$ & 17 & IGHV1-74 & CVLRLFYAMDYW & IGKV6-17 & CQQFYNTPWTF & $27 \mathrm{nt}(15)$ & n.d. \\
\hline 1.12 & 1 & $11-13$ & 17 & IGHV5-6 & CARDRYYGFSEWFAHW & IGKV4-53 & CQQWSSYPLTF & $20 \mathrm{nt}(12)$ & $27.8 \pm 7.1$ \\
\hline 1.14 & 1 & $14-15$ & 16 & IGHV1-80 & CARSGYGVFAFW & IGKV4-55 & CQQWSSYPPTF & $21 \mathrm{nt}(8)$ & $179.6 \pm 2.6$ \\
\hline 1.15 & 1 & 14-15 & 16 & IGHV1-61 & CARGGYGSFAYW & IGKV4-50 & CQQFTSFPSTF & $33 \mathrm{nt}(17)$ & $7.3 \pm 1.0$ \\
\hline 1.17 & 1 & 17 & 13 & IGHV1-55 & CTRYSRYGGAMDYW & IGKV14-111 & CLQYGDFPLTF & $26 \mathrm{nt}(17)$ & $5.2 \pm 1.9$ \\
\hline 1.20 & 1 & $18-24$ & 12 & IGHV7-3 & CARDIPGTVYW & IGKV4-57 & CQQRSTYPLTF & $7 \mathrm{nt}(5)$ & $14.1 \pm 2.6$ \\
\hline 1.26 & 1 & $25-28$ & 11 & IGHV1-26 & CARSGYATAFAYW & IGKV4-55 & CQQWSSYPLTF & $23 \mathrm{nt}(15)$ & $1.4 \pm 1.6$ \\
\hline 1.27 & 1 & $25-28$ & 11 & IGHV1-18 & CARGGYGNPFAYW & IGKV4-61 & CQQYHSYPLTF & $12 \mathrm{nt}(5)$ & $115.2 \pm 15.1$ \\
\hline 1.28 & 1 & $25-28$ & 11 & IGHV1-80 & CARSGYGAFAYW & IGKV4-55 & CQQWSSYPPTF & $25 \mathrm{nt}(10)$ & $148.4 \pm 34.2$ \\
\hline 1.29 & 1 & $29-36$ & 10 & IGHV1-4 & CGRAGYDSFAYW & IGKV14-111 & CLQYHEFPFTF & $16 \mathrm{nt}(8)$ & $9.6 \pm 5.0$ \\
\hline 1.32 & 1 & $29-36$ & 10 & IGHV1-4 & CARPFDYYGRRGAMDYW & IGKV3-10 & CQQNNEDPPTF & $16 \mathrm{nt}(8)$ & n.d. \\
\hline 1.40 & 1 & $40-46$ & 8 & IGHV1-76 & CARSELQNFVMDYW & IGKV3-7 & CQHSWEIPWTF & $36 \mathrm{nt}(17)$ & $15.2 \pm 2.3$ \\
\hline 1.42 & 1 & $40-46$ & 8 & IGHV8-12 & CARRDGITTAWYFDVW & IGKV3-5 & CQQSNEDPLTF & $9 \mathrm{nt}(4)$ & n.d. \\
\hline 1.43 & 1 & $40-46$ & 8 & IGHV1-64 & CARNEYDGVFAYW & IGKV3-12 & CQHSRELPWTF & $22 \mathrm{nt}(12)$ & n.d. \\
\hline 1.48 & 1 & $47-52$ & 7 & IGHV2-3 & CAKEDYYGSSWGLDYW & IGKV12-98 & CQQLYSTPYTF & $2 \mathrm{nt}(2)$ & n.d. \\
\hline 1.52 & 1 & $47-52$ & 7 & IGHV3-6 & CARGGYYVMDYW & IGKV10-94 & CQQYSKIPYTF & $8 \mathrm{nt}(5)$ & $71.2 \pm 70.2$ \\
\hline 1.53 & 1 & $53-63$ & 6 & IGHV9-3 & CTRRGGNYVYYYAMDYW & IGKV1-110 & CSQSTHVPPTF & $2 \mathrm{nt}(3)$ & $61.8 \pm 9.0$ \\
\hline 1.55 & 1 & $53-63$ & 6 & IGHV1-64 & CARLGVYW & IGKV15-103 & CQQGQSYPFTF & $16 \mathrm{nt}(6)$ & $10.0 \pm 10.6$ \\
\hline M1_low1 & 1 & $68-96$ & 5 & IGHV8-12 & CARADWITTVPDYW & IGKV6-23 & CQQYSTYPWTF & $14 \mathrm{nt}(4)$ & n.d. \\
\hline M1_low4 & 1 & $138-189$ & 3 & IGHV1-39 & CARSGYGTFAYW & IGKV4-50 & CQQFTSSPSTF & $25 \mathrm{nt}(13)$ & n.d. \\
\hline M1_low8 & 1 & $249-404$ & 1 & IGHV5-9-1 & CAGDRYDGYYAMDYW & IGKV4-57 & CQQRSSYPWTF & $12 \mathrm{nt}(11)$ & $183.6 \pm 11.0$ \\
\hline M1_low11 & 111 & $249-404$ & 1 & IGHV7-3 & CARDKGDSWFDYW & IGKV12-98 & CQQLYNTPYTF & $19 \mathrm{nt}(7)$ & $363.0 \pm 8.0$ \\
\hline M1_low13 & 31 & $249-404$ & 1 & IGHV9-3 & CARSNGNYLFAFW & IGKV4-55 & CQQWSSYPPITF & $6 \mathrm{nt}(4)$ & $167.5 \pm 3.4$ \\
\hline 2.1 & 2 & 1 & 55 & IGHV5-6 & CARRGGYYGFGYFDYW & IGLV1 & CALWYSNHLVF & $7 \mathrm{nt}(4)$ & n.d. \\
\hline 2.3 & 2 & 3 & 30 & IGHV2-6-8 & CARDYGGNNYAMDYW & IGKV4-57 & CQQRSSYPFTF & $8 \mathrm{nt}(7)$ & $80.3 \pm 15.1$ \\
\hline 2.4 & 2 & 4 & 28 & IGHV1-4 & CTNHGSSHGWFGYW & IGKV14-111 & CLQYDEFPLTF & $11 \mathrm{nt}(6)$ & $36.7 \pm 1.2$ \\
\hline 2.6 & 2 & 6 & 25 & IGHV2-6-8 & CARDYGSNNYAMDFW & IGKV4-57 & CQQRSSYPFTF & $9 \mathrm{nt}(5)$ & $14.1 \pm 19.5$ \\
\hline 2.7 & 2 & 7 & 24 & IGHV1-76 & CARYGYEEGYFDYW & IGKV3-7 & CQHSWEIPYTF & $29 \mathrm{nt}(15)$ & n.d. \\
\hline 2.8 & 2 & 8 & 20 & IGHV1-26 & CARSGYASFAYW & IGKV4-63 & CFQGSGYPFTF & $29 \mathrm{nt}(17)$ & $17.0 \pm 3.4$ \\
\hline 2.9 & 2 & 9 & 19 & IGHV1-69 & CARCLYYYGSSSCAMDYW & IGKV5-43 & CQQSNSWPLTF & $36 \mathrm{nt}(15)$ & n.d. \\
\hline 2.12 & 2 & $12-13$ & 15 & IGHV1-52 & CARGGYW & IGKV8-24 & CQQHYSTPFTF & $14 \mathrm{nt}(5)$ & $77.2 \pm 27.9$ \\
\hline 2.15 & 2 & $14-16$ & 14 & IGHV2-6-8 & CARDYGGNNYAMDYW & IGKV4-57 & CQQRSRYPFTF & $12 \mathrm{nt}(8)$ & $12.3 \pm 4.7$ \\
\hline 2.18 & 2 & $17-18$ & 13 & IGHV1-55 & CTRSQRYFYLDVW & IGKV14-111 & CLQYDEFPYTF & $15 \mathrm{nt}(8)$ & $180.2 \pm 121.2$ \\
\hline 2.22 & 2 & $22-25$ & 11 & IGHV1-5 & CVRSEDYYYFDYW & IGKV14-111 & CLQYDEFPYTF & $15 \mathrm{nt}(9)$ & $5.2 \pm 3.0$ \\
\hline 2.24 & 2 & $22-25$ & 11 & IGHV1-4 & CTSHGSMFGWFSYW & IGKV14-111 & CLQYDEFPLTF & $17 \mathrm{nt}(8)$ & $17.8 \pm 3.1$ \\
\hline 2.27 & 2 & $26-28$ & 10 & IGHV1-66 & CASTTATSSWFAYW & IGKV14-111 & CLQYDEFPYTF & $16 \mathrm{nt}(11)$ & $18.4 \pm 3.0$ \\
\hline 2.33 & 2 & $33-39$ & 8 & IGHV1-18 & CARGGYGVPFAYW & IGKV4-63 & CFQGSGYPLTF & $11 \mathrm{nt}(5)$ & $37.9 \pm 6.4$ \\
\hline 2.34 & 2 & $33-39$ & 8 & IGHV6-6 & CTRPGRVYQRYFDVW & IGKV12-41 & CQHFWGTPPTL & $17 \mathrm{nt}(7)$ & $37.3 \pm 10.6$ \\
\hline 2.39 & 2 & 33-39 & 8 & IGHV1-55 & CTRSQRYFYFDVW & IGKV14-111 & CLQYDEFPYTF & $11 \mathrm{nt}(6)$ & $80.3 \pm 17.0$ \\
\hline 2.40 & 2 & $40-48$ & 7 & IGHV1-4 & CTSHASMYGWFSYW & IGKV14-111 & CLQYDEFPLTF & $23 \mathrm{nt}(14)$ & $9.9 \pm 2.1$ \\
\hline 2.41 & 2 & $40-48$ & 7 & IGHV1-9 & CARSGYGSFAYW & IGKV4-55 & CQQWSSYPPTF & $22 \mathrm{nt}(15)$ & $10.9 \pm 1.9$ \\
\hline 2.45 & 2 & $40-48$ & 7 & IGHV1-34 & CAREYEAWFAYW & IGKV10-96 & CQQGNTLPWTF & $1 \mathrm{nt}(1)$ & n.d. \\
\hline 2.49 & 2 & $49-56$ & 6 & IGHV1-5 & CTRSEDYYYFDYW & IGKV14-111 & CLQYDEFPYTF & $13 \mathrm{nt}(11)$ & $7.4 \pm 1.5$ \\
\hline 2.51 & 2 & $49-56$ & 6 & IGHV1-5 & CTRSEGYYYFDYW & IGKV14-111 & CQQYDEFPYTF & $18 \mathrm{nt}(12)$ & $12.1 \pm 2.1$ \\
\hline 2.55 & 2 & $49-56$ & 6 & IGHV2-6-8 & CARDYGSDNYALDFW & IGKV4-57 & CQQRSSYPFTF & $14 \mathrm{nt}(7)$ & $3.6 \pm 6.0$ \\
\hline 5.1 & 5 & 1 & 41 & IGHV1-63 & CARKNYYGNTYFDYW & IGKV1-117 & CFQGSHVPWTF & $30 \mathrm{nt}(16)$ & $18.7 \pm 3.7$ \\
\hline 5.2 & 5 & 2 & 34 & IGHV1-9 & CARSGYGTFAFW & IGKV4-55 & CQQWSSYPPTF & $21 \mathrm{nt}(12)$ & $451.8 \pm 161.9$ \\
\hline 5.3 & 5 & 3 & 29 & IGHV1-4 & CARGGYGSLAYW & IGKV4-50 & CQQFTSSPYTF & $16 \mathrm{nt}(8)$ & $12.7 \pm 2.3$ \\
\hline 5.4 & 5 & 4 & 28 & IGHV1-66 & CARRVLYYFDYW & IGKV6-32 & CQQDYRYPYTF & $7 \mathrm{nt}(7)$ & $8.8 \pm 2.0$ \\
\hline 5.5 & 5 & $5-6$ & 24 & IGHV1-18 & CARTNWDFYYFDYW & IGKV14-111 & CLQYDEFPWTF & $22 \mathrm{nt}(13)$ & n.d. \\
\hline 5.6 & 5 & $5-6$ & 24 & IGHV1-18 & CARSGYDFFAYW & IGKV4-61 & CQQCHSFPLTF & $29 \mathrm{nt}(18)$ & $61.1 \pm 30.5$ \\
\hline 5.7 & 5 & 7 & 20 & IGHV1-4 & CTRSAFGFDYYW & IGKV4-61 & CQQYHSYPLTF & $18 \mathrm{nt}(11)$ & $11.0 \pm 1.9$ \\
\hline 5.12 & 5 & 12 & 15 & IGHV8-12 & CVRRPLGISDGYYFTYW & IGKV6-23 & CQQYSSFPLTF & $16 \mathrm{nt}(8)$ & n.d. \\
\hline 5.13 & 5 & $13-14$ & 14 & IGHV1-9 & CARSGYGSFAFW & IGKV4-55 & CQQWSSYPPTF & $19 \mathrm{nt}(11)$ & $39.7 \pm 7.7$ \\
\hline 5.14 & 5 & $13-14$ & 14 & IGHV1-63 & CARKIYYGSTYFDYW & IGKV1-117 & CFQGSHVPWTF & $18 \mathrm{nt}(8)$ & $44.2 \pm 5.9$ \\
\hline 5.15 & 5 & $15-16$ & 13 & IGHV1-18 & CARSGYGSSFAYW & IGKV4-61 & CQQYHSYPPTF & $14 \mathrm{nt}(5)$ & $12.6 \pm 2.3$ \\
\hline 5.16 & 5 & $15-16$ & 13 & IGHV9-3 & CARLQSYWYFDVW & IGKV3-12 & CQHSRELRTF & $7 \mathrm{nt}(6)$ & $5.0 \pm 1.3$ \\
\hline 5.17 & 5 & $17-18$ & 12 & IGHV9-3 & CAREASYWYFDVW & IGKV3-12 & CQHSRDLRTF & $8 \mathrm{nt}(6)$ & $20.2 \pm 2.0$ \\
\hline 5.18 & 5 & $17-18$ & 12 & IGHV1-4 & CTRSAYGYDYYW & IGKV4-61 & CQQYHSYPLTF & $11 \mathrm{nt}(4)$ & $11.8 \pm 2.0$ \\
\hline 5.20 & 5 & $19-21$ & 11 & IGHV1-26 & CARSGLGAFAYW & IGKV4-55 & CQQWSNYPPITF & $27 \mathrm{nt}(15)$ & $35.2 \pm 6.2$ \\
\hline 5.25 & 5 & $25-28$ & 9 & IGHV5-6 & CARDPGLYGKGAYFSYW & IGKV3-12 & CQHSRELPLTF & $8 \mathrm{nt}(2)$ & $5.9 \pm 5.4$ \\
\hline 5.29 & 5 & $29-38$ & 8 & IGHV1-22 & CAREGLRENYAMDYW & IGKV6-23 & CQQFTNYPYTF & $23 \mathrm{nt}(15)$ & n.d. \\
\hline 5.33 & 5 & $29-38$ & 8 & IGHV2-3 & CAKLDYGSSLYYAVDLW & IGKV13-85 & CQQYWSTPYTF & $11 \mathrm{nt}(4)$ & $27.7 \pm 4.2$ \\
\hline 5.37 & 5 & $29-38$ & 8 & IGHV1-4 & CTRSAYGFDYYW & IGKV4-61 & CQQYYSYPLTF & $14 \mathrm{nt}(6)$ & $4.6 \pm 0.9$ \\
\hline 5.38 & 5 & $29-38$ & 8 & IGHV1-76 & CARWGDSSGTGAMDYW & IGKV3-7 & CQHSWEFPLTY & $36 \mathrm{nt}(15)$ & $20.0 \pm 3.7$ \\
\hline 5.41 & 5 & $39-48$ & 7 & IGHV2-3 & CAKFSYGSSYYYAIDYW & IGKV12-41 & CQHFWRTPYTF & $16 \mathrm{nt}(11)$ & $34.0 \pm 3.1$ \\
\hline 5.44 & 5 & $39-48$ & 7 & IGHV5-9-1 & CSRYQGYYGSSPYFDYW & IGKV3-12 & CQHSRELPFTF & $9 \mathrm{nt}(7)$ & n.d. \\
\hline 5.50 & 5 & $49-54$ & 6 & IGHV14-1 & CTRSGYAAWFPYW & IGKV4-74 & CHQYHRSPLTF & $10 \mathrm{nt}(7)$ & n.d. \\
\hline 5.51 & 5 & $49-54$ & 6 & IGHV5-9-1 & CAREGLYGNYAMDYW & IGKV13-84 & CQQYWSTPLTF & $4 \mathrm{nt}(3)$ & n.d. \\
\hline 3.1 & 3 & 1 & 21 & IGHV1-18 & CTRSGYGSFAYW & IGKV4-61 & CQQYHSYPPTF & $23 \mathrm{nt}(15)$ & n.d. \\
\hline 3.2 & 3 & $2-3$ & 14 & IGHV1-5 & CTRSDDYYYFDYW & IGKV14-111 & CLQYDEFPYTF & $12 \mathrm{nt}(9)$ & n.d. \\
\hline 3.5 & 3 & 5 & 12 & IGHV1-18 & CVRSGYGSFAYW & IGKV4-61 & CQQYHSYPPTF & $15 \mathrm{nt}(7)$ & n.d. \\
\hline 4.1 & 4 & 1 & 45 & IGHV1-76 & CARAIYNDTTGAFEYW & IGKV3-7 & CHHSWEIPYTF & $35 \mathrm{nt}(13)$ & n.d. \\
\hline 4.2 & 4 & 2 & 43 & IGHV1-19 & CARYYRGKGAMDYW & IGKV3-2 & CQQSKEVPYTF & $14 \mathrm{nt}(8)$ & n.d. \\
\hline 4.8 & 4 & 8 & 18 & IGHV1-53 & CTRDFYYDYGGDAYW & IGKV4-57 & CHQRSIYPRTF & $21 \mathrm{nt}(11)$ & n.d. \\
\hline 4.11 & 4 & 11 & 14 & IGHV1-64 & CTRTGGTWGAMDYW & IGKV8-24 & CQQHYSTPFTF & $15 \mathrm{nt}(6)$ & n.d. \\
\hline 4.13 & 4 & 13 & 13 & IGHV1-5 & CIRSGYGSFAYW & IGKV4-50 & CQQFTSFPYTF & $16 \mathrm{nt}(11)$ & n.d. \\
\hline
\end{tabular}

Extended Data Table 1. Overview and characteristics of OVA binders. Clone ID corresponds to mouse number followed by clone index number corresponding to Fig. 19. 
bioRxiv preprint doi: https://doi.org/10.1101/2021.07.16.452687; this version posted July 16, 2021. The copyright holder for this preprint

(which was not certified by peer review) is the author/funder, who has granted bioRxiv a license to display the preprint in perpetuity. It is made available under aCC-BY-ND 4.0 International license.

\begin{tabular}{|c|c|c|c|c|c|c|c|}
\hline ID & Mouse & IgG clone rank in mouse & \# cells & $\mathrm{V}_{\mathrm{H}}$ & CDRH3 & $\mathrm{v}_{\mathrm{L}}$ & CDRL3 \\
\hline 1.6 & 1 & 6 & 31 & IGHV5-9-1 & CTGDRYDGYYAMDYW & IGKV4-57 & CQQRSSYPWTF \\
\hline 1.8 & 1 & 8 & 22 & IGHV10-1 & CVRQGKIYYDYDYFDYW & IGKV17-127 & CLQSDNMPYTF \\
\hline 1.9 & 1 & $9-10$ & 18 & IGHV9-3 & CTRRGGNYVYYYAMDYW & IGKV14-111 & CLQYDELYTF \\
\hline 1.10 & 1 & $9-10$ & 18 & IGHV9-3 & CARSDGNYLFAYW & IGKV4-55 & CQQWSSYPPITF \\
\hline 1.13 & 1 & $11-13$ & 17 & IGHV1-34 & CARSLYDGYPHFDYW & IGKV4-50 & CQQFTSSPFTF \\
\hline 1.16 & 1 & 16 & 14 & IGHV1-80 & CARSGYGTGFAYW & IGKV4-55 & CQQWNSYPWTF \\
\hline 1.18 & 1 & $18-24$ & 12 & IGHV1-5 & CTRSDSNFYYFDYW & IGKV14-111 & CLQYDEFPYTF \\
\hline 1.19 & 1 & $18-24$ & 12 & IGHV5-6 & CARYDNYVRVNAMDYW & IGKV4-74 & CHQYHRSPYTF \\
\hline 1.21 & 1 & $18-24$ & 12 & IGHV13-2 & CSRAFHYDYYYGMDYW & IGKV9-124 & CLQYASYPWTF \\
\hline 1.23 & 1 & $18-24$ & 12 & IGHV1-80 & CARSGYGTGFAYW & IGKV4-55 & CQQWSSYPWTF \\
\hline 1.25 & 1 & $25-28$ & 11 & IGHV5-6 & CARQRGYYGSPYYFDYW & IGKV6-15 & CQQYNSYPLTF \\
\hline 1.30 & 1 & $29-36$ & 10 & IGHV1-4 & CAVRRENYAMEYW & IGKV4-79 & CHQWSSFPPTF \\
\hline 1.31 & 1 & $29-36$ & 10 & IGHV7-3 & CARDIPYAMDYW & IGKV1-135 & CWQGTHFPRTF \\
\hline 1.33 & 1 & $29-36$ & 10 & IGHV1-4 & CARGFGGLYFDYW & IGKV4-57 & CHQRSSYPPTF \\
\hline 1.37 & 1 & $37-39$ & 9 & IGHV1-5 & CARTGTHWYFDVW & IGKV3-5 & CQQSNEDPWTF \\
\hline 1.38 & 1 & $37-39$ & 9 & IGHV14-3 & CVRFGAVPRFSYW & IGKV1-117 & CFQGSHVPYTF \\
\hline 1.39 & 1 & $37-39$ & 9 & IGHV5-6 & CAKDIGYYGYGWFAFW & IGKV4-61 & CQQYHSYPPTF \\
\hline 1.41 & 1 & $40-46$ & 8 & IGHV14-1 & CCFFYGYGAWFGYW & IGKV6-17 & CQQHYTSPRTF \\
\hline 1.44 & 1 & $40-46$ & 8 & IGHV9-3 & CARRGGNYVYYYAVDYW & IGKV14-111 & CLQYDELYTF \\
\hline 1.47 & 1 & $47-52$ & 7 & IGHV5-17 & CARQNWDYW & IGKV12-44 & CQHHYGTPLTF \\
\hline 1.49 & 1 & $47-52$ & 7 & IGHV1-80 & CARSGYGVFAYW & IGKV4-55 & CQQWSSYPPTF \\
\hline 1.50 & 1 & $47-52$ & 7 & IGHV1-18 & CGRGGYGNPFAYW & IGKV4-63 & CFQGSGYPLTF \\
\hline 1.51 & 1 & $47-52$ & 7 & IGHV9-3 & CARSPTWFAYW & IGKV15-103 & CQQGQSFPYTF \\
\hline 1.54 & 1 & $53-63$ & 6 & IGHV1-4 & CARKSNNLFPYW & IGKV6-20 & CGQTYSYPFTF \\
\hline 1.56 & 1 & $53-63$ & 6 & IGHV1-26 & CGRSYGYSYAMDYW & IGKV16-104 & CQQHNEYPYTF \\
\hline 1.57 & 1 & $53-63$ & 6 & IGHV5-17 & CARSYGSSLDYW & IGKV12-41 & CQHFWSTPFTF \\
\hline M1_low2 & 1 & $97-137$ & 4 & IGHV1-4 & CARDYDGFAYW & IGKV1-110 & CQQFTSSPSTF \\
\hline M1_low3 & 1 & $97-137$ & 4 & IGHV1-18 & CARSGYATAFAYW & IGKV4-55 & CQQGNTLLMYTF \\
\hline M1_low5 & 1 & $190-248$ & 2 & IGHV1-26 & CARYGNYYFDYW & IGKV10-96 & CLQYASSPLTF \\
\hline M1_low6 & 1 & $249-404$ & 1 & IGHV1-19 & CARRGDSYSQFPYYAMDYW & IGKV1-110 & CQQRSSYPWTF \\
\hline M1_low7 & 1 & $249-404$ & 1 & IGHV1-26 & CARSTAIYYGMDYW & IGKV9-120 & CHQRSSYPSTF \\
\hline M1_low9 & 1 & $249-404$ & 1 & IGHV8-11 & CARIEGLLAWFGYW & IGKV1-110 & CSQSTHVPWTF \\
\hline M1_low10 & 01 & $249-404$ & 1 & IGHV1-82 & CARAGYGTGFAYW & IGKV4-55 & CQQWSTYPWTF \\
\hline M1_low12 & 21 & $249-404$ & 1 & IGHV1-4 & CVRSDGDYYGYVRPWFGYW & IGKV8-27 & CHQYLSSYTF \\
\hline M1_low14 & 41 & $249-404$ & 1 & IGHV5-9-1 & CQRLRGYFDVW & IGKV1-110 & CSQSTHVPYTF \\
\hline M1_low15 & 51 & $249-404$ & 1 & IGHV13-2 & CSRSFYYDYYYAMDYW & IGKV9-124 & CLQYASYPWTF \\
\hline 2.2 & 2 & 2 & 32 & IGHV2-6-8 & CARDYGANNYAMDYW & IGKV4-57 & CQQRSSYPFTF \\
\hline 2.5 & 2 & 5 & 27 & IGHV7-3 & CARDMNNGSIYWYLDVW & IGKV12-89 & CQNVLYSPWTF \\
\hline 2.10 & 2 & 10 & 18 & IGHV1-26 & CARNPYW & IGKV1-117 & CFQGSHVPLTF \\
\hline 2.11 & 2 & 11 & 16 & IGHV1-19 & CASQLGSWFAYW & IGKV14-111 & CLQYDEFPYTF \\
\hline 2.13 & 2 & $12-13$ & 15 & IGHV1-9 & CARSGGFYDPGRGYAMDYW & IGKV4-74 & CHQYYRSPRTF \\
\hline 2.14 & 2 & $14-16$ & 14 & IGHV8-12 & CARSYADFDYW & IGKV4-80 & CHQWSSYPTF \\
\hline 2.16 & 2 & $14-16$ & 14 & IGHV1-55 & CTRSLRYWYLDVW & IGKV14-111 & CLQYDEFPYTF \\
\hline 2.17 & 2 & $17-18$ & 13 & IGHV9-3 & CATPDYFAMDYW & IGKV8-21 & CKQSYILPWTF \\
\hline 2.19 & 2 & $19-21$ & 12 & IGHV1-5 & CTRSEGYYYFDYW & IGKV14-111 & CLQYDEFPYTF \\
\hline 2.20 & 2 & $19-21$ & 12 & IGHV5-6 & CTRRDFYGYAMDYW & IGKV8-28 & CQNDHSYPYTF \\
\hline 2.23 & 2 & $22-25$ & 11 & IGHV6-6 & CTRDFWFAYW & IGKV1-135 & CWQGTHFPQTF \\
\hline 2.26 & 2 & $26-28$ & 10 & IGHV5-6 & CARRGGYYGYGYFDYW & IGLV1 & CALWYSNHLVF \\
\hline 2.28 & 2 & $26-28$ & 10 & IGHV8-8 & CARDLYDDDGTAYYFDYW & IGKV8-27 & CHQYLSSRSF \\
\hline 2.29 & 2 & $29-32$ & 9 & IGHV14-1 & CTPYDYDVSAFAYW & IGKV12-44 & CQHHHGSPRTF \\
\hline 2.30 & 2 & $29-32$ & 9 & IGHV1-39 & CARWGEIYPYAVDYW & IGKV10-96 & CQQGNTFPWTF \\
\hline 2.31 & 2 & $29-32$ & 9 & IGHV1-5 & CTRCYGNPFYFDYW & IGKV4-74 & CHQHHRSPFTF \\
\hline 2.32 & 2 & 29-32 & 9 & IGHV2-2 & CARKGPQLVFDYW & IGKV6-23 & CQQYSSYPYTF \\
\hline 2.35 & 2 & $33-39$ & 8 & IGHV1-81 & CARLLYGYGYLDYW & IGKV14-111 & CLQYDEFPWTF \\
\hline 2.36 & 2 & 33-39 & 8 & IGHV1-39 & CARWGEIYPYAMDYW & IGKV10-96 & CQQGNTLPWTF \\
\hline 2.37 & 2 & $33-39$ & 8 & IGHV1-54 & CARSDGNEDYW & IGKV4-55 & CQQWSSYPFAF \\
\hline 2.38 & 2 & $33-39$ & 8 & IGHV8-11 & CARIYYYGSSRHFDYW & IGKV3-4 & CQQSYEDPTF \\
\hline 2.42 & 2 & $40-48$ & 7 & IGHV1-4 & CARSNDGGFAYW & IGKV4-59 & CQQWSSNPPTF \\
\hline 2.43 & 2 & $40-48$ & 7 & IGHV1-61 & CARSDDGYWFAYW & IGKV3-7 & CQHSWEIPPTF \\
\hline 2.44 & 2 & $40-48$ & 7 & IGHV1-22 & CARGLPYHGLDNW & IGKV4-61 & CQQYHSSPFTF \\
\hline 2.50 & 2 & $49-56$ & 6 & IGHV2-2 & CAKSPYYGAMDYW & IGKV5-43 & CQQSNSWPFTF \\
\hline 2.52 & 2 & $49-56$ & 6 & IGHV1-69 & CTRDYHGTSSMDYW & IGKV1-110 & CSQSTHVPWTF \\
\hline 2.53 & 2 & $49-56$ & 6 & IGHV2-3 & CAKTYYGAMDYW & IGKV4-63 & CLQGSGYPFTF \\
\hline 2.54 & 2 & $49-56$ & 6 & IGHV1-26 & CARGITTVVPYAMDYW & IGKV10-96 & CQQGNTLPWTF \\
\hline 5.8 & 5 & $8-9$ & 17 & IGHV1-15 & CTREGYFYDVRVWFAYW & IGKV2-109 & CAQNLELPTF \\
\hline 5.9 & 5 & $8-9$ & 17 & IGHV14-3 & CASAATWAYWYFDVW & IGKV4-91 & CQQGSSIPLTF \\
\hline 5.10 & 5 & $10-11$ & 16 & IGHV9-3 & CARGDYGNYERVAWHAYW & IGKV10-96 & CQQGDTVPFTF \\
\hline 5.11 & 5 & $10-11$ & 16 & IGHV14-3 & CARFGNYPYWYFDVW & IGKV4-70 & CHQRSSYPYTF \\
\hline 5.19 & 5 & $19-21$ & 11 & IGHV4-1 & CARPGFRYGYAMDYW & IGKV6-25 & CQQHYSTPYTF \\
\hline 5.21 & 5 & $19-21$ & 11 & IGHV5-9-1 & CSRDSYYGSYYGYFDVW & IGKV13-85 & CQQYWSSPPTF \\
\hline 5.22 & 5 & $22-24$ & 10 & IGHV2-3 & CAKFSYGSSYYYAIDYW & IGKV6-17 & CQQHYSTPLTF \\
\hline 5.23 & 5 & $22-24$ & 10 & IGHV5-17 & CAREFAYW & IGKV12-44 & CQHHYGSPYTF \\
\hline 5.24 & 5 & $22-24$ & 10 & IGHV1-64 & CARFSGYFDVW & IGKV4-50 & CQQFTSSPFTF \\
\hline 5.26 & 5 & $25-28$ & 9 & IGHV1-18 & CARSGYDFFAYW & IGKV9-124 & CLQYSTYPWTF \\
\hline 5.27 & 5 & $25-28$ & 9 & IGHV3-1 & CARFYRSTGIAYW & IGKV4-70 & CHQRIIYPWTF \\
\hline 5.28 & 5 & $25-28$ & 9 & IGHV9-1 & CTQLGLLAWFAYW & IGKV10-94 & CQQYSKLPPTF \\
\hline 5.30 & 5 & $29-38$ & 8 & IGHV1-63 & CARKNYYGSTYFDYW & IGKV1-117 & CFQGSHVPWTF \\
\hline 5.31 & 5 & $29-38$ & 8 & IGHV1-9 & CVRGRSPIYYDYYYDNW & IGKV17-127 & CFQSDNMPYTF \\
\hline 5.32 & 5 & $29-38$ & 8 & IGHV1-66 & CAKNYGIHYGMDYW & IGKV13-85 & CQQYWTIPYTF \\
\hline 5.34 & 5 & $29-38$ & 8 & IGHV5-6 & CARQVYYDYGTMDYW & IGKV10-96 & CQQGNTLPRTF \\
\hline 5.35 & 5 & $29-38$ & 8 & IGHV8-8 & CARKAYFGYDYFDYW & IGKV6-23 & CQQYSSYPLTF \\
\hline 5.36 & 5 & $29-38$ & 8 & IGHV9-3 & CARGWGYFDYW & IGKV6-17 & CQQHYSTPLTF \\
\hline 5.39 & 5 & $39-48$ & 7 & IGHV1-4 & CARRVGEYYFDYW & IGKV4-79 & CHQWSNYPPTF \\
\hline 5.40 & 5 & $39-48$ & 7 & IGHV9-3 & CARAPLFYYAMDYW & IGLV1 & CALWYSNHWVF \\
\hline 5.42 & 5 & $39-48$ & 7 & IGHV1-76 & CARWGDSSGTGAMDYW & IGKV3-7 & CQHSWEIPLTF \\
\hline 5.43 & 5 & $39-48$ & 7 & IGHV4-1 & CARPGFRYGYAMDYW & IGKV12-44 & CQHHYGTPLTF \\
\hline 5.45 & 5 & $39-48$ & 7 & IGHV8-12 & CARLYDGYSYALDYW & IGKV12-44 & CQHHYGTPRTF \\
\hline 5.46 & 5 & $39-48$ & 7 & IGHV1-85 & CTTGDYLYVHFDSW & IGKV15-103 & CQQGQSYPYTF \\
\hline 5.47 & 5 & $39-48$ & 7 & IGHV2-9-1 & CVRRGGYYGNFYWFFDVW & IGKV1-117 & CFQGSHVPYTF \\
\hline 5.49 & 5 & 49-54 & 6 & IGHV1-26 & CARRGSRYFDVW & IGKV6-32 & CQQDYNSPWTF \\
\hline
\end{tabular}

Extended Data Table 2. Overview and characteristics of non-binders. Clone ID corresponds to mouse number followed by clone index number corresponding to Fig. 19. 
bioRxiv preprint doi: https://doi.org/10.1101/2021.07.16.452687; this version posted July 16, 2021. The copyright holder for this preprint (which was not certified by peer review) is the author/funder, who has granted bioRxiv a license to display the preprint in perpetuity. It is made available under aCC-BY-ND 4.0 International license.

\begin{tabular}{lccclllll} 
ID & Mouse & IgG clone rank in mouse & \# cells & $\mathbf{V}_{\mathbf{H}}$ & CDRH3 & $\mathbf{V}_{\mathbf{L}}$ & CDRL3 & nt dist. (aa-changes) \\
\hline 3.3 & 3 & $2-3$ & 14 & IGHV1-5 & CTRSDDYYYFDYW & IGKV4-70 & CHQRSNYPLTF & $13 \mathrm{nt}(11)$ \\
3.4 & 3 & 4 & 13 & IGHV8-12 & CARTRWEKYYAMDYW & IGKV19-93 & CLQYDNLYTF & 9 nt (7) \\
4.3 & 4 & 3 & 30 & IGHV1-54 & CARSDSSGDYW & IGKV4-55 & CQQWSSYPFTF & 12 nt (5) \\
4.5 & 4 & $5-6$ & 19 & IGHV5-6 & CSRRGLVDGVYPMDYW & IGKV6-23 & CQQYRTYPTF & 21 nt (11) \\
4.6 & 4 & $5-6$ & 19 & IGHV8-12 & CVRRLWSLDYAMDNW & IGKV10-96 & CQQGNTLPYF & 16 nt (9) \\
4.14 & 4 & 14 & 12 & IGHV1-19 & CAITRLDYW & IGKV4-80 & CHQWSSYPFTF & 14 nt (4)
\end{tabular}

Extended Data Table 2 (continued). Overview and characteristics of non-binders. Clone ID corresponds to mouse number followed by clone index number corresponding to Fig. $\mathbf{1 g}$.

\begin{tabular}{ll} 
Primer & Description \\
\hline EpMap_1 & Reverse primer for pB33eCPX plasmid linearisation (step 1) \\
EpMap_2 & Forward primer for pB33eCPX plasmid linearisation (step 1) \\
EpMap_3 & Reverse primer for plasmid linearisation (step 2; library generation) \\
EpMap_4 & Forward primer for plasmid linearisation (step 2; library generation) \\
EpMap_5 & Forward primer Sanger sequencing \\
EpMap_7 & Forward primer NGS PCR 1 \\
EpMap_8 & Reverse primer NGS PCR 1 \\
EpMap_9 & Forward primer NGS PCR 2 \\
EpMap_idx & Reverse primer NGS PCR 2 encoding TruSeq IDX1
\end{tabular}

Sequence [5' -> 3']

CCAGTGCTGAAAGACATGCAA

ACAACAAAAACCAGTACTACGGC

TTGTCCAGATTGTCCAGCTACAGAAG

GGAGGGCAGTCTGGGCAG

GTGGTTATGAAAAAAATTGCATGTC

CCCTCCTTTAATTCCCGTGGTTATGAAAAAAATTGCATGTC

GAGGAGAGAGAGAGAGATGCTTGCCCAGTCGTTA

AATGATACGGCGACCACCGAGATCTACACTCTTTCCCTACAC GACGCTCTTCCGATCTNNNNCCCTCCTTTAATTCCC

CAAGCAGAAGACGGCATACGAGATCGTGATGTGACTGGAGTT CAGACGTGTGCTCTTCCGATCTNNNNGAGGAGAGAGAGAGA $\mathrm{G}$

Extended Data Table 3. Primers used for bacterial epitope mapping and NGS library generation.

\begin{tabular}{lll} 
ssODN & Description & \multicolumn{1}{c}{ Sequence [5' $->$ 3'] $^{\prime}$} \\
\hline EpMap1_ssODN & Generation of epitope mapping starting plasmid & TGAAAAAAATTGCATGTCTTTCAGCACTGGCCGCAGTTCTGGCTTTCACAGCAGGAACTTCTGTAGCTGGA \\
& & CATCTGGACAAGGAGGGCAGTCTGGGCAGTCAGGTGATTACAACAAAACCAGTACTACGGCATCACTG \\
EpMapW1_ssODN & Exemplary library ssODN for OVA index1 & GGAACTTCTGTAGCTGGACAATCTGGACAAATGGGGTCCATTGGTGCAGCGAGTATGGAGTTCTGTTTTGA
\end{tabular}

Extended Data Table 4. ssODNs for epitope mapping library generation. Cloning overhang sequences are indicated in bold. Insert sequence shown in red for exemplary library ssODN encodes for the first 15 a.a. of OVA. 